\title{
Managing paradoxes of ambidexterity: The impact of exploration and exploitation on firm performance
}

\author{
Lixun Su \\ West Virginia University, lisu@mix.wvu.edu
}

Follow this and additional works at: https://researchrepository.wvu.edu/etd

Part of the Marketing Commons

\section{Recommended Citation}

Su, Lixun, "Managing paradoxes of ambidexterity: The impact of exploration and exploitation on firm performance" (2020). Graduate Theses, Dissertations, and Problem Reports. 7538.

https://researchrepository.wvu.edu/etd/7538

This Dissertation is protected by copyright and/or related rights. It has been brought to you by the The Research Repository @ WVU with permission from the rights-holder(s). You are free to use this Dissertation in any way that is permitted by the copyright and related rights legislation that applies to your use. For other uses you must obtain permission from the rights-holder(s) directly, unless additional rights are indicated by a Creative Commons license in the record and/ or on the work itself. This Dissertation has been accepted for inclusion in WVU Graduate Theses, Dissertations, and Problem Reports collection by an authorized administrator of The Research Repository @ WVU.

For more information, please contact researchrepository@mail.wvu.edu. 


\title{
Managing paradoxes of ambidexterity: The impact of exploration and exploitation on firm performance
}

\author{
Lixun $\mathrm{Su}$ \\ Dissertation submitted \\ to the John Chambers College of Business and Economics \\ at West Virginia University \\ in partial fulfillment of the requirements for the degree of \\ Doctor of Philosophy in \\ Business Administration-Marketing
Annie P. Cui, Ph. D., Chair
Jody L. Crosno, Ph.D.
Xinchun Wang, Ph.D.
Saeed Samiee, Ph.D.
Shaoming Zou, Ph.D.
Department of Marketing
Morgantown, West Virginia
2020

Keywords: Exploration, exploitation, ambidexterity, SMEs, cross-border acquisitions, emerging markets, meta-analysis, post-merger integration, adaptive marketing capability, resource orchestration theory

Copyright: 2020 Lixun Su 


\section{ABSTRACT \\ Managing paradoxes of ambidexterity: \\ The impact of exploration and exploitation on firm performance}

\section{Lixun $\mathrm{Su}$}

This dissertation examines the impacts of exploration, exploitation, and ambidexterity on firm performance in three essays. Since exploration and exploitation have their own advantages and disadvantages, there are many debates over their impacts on firm performance. To synthesize the conflicting empirical results, the first essay conducted a meta-analytic study and demonstrates that ambidexterity in the product domain increases firm performance while ambidexterity in the market domain does not significantly influence firm performance. In addition, the results show that it is not necessary for all firms (e.g., resource-constrained firms) to pursue ambidexterity. Thus, the second and third essays examine how to leverage exploration and exploitation among two types of resource-constrained firms: U.S.-based international smalland medium-sized enterprises (ISMEs) and emerging-market (EM) firms.

In the second essay, I examined contingences of the impacts of exploration, exploitation, and ambidexterity on performance of U.S.-based ISMEs. The results based on 119 ISMEs show that the impacts of exploration, exploitation, and ambidexterity on firm performance depend on home-host country similarity and adaptive marketing capability. For instance, when ambitious ISMEs want to pursue ambidexterity, they should do so in a similar foreign country because home-host country similarity could mitigate the negative influence of ambidexterity on firm performance.

In the third essay, I examined how relative-exploration orientation mobilizes EM firms' acquired marketing resources from firms based in developed economies. The results show that brand resources integration increases post-merger performance when relative-exploration orientation is high, and market resources integration increases post-merger performance when relative-exploration orientation is low.

The major contribution of this dissertation is enriching understandings of exploration and exploitation and provide relevant guidance for firms on selecting appropriate strategies to increase firm performance. 


\section{DEDICATION}

The author wishes to dedicate this research to his parents and grandparents, who always believe in him and unconditionally support him to purse his dreams. 


\section{ACKNOWLEDGEMENTS}

I had received plenty of support and help with the dissertation from many wonderful people.

I would like to express my deepest gratitude to my dissertation chair, Dr. Annie Cui, who always supports and encourages me to try something bold in my dissertation. In all these years, Dr. Cui uses her own way to foster my confidence, train me to become a critical thinker, and boost my research skills. Dr. Cui has always used her acuity to polish my research ideas and has my head screwed on the right track. Dr. Cui also serves as my Ph.D. program mentor. Many times, she put my interests in the first place and prioritized all my requests so that I could finish the program with much fun. I feel extremely lucky and grateful that Dr. Cui would like to serve as my dissertation chair and mentor.

I would like to thank Dr. Jody Crosno, Dr. Xinchun Wang, Dr. Saeed Samiee, and Dr. Shaoming Zou for being my committee members. They provided many insightful feedbacks on my dissertation. Every time when I received their comprehensive and thorough comments, my horizons were broadened.

Also, I would like to thank all faculty members and doctoral students in the marketing department. Their extreme kindness, friendliness, and support help me overcome all difficulties and achieve each milestone in these years. These friends will be a priceless fortune in my whole life. In addition, my great appreciation also goes to Dr. Mo Chen, who encouraged me to consider a Ph.D. program and to pursue an academic career in the U.S. years ago.

Finally, I would like to thank my parents for their unconditional love and support. It is not easy to for them to decide to send their only child to the U.S. for a doctoral program, but they always support and feel proud of all my decisions. 


\section{TABLE OF CONTENTS}

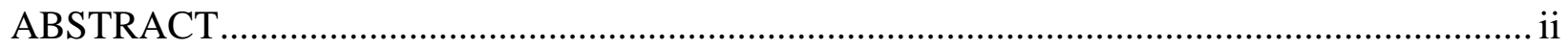

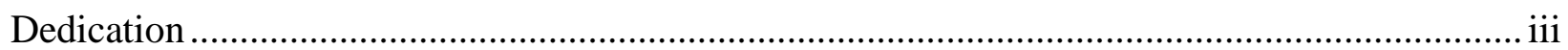

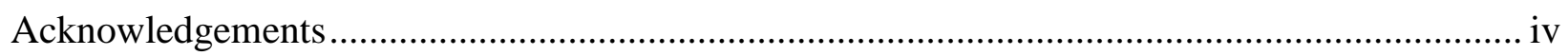

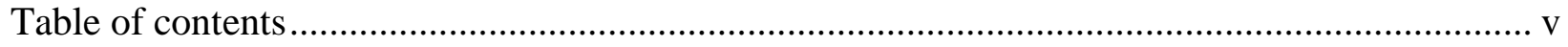

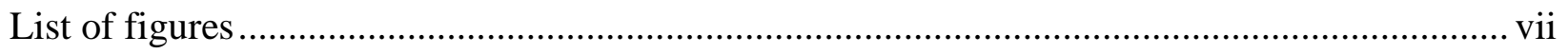

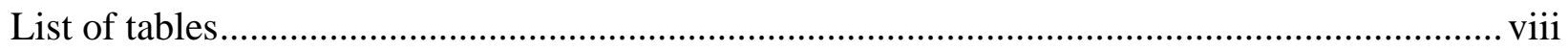

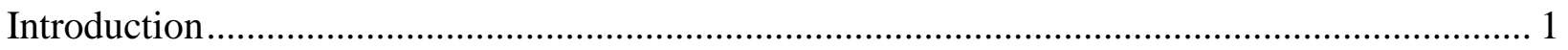

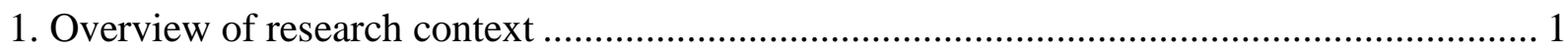

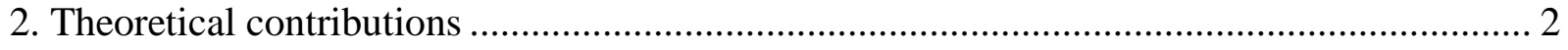

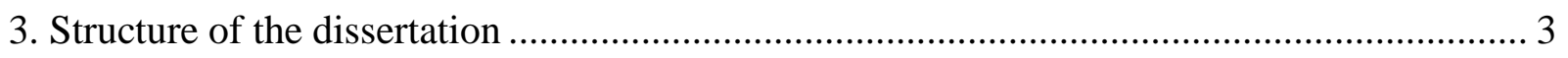

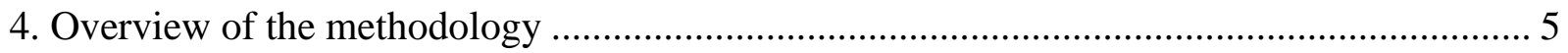

Article 1 - Balance within or across functional domains? The influence of exploration and exploitation on firm performance........................................................................... 7

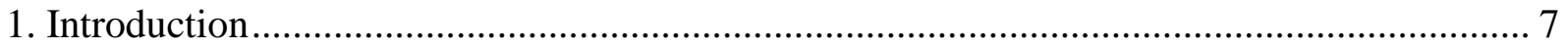

2. Theoretical background and hypotheses ........................................................................ 13

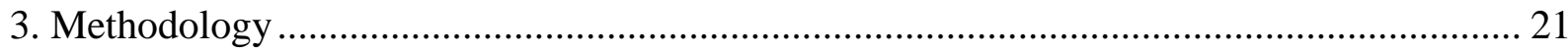

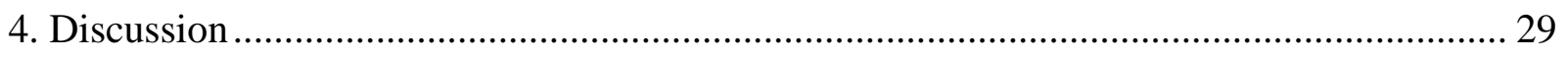

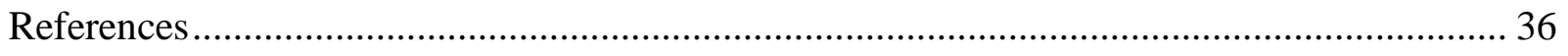

Article 2 - Exploration, exploitation, ambidexterity, and the performance of international small-

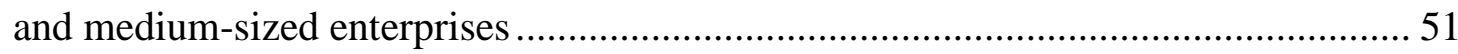




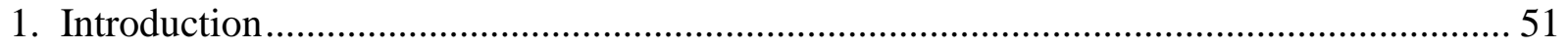

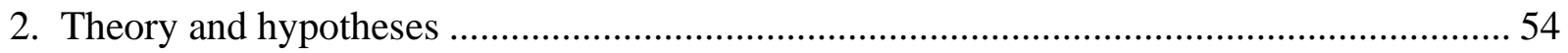

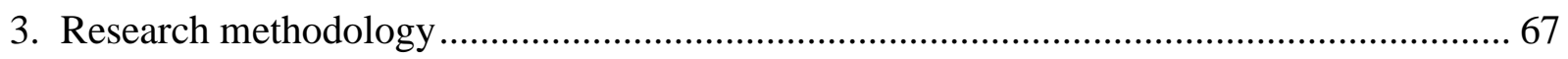

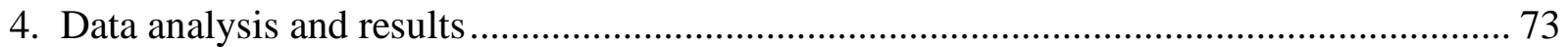

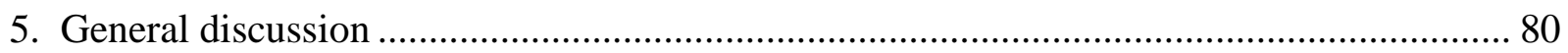

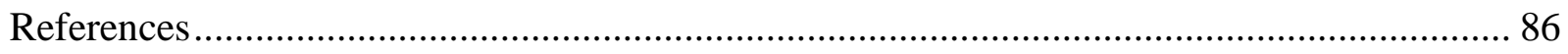

Article 3 - Understanding the marketing resources integration in cross-border acquisitions ....... 96

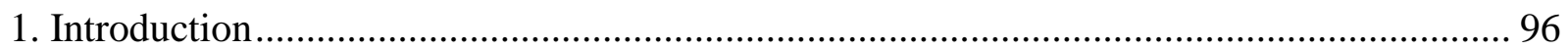

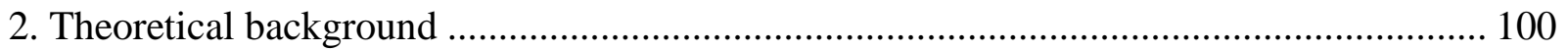

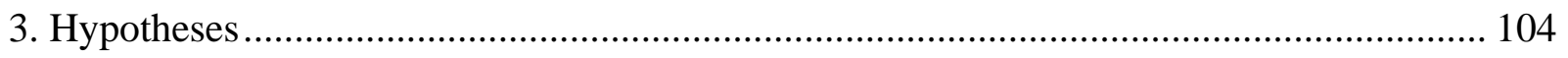

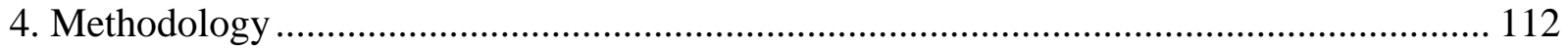

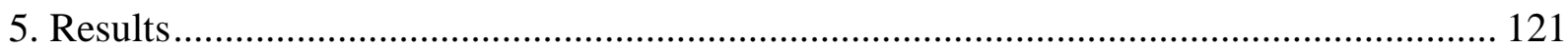

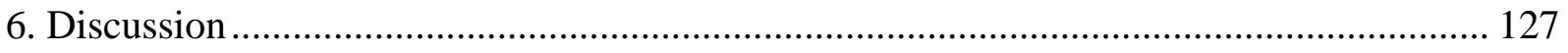

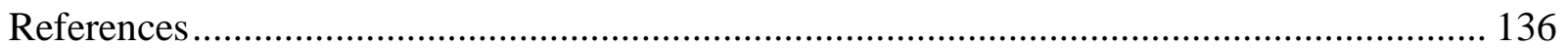




\section{LIST OF FIGURES}

Figure 1: The impacts of strategic emphasis combinations on firm performance ..................... 12

Figure 2: The moderating effect of AMCs and home-host country similarity ......................... 56

Figure 3: Plotting significant two-way interactions ..................................................... 78

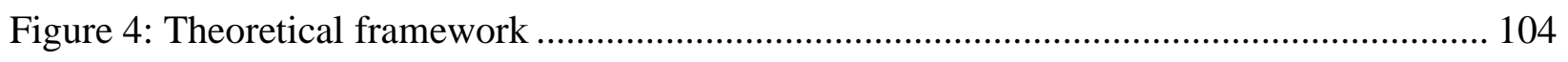

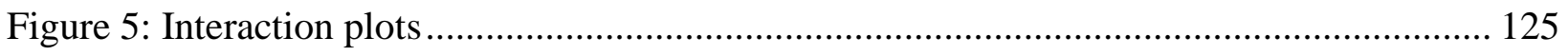




\section{LIST OF TABLES}

Table 1: Definitions of strategic emphasis combinations ................................................. 9

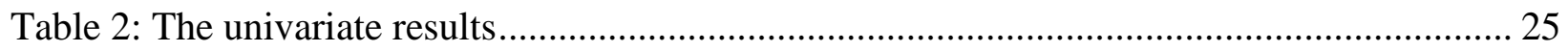

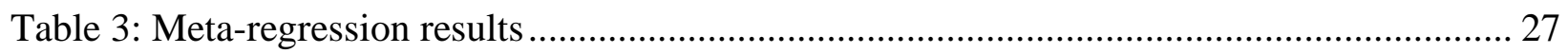

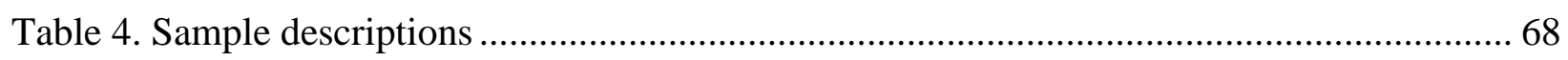

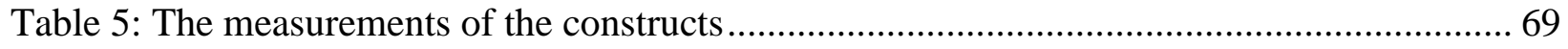

Table 6: The results of validity, reliability, and correlations ............................................... 74

Table 7: The results of regression models ............................................................................ 76

Table 8: The distribution of countries of acquired firms ............................................... 113

Table 9: Samples of marketing integration resources ................................................... 116

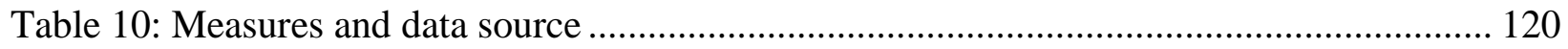

Table 11: Descriptive statistic and correlation matrix ................................................... 121

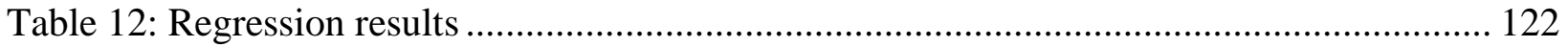




\section{INTRODUCTION}

\section{Overview of research context}

Since Cyert and March's (1963) seminal paper was published, exploration and exploitation strategy have been extensively investigated in the fields of management (e.g., Jansen et al. 2006; Phene et al. 2012), marketing (e.g., Kouropalatis et al. 2012; Mavondo et al. 2005; Strese et al. 2016; Wang and Dass 2017), and international business (e.g., Bass and Chakrabarty 2014; Jin et al. 2016; Vasilchenko and Morrish 2011). Exploration is defined as "the search for new knowledge" (Vermeulen and Barkema 2001, p. 459) and exploitation as "the ongoing use of a firm's knowledge base" (Vermeulen and Barkema 2001, p. 459). However, previous studies have not reached a consensus on the influence of exploration and exploitation on firm performance. For example, some studies show that firms should deploy either exploration or exploitation to avoid diluting resources (e.g., Voss and Voss 2013; Lin et al. 2009), but some studies show that firms should simultaneously implement exploration and exploitation (i.e. ambidexterity) to guarantee competitive advantages in both the short and long term (e.g., March 1991; Lubatkin et al. 2006; Levinthal and March 1993). These inconsistent results provide firms with limited insights on what strategies firms should use to increase performance. Especially when firms are constrained by resources and capabilities such as small- and medium-sized enterprises (SMEs) with fewer than 500 employees and emerging-market (EM) firms, should they use exploration, exploitation, and ambidexterity to leverage the resources? This dissertation is dedicated to reconciling the inconsistent results and providing some important insights for the underdogs in the markets.

Overall, this dissertation answers three questions in three essays. The first essay synthesizes the existing empirical studies on the influence of exploration, exploitation, and 
ambidexterity on firm performance in a meta-analytic study. The second essay examines whether and how U.S.-based small-and-medium-sized exporters could benefit from the strategies. Finally, the third essay examines how EM firms use exploration to leverage marketing resources acquired from firms based in developed economies to increase firm performance.

\section{Theoretical contributions}

This research is expected to advance the knowledge of exploration and exploitation and international business in several important ways. First, this research aims to clarify how the influence of exploration and exploitation varies depending on firm characteristics and approaches to implementing the strategies by synthesizing previous empirical studies. Since thousands of published empirical studies have found inconsistent results, it is urgent to know what firm-specific characteristics cause the inconsistency and in which functional domains firms should deploy exploration, exploitation, or ambidexterity.

Second, this dissertation explicates whether U.S.-based international SMEs (ISMEs) could benefit from exploration, exploitation, or ambidexterity. According to the 2016 U.S. Trade Overview published by the Department of Commerce, $98 \%$ of U.S. exporters were small- and medium-sized firms with fewer than 500 employees. However, for $47 \%$ of those firms, exporting accounts for less than $10 \%$ of sales. In addition, $59 \%$ of all ISMEs export to only one foreign market (NSBA Report, 2016). These statistics show that although many ISMEs are doing business internationally, very few of them have realized the full potentials of their exporting capacity. To increase ISMEs' international performance, I posit that these ISMEs should appropriately deploy exploration or exploitation instead of ambidexterity. More importantly, this research finds that when implementing the strategies, firms must fit their strategies with adaptive marketing capabilities and home-host country similarity. 
Third, this dissertation could help EM acquirers succeed in cross-border acquisitions (CBAs). In order to overcome resource constraints and improve global competitiveness, an increasing number of EM firms have been acquiring firms from developed economies over the last two decades. However, not all EM acquirers were able to increase their competitiveness via CBAs (Liu and Woywode 2013; Ma et al. 2016). Given the high opportunity costs of CBAs, it is necessary to investigate what is the best way to use marketing resources that are purchased from firms based in developed economies. Specifically, this dissertation investigates the moderating effects of exploration between marketing resources integration and firm performance. Specifically, the results show that firms could benefit from brand integration when the level of exploration is high. By contrast, firms could benefit from market integration when the level of exploration is low and benefit from supply chain integration regardless of the level of exploration.

\section{Structure of the dissertation}

This dissertation comprises three essays that are connected by the core question of how firms could benefit from exploration and exploitation. The purpose of essay 1 is to reconcile the inconsistent results by synthesizing empirical studies on exploration, exploitation, and ambidexterity. Specifically, the essay explains the rationale of why exploration, exploitation, and ambidexterity are likely to increase or decrease firm performance, followed by hypotheses regarding the influence of strategies on firm performance and five moderators: firm size, firm age, firm international orientation, data collection method, and ambidexterity measurement method. After proposing the theoretical framework, the process of collecting sample studies and analyzing data is discussed. Overall, the results show that ambidexterity in the product domain could increase firm performance while ambidexterity in the market domain does not significantly 
influence firm performance. I close the first essay with discussions, implications, and future research discussions.

The comprehensive research of existing empirical studies in essay 1 reveals that previous literature provides limited insights for two types of resource-constrained firms, U.S.-based ISMEs and EM firms, on the adoption of exploration, exploitation, and ambidexterity. Hence, essay 2 aims to examine what strategies resource-constrained firms should adopt and how to leverage advantages and attenuate disadvantages of the strategies. Specifically, the essay first discusses how exploration, exploitation, and ambidexterity affect firm performance since firms are constrained by resources and capabilities. Then a research framework is proposed, in which exploration and exploitation positively influence ISMEs' performance, and the positive influence could be strengthened by adaptive marketing capabilities. In addition, ambidexterity negatively influences firm performance, and the negative influence could be attenuated by home-host country similarity. Following the theory setup, the data and methodology being used to test the model is discussed. Finally, the results, implications, and future research are provided.

Essay 3 focuses on strategy adoption of another type of resource-constrained firm: EM firms. This essay examines how EM firms could benefit from acquiring firms from developed economies through matching exploration and integrated marketing resources. The paper first reviews literature on the EM firms' internationalization and resource-based view. According to the theories, the research proposes what marketing resource should be integrated and how exploration could leverage integrated resources. Then a theoretical framework examining the interactive effects of marketing resources integration and exploration on post-merger (PM) performance is proposed. Finally, I use data on transactions between Chinese acquirers and 
acquired firms in 23 developed economies to examine the model. I conclude the third essay with discussions, implications, and future research directions.

\section{Overview of the methodology}

In the meta-analytic essay, I performed a keyword search (e.g., exploration, exploitation, or ambidexterity) of the management (83) and marketing (78) journals included in ABI/Global Inform and Business Source Premiere databases between 1990-2019. Two criteria were used to screen each paper: (1) it included the correlations between strategic emphasis combinations and firm performance, and (2) it had sufficient information to calculate effect sizes. After deleting the outliers, 160 effect sizes from 65 studies remained for further analysis. Two independent researchers coded the studies, and disagreements were resolved through discussion (overall agreement $>90 \%$ ). Next, I used the package of "metafor" in R program to calculate sampleweighted r, 95\% confident intervals for the sample-weighted r, fail-safe N, $I$ square, and chisquare test of homogeneity. Finally, I conducted a meta-regression analysis on the effect sizes when possible.

In the second essay, a survey was used to collect data to test the theoretical model. Data collection was outsourced to a market research firm, which sent out 1,660 questionnaires to firms in their pool. After deleting incomplete responses and outliers, 119 cases were used for data analysis. Following tests of non-response bias, common method bias, reliability, and validity, regression was used to test the hypotheses.

In the third essay, I garnered secondary data and text data to test the model. Data was collected from multiple data sources, including SDC, firms' annual reports, COMPUST, MergentOnline, Factiva, and Hofstede Insights. First, I used the SDC platinum database to identify transactions where Chinese public firms purchased at least half of the shares of target 
firms from 23 developed economies between 2003 and 2015. After removing transactions with missing values, 115 transactions remained to test the model. Then, I collected new press covering transactions from Factiva to measure marketing resource integration activities. To measure firm performance, exploration, and control variables, I collected firms' financial data from annual report, COMPUST, and MergentOnline. National culture data was collected from Hofstede Insights. Finally, I used linear regression to test the proposed model. 


\section{ARTICLE 1 - BALANCE WITHIN OR ACROSS FUNCTIONAL DOMAINS? THE INFLUENCE OF EXPLORATION AND EXPLOITATION ON FIRM PERFORMANCE}

\section{Introduction}

Many scholars have been devoted to investigating advantages and disadvantages of exploration and exploitation strategies since Cyert and March (1963) published the seminal research on these strategies (e.g., Auh and Menguc 2005; Gupta et al. 2006; Levinthal and March 1993; Nosella et al. 2012; Yalcinkaya et al. 2007). Broadly speaking, exploration emphasizes probing something new, so it is likely to help firms achieve breakthroughs and leapfrog their competitors but entails risks and uncertainties in nature (March 1991). By contrast, exploitation emphasizes refining something existing, so it could bring stable cash flow with only minimal risks and uncertainties but suffers possible obsolescence of products and technologies (March 1991). Because exploration and exploitation have their own advantages and disadvantages, many studies have investigated their effectiveness under different conditions by extensively examining moderators such as firm characteristics, competitive intensity, environmental turbulence, and research methodologies, among others (e.g., Choi and McNamara 2018; Cui and Wu 2016; Dasí e al. 2015; Dunlap et al. 2016; Josephson et al. 2016; Junni et al. 2013).

In addition, because exploration and exploitation demand different resources and capabilities, how to balance the two strategies when firms pursue both (i.e., ambidexterity) attracts a plethora of research interests. Despite scholars' efforts over the decades, there are conflicting results on the influence of exploration, exploitation, and ambidexterity on firm performance with some research reporting positive influences while other research reports negative or non-significant influences (Gupta et al. 2006; Hughes 2018; Raisch and Birkinshaw 2008). Consequently, it is still unclear what strategies a firm should implement. 
I argue that to answer the above question, it is necessary to categorize explorative and exploitative activities into two different functional domains: product and market domains. This necessity is because the learning process of product knowledge differs from that of market knowledge. Basically, in the product domain, exploitation is more likely to support exploration because the process of developing radical new products is usually based on current products in a relatively accumulative fashion (Kogut and Zander 1992; Sorescu et al. 2003). By contrast, in the market domain, exploitation might not support exploration because very often current market knowledge is not applicable to new markets due to gaps between old and new markets (Lord and Ranft 2000; Vorhies et al. 2011). In other words, the learning process of product knowledge is more continuous than that of market knowledge. As a result, exploitation and exploration might boost each other in the product domain but not in the market domain. Since the relationship between exploration and exploitation in the product domain differs from that in the market domain, it is imperative to investigate the effectiveness of combinations of different strategic emphasis.

Specifically, by breaking down exploration and exploitation into two domains, there are four types of strategic emphasis combinations (see Table 1): within-functional ambidexterity (i.e., simultaneously implement exploration and exploitation within one functional domain), cross-functional ambidexterity (i.e., implement exploration in one domain but exploitation in the other domain), cross-functional exploration (i.e., exploration in both product and market domains), and cross-functional exploitation (i.e., exploitation in both product and market domains). The present study tests the influences of the four types of strategic emphasis combinations on firm performance and relevant moderators. 
Table 1: Definitions of strategic emphasis combinations

\begin{tabular}{c|ccc}
\hline & Market exploration & Product exploration & Market exploitation \\
\hline Market exploration & \multicolumn{3}{|c}{$\begin{array}{c}\text { Cross-functional } \\
\text { exploration }\end{array}$} \\
Market exploitation & $\begin{array}{c}\text { Within-functional } \\
\text { ambidexterity }\end{array}$ & $\begin{array}{c}\text { Cross-functional } \\
\text { ambidexterity }\end{array}$ & \\
Product exploitation & $\begin{array}{c}\text { Cross-functional } \\
\text { ambidexterity }\end{array}$ & $\begin{array}{c}\text { Within-functional } \\
\text { ambidexterity }\end{array}$ & $\begin{array}{c}\text { Cross-functional } \\
\text { exploitation }\end{array}$ \\
\hline
\end{tabular}

By studying exploration and exploitation in two domains, the present study is expected to make contributions in at least three ways. First, the present study is expected to provide a more comprehensive and precise understanding of the influence of these strategies on firm performance. Even though exploration and exploitation originate from learning theory (March 1991), surprisingly, extant studies on exploration and exploitation largely overlook different learning processes of product knowledge vis-à-vis market knowledge. As a result, previous studies on exploration and exploitation have paid disproportionately less attention to market domain than product domain. Specifically, the majority of studies in this field have mixed product and market ambidexterity or merely focused on product ambidexterity (e.g., He and Wong 2004; Luger et al. 2018; Uotila et al. 2009; Yalcinkaya et al. 2007), and only a small number of studies have focused on market ambidexterity (e.g., Josephson et al. 2016; Voss and Voss 2013; Zhang et al. 2015). However, it is noticeable that the processes of exploration and exploitation of market knowledge differ from those of product knowledge, and therefore the relationship between exploration and exploitation might differ in the two domains (Zhou et al. 2005). Hence, it is necessary to separately investigate exploration, exploitation, and 
ambidexterity in the product versus market domain and examine the outcomes of strategic emphasis combinations on firm performance to thoroughly understand these strategies.

Second, the results of this study reconcile the inconsistent results on the influence of strategies on firm performance in extant studies. For example, the influence of ambidexterity on firm performance is highly debated in the literature (Jin et al. 2016; Lubatkin et al. 2006; Nielsen and Gudergan 2012; Stubner et al. 2012; Yalcinkaya et al. 2007). To reconcile the inconsistencies, the present study tests whether a firm should pursue ambidexterity within a domain or across domains. Many studies show that ambidexterity is a challenging task for firms because of exploration-exploitation tensions caused by the fact that the two strategies demand different resources and capabilities and thus compete for limited resources within firms (Uotila et al. 2009). However, I argue that when firms implement exploration in one domain but exploitation in the other domain (i.e., cross-functional ambidexterity), competition for resources between the two strategies might not be as intensive as it is when firms implement exploration and exploitation within one functional domain (i.e., within-functional ambidexterity). Therefore, exploration-exploitation tensions within firms should be smaller when pursuing cross-functional ambidexterity than within-functional ambidexterity.

Following this logic, the relationship between ambidexterity and firm performance should vary depending on the domains where ambidexterity is executed, the core question this essay aims to answer. In addition, the present study also examines possible moderators between ambidexterity and firm performance, including firm characteristics and methodological moderators. For example, many debates exist on what is the most appropriate method to measure ambidexterity (e.g., Fernhaber and Patel 2012; Gurtner and Reinhardt 2016; Josephson et al. 2016; Lin et al. 2009; Wei et al. 2013). Hence, this study examines whether different 
measurements of ambidexterity could lead to different empirical results on the influence of product ambidexterity on firm performance. Answering these questions will help us understand the contingencies of the influence of strategies on firm performance.

Finally, the findings will help firms understand how to leverage exploration or exploitation. As more and more scholars point out that firms should pursue ambidexterity, simple focus on exploration or exploitation across functional domains within firms seems to be doomed (Van Looy et al. 2005; Simsek et al. 2009). However, it is not feasible for all firms to implement ambidexterity (Ebben and Johnson 2005), especially for firms that do not have capabilities to coordinate exploration and exploitation (Voss and Voss 2013). Given that cross-functional exploration or exploitation might be the only viable option for some firms, it is critical to know under what conditions they could increase firm performance so that the firms could avoid the disadvantages of cross-functional exploration or exploitation. However, extant empirical studies have revealed inconsistent, if not opposite, results on the influences of cross-functional exploration or exploitation on firm performance. For example, Voss and Voss (2013) have found that engaging in exploitation in both product and market domains (i.e., cross-functional exploitation) positively influences firm performance because doing so could achieve congruent mindsets and goals within a firm. By contrast, Zhang et al. (2017) have demonstrated the negative influences of cross-functional exploitation on firm performance because such a strategy could lead to obsolescence of products and market knowledge. The inconsistent results indicate the existence of moderators. Thus, the present study examines moderators between crossfunctional exploration and exploitation and firm performance so that firms might capitalize on the strategies according to their own characteristics. 
In sum, previous literature has provided limited insight on the influence of withinfunctional ambidexterity, cross-functional ambidexterity, cross-functional exploration, and crossfunctional exploitation on firm performance. To enrich the literature, this essay examines the influence of strategic emphasis combinations on firm performance and the relevant moderators (See Figure 1). The examinations of these relationships will shed insight on how firms choose appropriate strategies according to their own characteristics. In addition, the results could help reconcile inconsistent findings.

Figure 1: The impacts of strategic emphasis combinations on firm performance adapted from Voss and Voss (2013)

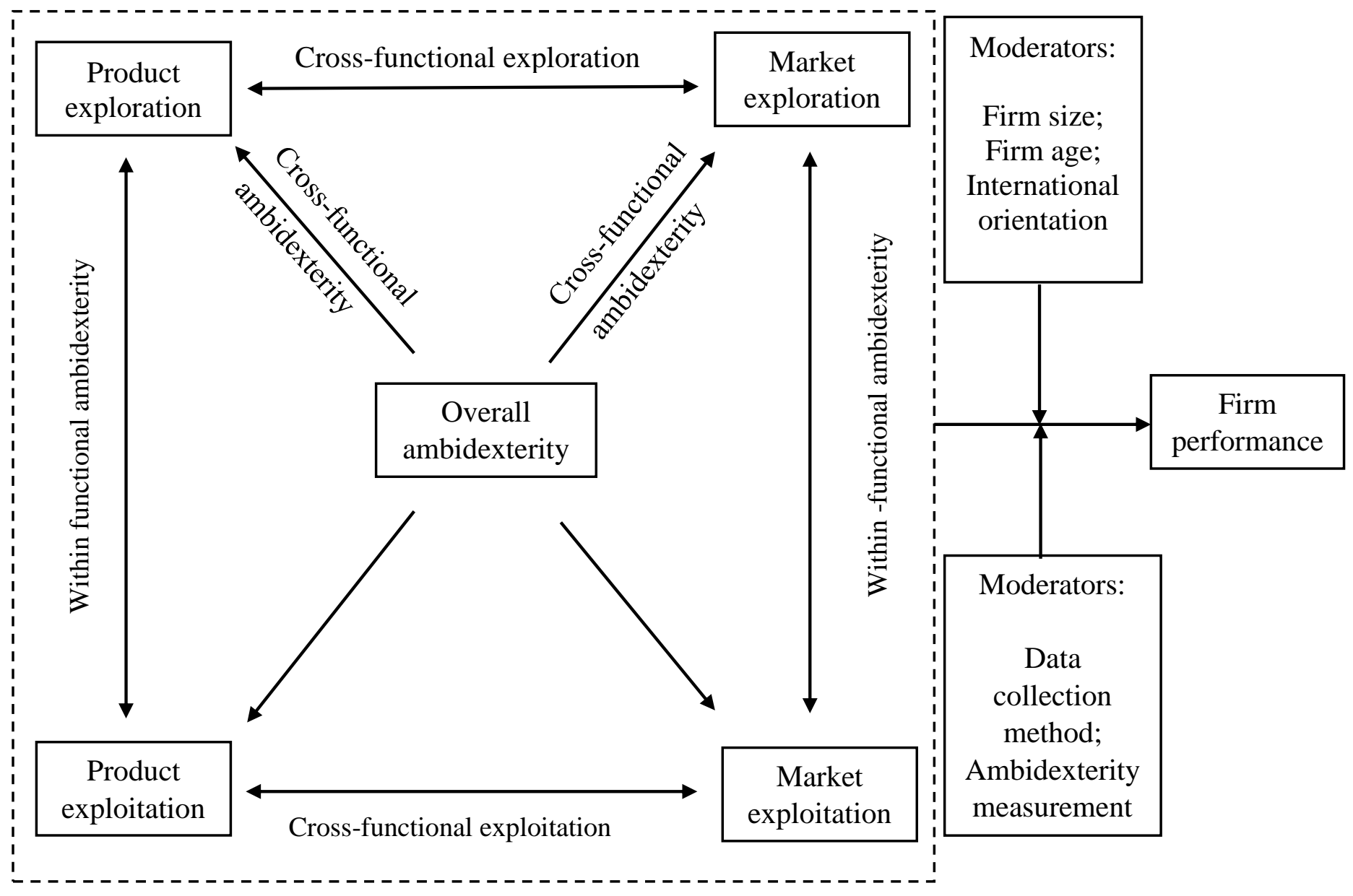

In the remainder of this essay, I first review the literature on exploration and exploitation and then propose hypotheses about the influence of within-functional ambidexterity, cross- 
functional ambidexterity, cross-functional exploration, and cross-functional exploitation on firm performance. Next, I explain the methodology and results. I conclude the essay with discussions, implications, limitations, and future research directions.

\section{Theoretical background and hypotheses}

\subsection{Exploration and exploitation}

Exploration includes firm activities "such as search, variation, risk taking, experimentation, play, flexibility, discovery, and innovation," whereas exploitation includes activities such as "refinement, choice, production, efficiency, selection, implementation, and execution" (March 1991, p. 71). Previous studies posit that exploration and exploitation reflect different orientations and goals and involve different activities, so they demand different resources and capabilities within firms (Beverland et al. 2015; March 1991). Since many resources such as facilities and managers cannot be shared between exploration and exploitation (Beverland et al. 2015; Koryak et al. 2018), ambidexterity causes tensions within firms, which in turn might hinder firm performance (Koryak et al. 2018).

Firm performance may be influenced by multiple forms of exploration-exploitation tensions: outside vs. inside, new vs. old, determined vs. emergent, and freedom vs. responsibility (Dougherty 1996). However, it is noticeable that the degree of exploration-exploitation tensions should be different in the product domain from that in the market domain. Specifically, I propose that the tensions in the product domain should be smaller than in the market domain because exploration and exploitation are likely to boost each other in the product domain but not in the market domain. In addition, I propose that exploration-exploitation tensions will be further reduced when firms pursue cross-functional ambidexterity rather than within-functional ambidexterity. This is because when resources for exploration are from one domain and 
exploitation from the other domain, ambidexterity may not stretch resources within firms (Voss and Voss 2013). Finally, the tensions will vanish when firms deploy cross-functional exploration or cross-functional exploitation. In sum, I propose that exploration-exploitation tensions are greatest when firms pursue market ambidexterity, followed by product ambidexterity, crossfunctional ambidexterity, and cross-functional exploration or exploitation. Therefore, ambidexterity is expected to decrease firm performance in the market domain but increase firm performance in the product domain or across functional domains. Moreover, cross-functional exploration and exploitation are expected to increase firm performance. The following section will discuss these influences in detail.

\subsection{Within-functional ambidexterity}

In the product domain, exploration highlights invention of new products and technologies and radical improvements of existing products; while exploitation highlights reducing production costs, increasing product quality, and refining existing products (Voss and Voss 2013). I argue that exploration-exploitation tensions in the product domain are moderate because when firms proactively engage in product exploration, current product knowledge usually constitutes a foundation of new products (Cohen and Levinthal 1990; McDermott and O'Connor 2002). Typically, firms invent new technologies by building on previous knowledge stock (Dewar and Dutton 1986). As Kogut and Zander (1992) posit, “in general, innovations are new combinations of existing knowledge and incremental learning" (Kogut and Zander 1992, p. 392). In addition, the effectiveness of firms' capitalizing on new technologies depends on the depth and width of the firms' existing knowledge base (Dewar and Dutton 1986; Kogut and Zander 1992). This notion is also confirmed by the fact that many radical innovations emerge in large firms rather than small firms because the former usually have more extensive knowledge base (Ettlie et al. 
1984). In sum, product exploration is "likely to arise from well-funded, sophisticated research labs where many top scientists spend their days putting together the technologies of the future" (Sorescu et al. 2003, p. 85). It can be argued that product exploration and exploitation are built upon each other and are less likely to cause tensions within the firm. Therefore, explorationexploitation tensions in the product domain should be moderate and could be overcome by firms' management, and therefore, should not hinder firm performance.

Furthermore, the present study proposes that product ambidexterity increases firm performance. Since exploration-exploitation tensions in the product domain could be surmounted (Yang et al. 2013), product ambidexterity may function as a core driver of building and sustaining competitive advantages in the marketplace (Benner and Tushman 2003; Lubatkin et al. 2006). This situation is especially true in the contemporary marketplace where products are being upgraded at an accelerated speed (Carbonell and Rodriguez 2006). In a fast-changing marketplace, many firms consider launching new products an effective tool to beat their competitors (Holahan et al. 2014; Scott 2000). Therefore, dynamic market environments force all firms to keep exploring and upgrading products to guarantee a long-term survival (Fethke and Birch 1982). However, product exploration certainly entails high risks and uncertainties and requires considerable investments (Shi et al. 2020). To guarantee sufficient capital resources for product exploration, firms must rely on products that already could bring stable profits in the short term (Wang and Dass 2017). Therefore, firms should deploy product ambidexterity where product exploitation provides capital resources for product exploration so as to beat competitors in the market (Morgan and Berthon 2008). More importantly, when firms deploy product ambidexterity, it is difficult for competitors to encrypt and imitate product innovation and improvement processes (Zhang et al. 2016). Thus, product ambidexterity could make product 
innovation capabilities more sustainable (Li and Huang 2012; Tushman and O’Reilly 1996). Therefore, I hypothesize that:

H1: Product ambidexterity is related positively to firm performance.

In the market domain, exploration highlights developing marketing programs to attract new customers while market exploitation highlights developing marketing programs to retail and evoke more purchases from current customers (Voss and Voss 2013). Market ambidexterity means that firms develop marketing programs to stimulate more purchases in the current markets and to attract customers in new markets. Market exploration is likely to arise when firms want to "nullify their competitors' strength" and avoid head-to-head competition with rivals (Zhou et al. 2005, p. 47). Therefore, target market choice might not always be at firms' hands, but sometimes firms must enter a market featured with less fierce competition. In this sense, when firms are pushed to a new market by competitors, the new market might be rather distinct from the old market in terms of consumer characteristics, consumers' demands on products and services, institutional environments, social norms, etc. The distinctions make it difficult for firms to transfer current market knowledge to the new market (Lord and Ranft 2000). That is to say, when firms enter a new market segment, many marketing resources that work well in current markets may underperform in the new market. For example, when Lenovo enters business-tobusiness market with the same products, they must invest different marketing resources, develop different marketing programs, and learn new market knowledge according to the new target markets. Therefore, I argue that marketing knowledge learned from current markets may not facilitate market exploration in a new market segment. Consequently, exploration-exploitation tensions in the market domain will be high and not be easy to overcome. 
Additionally, I propose that market ambidexterity might decrease firm performance, which has been empirically demonstrated in the extant literature. For example, Zhang et al. (2015) have found that market ambidexterity decreases firm performance because heterogeneous information brought by market ambidexterity challenges firms' capabilities to interpret and integrate such information in a timely manner. In addition, market ambidexterity also stretches firms' resources (Zhang et al. 2015). Likewise, Vorhies et al. (2011) have demonstrated that market ambidexterity decreases firm performance by decreasing firms' market capability. In sum, previous studies suggest that attempts to maximize both exploration and exploitation in the market domain would backfire. Consistent with previous studies, I hypothesize that:

H2: Market domain ambidexterity is related negatively to firm performance.

\subsection{Cross-functional ambidexterity}

Since exploration-exploitation tensions exist when within-functional ambidexterity is implemented, scholars propose that firms could mitigate the tensions via achieving an ambidexterity across functional domains (Voss and Voss 2013). Cross-functional ambidexterity means that firms deploy exploration in one functional domain but exploitation in the other domain. Specifically, there are two types of cross-functional ambidexterity. First, firms implement exploration in the product domain but exploitation in the market domain, in which they highlight selling new products to current consumers (Voss and Voss 2013). Alternatively, firms implement exploration in the market domain but exploitation in the product domain, in which they sell current products to new markets (Voss and Voss 2013). Organizational learning theory provides explanations why cross-functional ambidexterity increases firm performance. Based on organizational learning theory, ambidexterity hinders firm performance when exploration and exploitation create uncompromisable tensions within firms (Belderbos et al. 
2009; March 1991). When firms allocate resources from one domain to exploration and resources from the other domain to exploitation, ambidexterity should create only moderate levels of tensions within firms. In addition, cross-functional ambidexterity should decrease exploration-exploitation tensions by reducing the complexity of coordination activities to a manageable level (Lavie and Rosenkopf 2006). Therefore, cross-functional ambidexterity should decrease managers' pressure to coordinate exploration and exploitation. In sum, because crossfunctional ambidexterity may not extensively stretch firms' resources and challenge managers' capabilities, the moderate exploration-exploitation tensions do not decrease firm performance.

Moreover, I propose that engaging in exploration in one functional domain and exploitation in the other functional domain could bring benefits from the equilibrium within firms (Lavie et al. 2011). For instance, when firms deploy exploration in the product domain and exploitation in the market domain, uncertainty and risks accompanied with exploration could be attenuated to a controllable level since exploration is conducted in only one domain. Moreover, stable benefits could be reaped because of specialization in the current markets. Likewise, engaging in exploration in the market domain and exploitation in the product domain is likely to increase firm performance. This is because expansion into new markets with existing products could leverage firms' skills and knowledge in broader markets, lead to economies of scale, and avoid missing valuable market opportunities (Edeling and Himme 2018; Kim et al. 1993; Vorhies et al. 2011), leading to growth and profitability (Zahra et al. 2000). In other words, cross-functional ambidexterity could decrease exploration-exploitation tensions within a firm by avoiding risks coupled with excessive exploration and perils with excessive exploitation (Winterhalter et al. 2016). In this sense, firms should benefit from cross-functional 
ambidexterity, and the notion has been demonstrated by empirical studies (Lavie and Rosenkopf 2006).

In addition, benefits of cross-functional ambidexterity echo with the congruence model of organizational behavior. The core problem that the congruence model attempts to solve is how to formulate and implement a strategy to increase firm performance given the business environment and a firm's resources and history (Nadler and Tushman 1980). The congruence model considers a firm a system consisting of a set of interrelated elements such as environment, resources, organizational culture, and strategy (Milliman et al. 1991; Priem 1994). To achieve superb performance, firms should achieve a congruence between those interrelated elements (Fry and Smith 1987; Nadler and Tushman 1980). Congruences between two elements are defined as "the degree to which the needs, demands, goals, objectives, and/or structures of one component are consistent with the needs, demands, goals, objectives, and/or structures of another component" (Nadler and Tushman 1980, p. 45). Firm performance is a function of the extent to which components within a firm fit together (Nadler and Tushman 1980). Generally speaking, the greater the congruence between components within firms, the better the firm performance will be. Moreover, firms also could achieve great performance when a small number of incongruences exist within firms because the incongruences may trigger firms to make changes (Nadler and Tushman 1980).

When a firm engages in cross-functional ambidexterity, only a small amount of exploration-exploitation tensions would be aroused because product-oriented learning is somehow independent of market-oriented learning (Voss and Voss 2013). It is likely that the small tensions could foster creative thoughts and activities instead of sabotaging firm performance (Voss and Voss 2013). As the congruence model posits, one critical characteristic 
of an organization is its adaptation to environmental conditions, and the small tensions could increase a firm's adaptability and responsiveness to environmental changes (Nadler and Tushman 1980). For example, when newly launched products are not well accepted in current markets, firms sense that they need to adapt the products to the markets. If firms could adjust their products accordingly, they would eventually survive in the market (Nadler and Tushman 1980). In this sense, the small tensions caused by cross-functional ambidexterity could make firms alert and responsive to environments and survive in the long run.

In sum, based on organizational learning theory and the congruence model of organizational behavior, I propose that cross-functional ambidexterity could attenuate exploration-exploitation tensions, help firms enjoy benefits of the balance, and capitalize on advantages of specialization and adaptation. Therefore, I hypothesize that:

H3: Cross-functional ambidexterity is related positively to firm performance.

\subsection{Cross-functional exploration and cross-functional exploitation}

Because of exploration-exploitation tensions, ambidexterity might not be feasible for resource-constrained firms. Therefore, such firms must adopt a simple focus on exploration or exploitation across functional domains (Voss and Voss 2013). Specifically, cross-functional exploration means that firms only deploy exploration in both product and market domains, while cross-functional exploitation means that firms only deploy exploitation in both domains (Voss and Voss 2013). Specifically, cross-functional exploration highlights developing and selling new products when entering new markets; while cross-functional exploitation highlights refining current products to evoke more purchases by current consumers.

The congruence model of organizational behavior serves as a theoretical foundation to examine the influence of cross-functional exploration or exploitation on firm performance. I 
propose that firms could easily build congruence between components within firms when deploying cross-functional exploration or exploitation. Exploration emphasizes something new while exploitation emphasizes something old (March 1991). Specifically, exploration requires firms' greater entrepreneurship, openness to uncertainty, and tolerance for failures while exploitation requires firms' focus on efficiency and a deep understanding of current knowledge (Andriopoulos and Lewis 2009). If both product and market domains pursue the same strategy, people in both product and market departments would show congruent behavioral patterns and have aligned goals (Andriopoulos and Lewis 2010). Under this circumstance, explorationexploitation tensions are not expected to be high; thus it is more likely for firms to achieve better performance. Formally, I hypothesize that:

H4: Cross-functional exploration and cross-functional exploitation are related positively to firm performance.

\section{Methodology}

To test the hypotheses, I conducted a meta-analytic study, which has been commonly used to reconcile conflicting results via testing moderators in the marketing field (e.g., Crosno and Brown 2015; Grewal et al. 2018; Verma et al. 2016). Specifically, the present study uses a meta-analysis to integrate conflicting results on the influences of strategic emphasis combinations on firm performance through testing relevant moderators including firm size, firm age, international orientation, data collection method, and ambidexterity measurement. This section describes the procedure of conducting the meta-analysis. Specifically, I detail the process of searching for literature, coding sample empirical studies, and analyzing data. Then, the results are explained and discussed. 


\subsection{Literature search}

I performed a keyword search (e.g., exploration, exploitation, or ambidexterity) of the management (83) and marketing (78) journals included in ABI/Global Inform and Business Source Premiere databases between 1990-2019. Two criteria were used to screen each paper: (1) it included the correlations between exploration, exploitation, and/or ambidexterity and firm performance, and (2) it had sufficient information to calculate effect sizes. Sample studies included in the meta-analytic study are published in the following journals: Academy of Management Journal, Asia Pacific Journal of Management, European Management Journal, Industrial Marketing Management, Journal of Business \& Industrial Marketing, Journal of Business Research, Journal of International Marketing, Journal of Knowledge Management, Journal of Management, Journal of Management Studies, Journal of Operations Management, Journal of Product Innovation Management, Journal of Services Marketing, Journal of Small Business Management, Journal of Strategic Marketing, Journal of World Business, Long Range Planning, Management Science, Organization Science, and Strategic Management Journal.

Based on my search, these journals publish the majority of the research on influence of ambidexterity on firm performance. Two independent researchers coded the studies, and disagreement were resolved through discussion (overall agreement > 90\%).

\subsection{Coding procedure}

The present study coded strategic emphasis combinations based on measurements. For instance, if a sample study measures product (or market) exploration and product (or market) exploitation, I coded it as product (or market) ambidexterity. If a sample study measures exploration in one domain but exploitation in the other domain, I coded it as cross-functional 
ambidexterity. If a sample study measures only exploration or exploitation in both fields, I coded it as cross-functional exploration or exploitation.

The present study coded five moderators: firm size, firm age, international orientation, data collection method, and ambidexterity measurements.

Firm size was measured by the average number of full-time employees, and firm age was measured by the average year since firms were established. Firm size is a proxy of firm resources and capabilities since usually large firms own more resources and stronger capabilities, and firm age reflects firm experience in managing tensions (McGrath et al. 1995; Shi et al. 2019). When firms have more resources for ambidexterity and more experienced in managing ambidexterity, ambidexterity should increase firm performance. Therefore, firm size and firm age should moderate the relationship between strategic emphasis combinations and firm performance.

Firm 's international orientation. Firms' international orientation should moderate the relationship between ambidexterity and firm performance because international firms confront more intense market competition and have more desire to learn new product and market knowledge. Since many studies do not measure this variable, this essay adopted a conservative method to code firms' international orientation. When a sample study is conducted in a context of exporting business, international alliance, or international joint venture, I coded firms in the study as high international orientation. Otherwise, international orientation is considered low.

Data collection method. I compared the effect sizes of sample studies using surveys to those using secondary data. I expected effect sizes to vary depending on data collection method because survey and secondary data have different degrees of measure errors (Shi et al. 2020). Ambidexterity measurement. Previous studies have used different methods such as addition, multiplication, division, and subtraction of exploration and exploitation to measure 
ambidexterity. And the different measurements lead to different results on the influence of ambidexterity on firm performance. Therefore, many debates have been aroused on the question of how to appropriately measure ambidexterity. Regarding the question, the present study examines the effect sizes in studies using different calculations of ambidexterity.

\subsection{Data analysis procedure and results}

\subsubsection{Data analysis process}

Consistent with previous studies (e.g., Crosno and Brown 2015), this study used Pearson's product moment correlation, $r$, to represent effect size. First, I used box-and-whisker plots to examine outliers. After deleting the outliers, I identified 160 effect sizes from 65 studies. Second, I conducted reliability correction to account for measurement errors in an Excel spreadsheet when sample studies reported reliabilities of variables. Next, I used the package of "metafor" in R program to calculate sample-weighted $r$, the $95 \%$ confident interval for the

sample-weighted $r$, fail-safe N, I square, and chi-square test of homogeneity. Finally, I conducted a meta-regression analysis on the effect sizes when possible.

\subsubsection{Univariate results}

Table 2 reports effect sizes of the relationships between strategic emphasis combinations and firm performance. The results show that product ambidexterity is related positively to firm performance $(\mathrm{r}=0.29, \mathrm{p}<0.05)$, supporting H1. However, the correlation between market ambidexterity and firm performance is not significantly related to firm performance, not supporting $\mathrm{H} 2(\mathrm{r}=0.34, \mathrm{p}>0.10)$. 
Table 2: The univariate results

\begin{tabular}{|c|c|c|c|c|c|}
\hline Strategic emphasis combinations & $\mathrm{k}$ & Total N & Simple & Sample- & Chi-square of \\
\hline & & & $\mathrm{r}$ & Weighted r & homogeneity \\
\hline Product ambidexterity & 16 & $4,871,550$ & 0.20 & $0.29 * *$ & $2264.96 * * *$ \\
\hline Division & 3 & $2,431,593$ & -0.03 & $-0.03 * *$ & 244.41 \\
\hline Multiplication & 6 & 880 & 0.22 & $0.31 * *$ & 86.76 \\
\hline Subtraction & 3 & $2,431,638$ & 0.05 & $0.12 * *$ & 1538.69 \\
\hline Addition & 2 & 405 & 0.34 & $0.50 * * *$ & 10.50 \\
\hline Market ambidexterity & 4 & 690 & 0.23 & 0.34 & $119.78 * * *$ \\
\hline Cross-functional Ambidexterity & 2 & 235 & 0.18 & 0.24 & 15.80 \\
\hline Cross-functional Exploration & 54 & 17,555 & 0.24 & $0.39 * * *$ & $950.87 * * *$ \\
\hline Cross-functional Exploitation & 37 & 20,057 & 0.27 & $0.47 * * *$ & $1230.16 * * *$ \\
\hline \multirow{2}{*}{\multicolumn{2}{|c|}{ Strategic emphasis combinations }} & Lower & Upper & $\mathrm{I}^{2}$ & Fail-safe \\
\hline & & $95 \% \mathrm{CI}$ & $95 \% \mathrm{CI}$ & & \\
\hline Product ambidexterity & & 0.06 & 0.53 & $100.00 \%$ & 1,253 \\
\hline Division & & -0.05 & -0.01 & $99.2 \%$ & 1,678 \\
\hline Multiplication & & 0.04 & 0.54 & $94.2 \%$ & 215 \\
\hline Subtraction & & 0.07 & 0.17 & $99.90 \%$ & 676 \\
\hline Addition & & 0.21 & 0.71 & $90.50 \%$ & 79 \\
\hline Market ambidexterity & & -0.12 & 0.79 & $97.21 \%$ & 10 \\
\hline Cross-functional Ambidexterity & & -0.30 & 0.79 & $93.67 \%$ & 5 \\
\hline Cross-functional Exploration & & 0.28 & 0.48 & $97.61 \%$ & 25,884 \\
\hline
\end{tabular}


$\begin{array}{lllll}\text { Cross-functional Exploitation } & 0.32 & 0.60 & 98.96 \% & 15,077\end{array}$

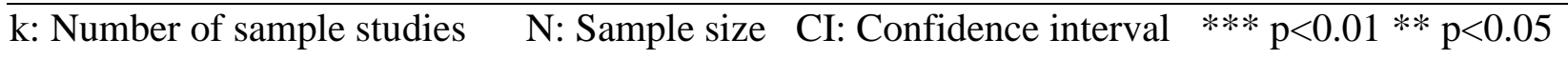

To test $\mathrm{H} 3$, which hypothesizes cross-functional ambidexterity is related positively to firm performance, I calculated the correlation between the strategy of product exploration/market exploitation and firm performance, since no sample studies have reported the correlations between the strategy of market exploration/product exploitation and firm performance. The results in Table 2 show that cross-functional ambidexterity is not significantly related to firm performance $(r=0.24, p>0.10)$. Therefore, $\mathrm{H} 3$ is not supported.

Finally, the results show that cross-functional exploration (i.e., exploration in product and market domains) and cross-functional exploitation (i.e., exploitation in product and market domains) are related positively to firm performance ( $r=0.39$ for exploration and $r=0.47$ for exploitation, $\mathrm{p}<0.05)$. Therefore, $\mathrm{H} 4$ is supported.

\subsubsection{Meta-regression results}

To identity the theoretical boundaries of the relationships, I conducted a meta-regression analysis on the effect sizes of the influence of product ambidexterity, cross-functional exploration, and cross-functional exploitation on firm performance (See Table 3). Compared to the subgrouping method, which has been commonly used to examine moderators in traditional meta-analytic studies, meta-regression avoids artificial dichotomization of continuous moderators (e.g., firm size and firm age) (Gonzalez-Mulé and Aguinis 2018). The small number of sample studies on market ambidexterity and cross-functional ambidexterity does not allow us to test possible moderators. In addition, because of plenty of missing values of moderators, I only conducted simple linear meta-regression, in which I incorporated only one moderator in the model at one time. Finally, because of the categorical nature of ambidexterity measurement, I 
conducted a subgroup analysis to test its moderating effects between product ambidexterity and firm performance.

Table 3: Meta-regression results

\begin{tabular}{llll}
\hline Independent variables & T value & P value & Number of observations \\
\hline DV: Effect size of the relationship between product ambidexterity and firm performance \\
Firm size & 0.00 & 0.86 & 5 \\
Firm age & $-0.18^{* * *}$ & $<0.01$ & 3 \\
International orientation & $0.29^{* *}$ & $<0.05$ & 15 \\
Research method & $0.45^{* * *}$ & $<0.05$ & 16 \\
(0-Secondary data; 1- Survey) & &
\end{tabular}

DV: Effect size of the relationship between cross-functional exploration and firm performance

Firm size

0.00

0.38

29

Firm age

$0.01 * *<0.05$

21

International orientation

0.03

0.13

54

Research method

$0.34 *$

0.08

53

(0-Secondary data; 1- Survey)

DV: Effect size of the relationship between cross-functional exploitation and firm performance

Firm size

0.00

0.17 23 


$\begin{array}{llll}\text { Firm age } & 0.01^{* *} & <0.05 & 19 \\ \text { International orientation } & 0.07 & 0.75 & 37 \\ \text { Research method } & 0.41^{* *} & <0.05 & 36 \\ \text { (0-Secondary data; 1- Survey) } & & & \end{array}$

$* * * \mathrm{p}<0.01 * * \mathrm{p}<0.05 * \mathrm{p}<0.10$

Moderating effects between product ambidexterity and firm performance. Firm size does not moderate the relationship between product ambidexterity and firm performance $(b<0.01, p$ $=0.86)$. Firm age, international orientation, and research method moderate the relationship. Specifically, the effect sizes are greater when firms age is young $(b=-0.18, p<0.01)$, when international orientation is high $(b=0.29, \mathrm{p}<0.05)$, or when survey is conducted than when secondary data is used $(b=0.45, p<0.05)$. Finally, I conducted a subgroup analysis to test the moderating effect of the ambidexterity measurement method. The results show that product ambidexterity negatively influences firm performance when division (i.e., |explorationexploitation|) is used to measure ambidexterity. When other methods are used, product ambidexterity positively influences firm performance, and the effect size is the biggest when addition is used.

Moderating effects between cross-functional exploration and firm performance. Firm size and international orientation do not moderate the relationship between cross-functional exploration and firm performance $(b<0.01, p=0.38$ for firm size; $b=0.03, p=0.13$ for international orientation). Firm age and research method positively moderate the relationship. Specifically, the effect sizes are greater when firms are older $(b=0.01, p<0.05)$ or when survey rather than secondary data is used $(b=0.34, \mathrm{p}<0.10)$. 
Moderating effects between cross-functional exploitation and firm performance. Firm size and international orientation do not moderate the relationship between cross-functional exploitation and firm performance $(b<0.01, p=0.17$ for firm size; $b=0.07, p=0.75$ for international orientation). Firm age and research method positively moderate the relationship. Specifically, the effect sizes are greater when firms are older $(b=0.01, p<0.05)$, or when survey rather than secondary data is used $(b=0.41, \mathrm{p}<0.05)$.

\section{Discussion}

\subsection{Overview of results}

Ambidexterity highlights simultaneous deployment of exploration, which highlights learning something new, and exploitation, which highlights improving something old. Because of the tensions between exploration and exploitation, many studies have investigated how to achieve a balance so that firms could capitalize on advantages and circumvent disadvantages of exploration and exploitation. However, how to achieve a balance has aroused many debates because of conflicting results on the influence of ambidexterity on firm performance. To reconcile the conflicting results and propose a solution to achieving the balance, the present study examines the influence of within-functional ambidexterity, cross-functional ambidexterity, cross-functional exploration, and cross-functional exploitation on firm performance. Moreover, to provide guidance for different types of firms on pursuing ambidexterity, I also test moderators between strategic emphasis combinations and firm performance.

Through quantitatively integrating previous studies via a meta-analytic study, I find that product ambidexterity positively influences firm performance while market ambidexterity does not significantly increase firm performance. The findings confirm the assertion that product ambidexterity and market ambidexterity influence firm performance differently because of the 
different processes and mechanisms through which firms learn product knowledge and market knowledge. Specifically, the process of exploration and exploitation is more continuous in the product domain than in the market domain. Therefore, exploration and exploitation boost each other in the product domain but not in the market domain. Hence, exploration-exploitation tensions in the product domain are only moderate and could increase firm performance. By contrast, the tensions in the market domain may be too extensive and thus go beyond firms' control. Consequently, market ambidexterity does not increase firm performance. In addition, the influence of product ambidexterity on firm performance is inflated when firms have high international orientation, or when survey is used to collect data rather than using secondary data. Opposing to the hypothesis, firm size does not moderate the relationship between product ambidexterity and firm performance, and firm age negatively moderates the relationship. Collectively, the results suggest that small or nascent firms could benefit from product ambidexterity as much as or even more than large or old firms. Many studies suggest that large or old firms should benefit more from product ambidexterity because they have more available resources and capabilities to coordinate exploration and exploitation. However, this essay reveals opposite findings. This might be because small or nascent firms are more flexible, and the flexibility enables those firms to refigure existing resources to respond more quickly to environmental changes.

Second, cross-functional ambidexterity does not increase firm performance, which contradicts the hypothesis. I hypothesize that adopting exploration in one functional domain but exploitation in the other domain should mitigate exploration-exploitation tensions to achieve a balance, which in turn increases firm performance. On the contrary, the results show that crossfunctional ambidexterity does not increase firm performance. The unexpected findings could be 
explained by at least two reasons. First, exploration in the product domain suffers high failure rates (March 1991). Because of the unavailability of studies, the present study examines only one situation of cross-functional ambidexterity, product exploration and market exploitation. Since the failure rate of product exploration is as high as 95\% (Christensen 2013), product exploration might not be able to increase firm performance even if firms are familiar with markets. The findings further shed light on the importance of ambidexterity in the product domain. Firms should sustain a level of product exploitation when engaging in product exploration. Otherwise, firm performance would be hurt. Second, the small number of sample studies does not allow us to examine possible moderators. Of the sample studies, only two report the correlations between cross-functional ambidexterity and firm performance. Therefore, I cannot conduct a moderator analysis. It is possible that cross-functional ambidexterity increases firm performance under some circumstances but decreases it under other circumstances.

Finally, the results show that cross-functional exploration and cross-functional exploitation increase firm performance. And the influences are greater in old firms than young firm, or when survey is used to collect data rather than secondary data. Moreover, firm size and international orientation do not moderate the relationships.

\subsection{Theoretical implications}

The findings of this essay make significant contributions to current literature. First, the findings deepen the understanding of ambidexterity. Ambidexterity refers to firms' simultaneous implementation of exploration and exploitation. Hence, to better understand the influence of ambidexterity, studies should clarify the relationship between exploration and exploitation. The findings of this essay provide two alternative perspectives to understand the relationship. First, studies investigating exploration and exploitation should separate product domain from market 
domain. Early studies highlight that firms should pursue exploration and exploitation simultaneously. However, they have not answered a key question: In which domains should a firm deploy exploration, and in which domains should a firm deploy exploitation? Therefore, some recent studies call for investigating exploration and exploitation across functional domains (Voss and Voss 2013). Corresponding to this call, this study investigates ambidexterity in two fundamental functional domains: product and market domains. The results show that product ambidexterity could increase firm performance, but market ambidexterity cannot. Second, the results answer a long-standing question: Do exploration and exploitation impel or impede each other? (Piao and Zajac 2016) The results of this study show that exploration and exploitation might impel each other in the product domain but impede each other in the market domain.

The findings challenge a traditionally held belief that firms should pursue ambidexterity. Previous studies posit that focus on exploration might lead to failure trap, in which firms often fail in exploration, and the failures lead to more exploration (Levinthal and March 1993). By contrast, exploitation might lead to competence trap, in which firms tightly stick to the products that help build competence and neglect possible obsolescence of products, trapping firms in their current comfort zones (Levinthal and March 1993). To avoid the failure or competence trap, previous studies posit that firms should pursue ambidexterity. As a result, cross-functional exploration or cross-functional exploitation seems to be doomed. However, my results show that these strategies could increase firm performance. Currently, many studies in this field take a perspective of a resource-based view and argue that with cross-functional exploration or crossfunctional exploitation it is difficult to develop resources and capabilities to build competitive advantages. This is because exploration entails too many risks, and exploitation might lead to myopia. However, by quantitively integrating previous empirical results, the present study shows 
that cross-functional exploration or exploitation could increase firm performance especially for old firms. In this sense, the results are consistent with the congruence model of organizational behavior, which has not yet attracted enough research attention in the field of ambidexterity. Specifically, implementing exploration or exploitation across two functional domains within a firm could achieve congruent goals and mindsets, thereby increasing efficiency. Therefore, the results of this study suggest that studies on exploration and exploitation should incorporate the congruence model of organizational behavior into their rationales.

Moreover, surprisingly, the results show that firm size does not moderate the relationship between the strategic emphasis combinations and firm performance. Previous studies suggest that ambidexterity should lead to better firm performance in large firms than in small firms because large firms have more available resources for ambidexterity and more talented managers to manage the tensions between exploration and exploitation. By contrast, the results of this study do not confirm this notion. Two reasons could explain the unexpected findings. First, admittedly, large firms have more available resources and talented managers. However, compared to small firms, they suffer perils of bureaucracy. As a result, large firms may not be able to rapidly place the right people and things in the right places to do the right tasks. And it is more difficult to align goals and mindsets in large firms than in small firms. By contrast, small firms are more responsive to environmental changes and rapidly formulate measures to issues in the process of implementing ambidexterity. Therefore, ambidexterity might not hinder small firms' performance. Second, although plenty of resources are needed for implementation of ambidexterity, small firms could scale down explorative and exploitative projects to save resources. For example, when pursuing exploration, small firms may register only a small 
number of patents to pay less in fees. As a result, small firms could make ambidextrous activities within their control.

Finally, the results also contribute to existing meta-analytic studies on ambidexterity. Previous meta-analytics studies attempt to identity how the influence of ambidexterity varies depending on conditions such as measurement, firm size, firm age, time span, and so on (Junni et al. 2013; Mathias, 2014; Mathias et al. 2018). However, those studies have not identified conditions under which ambidexterity negatively influences firm performance. By separating ambidexterity in product and market domains, the findings of this study show that ambidexterity reduces firm performance in the product domain when division is used to measure ambidexterity.

\subsection{Managerial implications}

The findings provide important implications for managers. First, the present study answers the question: How do firms implement ambidexterity? The results show that pursuing ambidexterity in the product domain could increase firm performance while pursuing ambidexterity in the market domain could not increase firm performance. Therefore, the findings suggest that firms should simultaneously invest in inventing new products and in refining current products. Many firms, especially high-tech firms often stop providing maintenance services for old-generation products after launching new-generation products. The results of this study show that this business practice might hinder firm performance. First, improving and refining current products might create some new ideas for innovating products, or increase production efficiency and reduce costs. Second, firms might irritate and lose consumers who use old-generation products if the consumers are neglected, and those customers are usually loyal customers. Therefore, firms should take appropriate measures to pursue product ambidexterity. By contrast, pursuing market ambidexterity is likely to decrease performance. This might be because 
marketing tactics to enter markets may hurt old consumers' feelings. Many times, we see that firms provide first-purchase discounts and rewards that old consumers do not get. In this case, old consumers may be resented and boycott the brand. Therefore, firms should pay special attention to balancing market exploration and exploitation.

In addition, the results show that pursuing ambidexterity is not a requirement. These findings are very important for resource-constrained firms. According to existing studies, it is plausible that firms would ultimately be eliminated from the competition if they do not adopt ambidexterity. The findings of this study show that if firms could competently execute either exploration or exploitation, they would survive in the market. In sum, I suggest that ambidexterity might be profitable only when firms are fully ready in terms of resources, top management support, employees' mindsets, and so on.

\subsection{Limitations and future research directions}

Like all meta-analysis studies, this study might overlook some studies, especially those that are unpublished. In addition, many studies have not reported correlations, reducing the availability of data.

Another limitation is that no sample studies have yet investigated the outcomes of a strategy where firms deploy exploration in the market domain but exploitation in the product domain. Therefore, future research should examine if this strategy increases firm performance.

Finally, the number of sample studies on market ambidexterity is somewhat small. The small number is caused by insufficient research attention on market ambidexterity. Future research should put more focus on market ambidexterity since firms use different strategies to process market knowledge from product knowledge. 


\section{References}

Andriopoulos, C., \& Lewis, M. W. (2009). Exploitation-exploration tensions and organizational ambidexterity: Managing paradoxes of innovation. Organization Science, 20(4), 696-717.

Andriopoulos, C., \& Lewis, M. W. (2010). Managing innovation paradoxes: Ambidexterity lessons from leading product design companies. Long Range Planning, 43(1), 104-122.

Auh, S., \& Menguc, B. (2005). Balancing exploration and exploitation: The moderating role of competitive intensity. Journal of Business Research, 58(12), 1652-1661.

Belderbos, R., Faems, D., Leten, B., \& Looy, B.V. (2009). Technological activities and their impact on the financial performance of the firm: Exploitation and exploration within and between firms. Journal of Product Innovation Management, 27(6), 869-882.

Benner, M. J., \& Tushman, M. L. (2003). Exploitation, exploration, and process management: The productivity dilemma revisited. Academy of Management Review, 28(2), 238-256.

Beverland, M. B., Wilner, S. J. S., \& Micheli, P. (2015). Reconciling the tension between consistency and relevance: Design thinking as a mechanism for brand ambidexterity. Journal of the Academy of Marketing Science, 43(5), 589-609.

*Calantone, R., \& Rubera, G. (2012). When should RD \& E and marketing collaborate? the moderating role of exploration-exploitation and environmental uncertainty. Journal of Product Innovation Management, 29(1), 144-157.

Carbonell, P., \& Rodriguez, A. (2006). The impact of market characteristics and innovation speed on perceptions of positional advantage and new product performance. International Journal of Research in Marketing, 2(1), 1-12.

*Cao, Q, Gedajlovic, E., \& Zhang, H. (2009). Unpacking organizational ambidexterity: Dimensions, contingencies, and synergistic effects. Organization Science, 20(4), 781-796. 
*Cenamor, J., Parida, V., \& Wincent, J. (2019). How entrepreneurial SMEs compete through digital platforms: The roles of digital platform capability, network capability and ambidexterity. Journal of Business Research, 100, 196-206.

*Chandrasekaran, A., Linderman, K., \& Schroeder, R. (2012). Antecedents to ambidexterity competency in high technology organizations. Journal of Operations Management, 30(1-2), 134-151.

*Chang, Y., \& Hughes, M. (2012). Drivers of innovation ambidexterity in small-to-mediumsized firms. European Management Journal, 30(1), 1-17.

*Chen, M., Yang, Z., Dou, W, \& Wang, F. (2018). Flying or dying? Organizational change, customer participation, and innovation ambidexterity in emerging economies. Asia Pacific Journal of Management, 35(1), 97-119.

Choi, S., \& McNamara, G. (2018). Repeating a familiar pattern in a new way: The effect of exploitation and exploration on knowledge leverage behaviors in technology acquisitions. Strategic Management Journal, 39(2), 356-378.

Christensen, C. M. (2013). The innovator's dilemma: when new technologies cause great firms to fail (Reprint ed.). Harvard Business Review Press

Cohen, W. M., \& Levinthal, D. A. (1990). Absorptive capacity: A new perspective on learning and innovation. Administrative Science Quarterly, 35(1), 128-153.

Crosno, J. L., \& Brown, J. R. (2015). A meta-analytic review of the effects of organizational control in marketing exchange relationships. Journal of the Academy of Marketing Science, 43(3), 297-314. 
*Cui, A. S., \& Wu, F. (2016). Utilizing customer knowledge in innovation: Antecedents and impact of customer involvement on new product performance. Journal of the Academy of Marketing Science, 44(4), 516-538.

Cyert, R., \& March, J. (1963). A behavioral theory of the firm. Englewood Cliffs, NJ: Prentice Hall.

*Dao, M. A., Strobl, A., Bauer, F., \& Tarba, S. Y. (2017). Triggering innovation through mergers and acquisitions: The role of shared mental models. Group \& Organization Management, 42(2), 195-236.

Dasí, À., Iborra, M., \& Safón, V. (2015). Beyond path dependence: Explorative orientation, slack resources, and managerial intentionality to internationalize in SMEs. International Business Review, 24(1), 77-88.

Dewar, R. D., \& Dutton, J. E. (1986). The adoption of radical and incremental innovations: An empirical analysis. Management Science, 32(11), 1422-1433.

Dougherty, D. (1996). Organizing for innovation. S. R. Clegg, C. Hardy, W. R. Nord, eds. Handbook of Organization Studies. Sage, Thousand Oaks, CA.

*Douglas, T. J., \& Judge, Jr., W. Q. (2001). Total quality management implementation and competitive advantage: The role of structural control and exploration. Academy of Management Journal, 44(1), 158-169.

Dunlap, D., McDonough III, E. F., Mudambi, R., \& Swift, T. (2016). Making up is hard to do: Knowledge acquisition strategies and the nature of new product innovation. Journal of Product Innovation Management, 33(4), 472-491.

Ebben, J. J., \& Johnson, A. C. (2005). Efficiency, flexibility, or both? Evidence linking strategy to performance in small firms. Strategic Management Journal, 26(13), 1249-1259. 
Edeling, A., \& Himme, A. (2018). When does market share matter? New empirical generalizations from a meta-analysis of the market share-performance relationship. Journal of Marketing, 82(3), 1-24.

Ettlie, J. E., Bridges, W. P., and O'Keefe, R. D. (1984). Organization strategy and structural differences for radical versus incremental innovation. Management Science, 30(6), 682-695.

Fethke, G. \& Birch, J. (1982). Rivalry and the timing of innovation. Bell Journal of Economics, 13(1), 272-279.

*Fernhaber, S. A., \& Patel, P. C. (2012). How do young firms manage product portfolio complexity? The role of absorptive capacity and ambidexterity. Strategic Management Journal, 33(13), 1516-1539.

Fry, L. W., \& Smith, D. A. (1987). Congruence, contingency, and theory building. The Academy of Management Review, 12(1), 117-132.

*Gibson, C. B., \& Birkinshaw, J. (2004). The antecedents, consequences, and mediating role of organizational ambidexterity. Academy of Management Journal, 47(2), 209-226.

Gonzalez-Mulé, E., \& Aguinis, H. (2018). Advancing theory by assessing boundary conditions with metaregression: A critical review and best-practice recommendations. Journal of Management, 44(6), 2246-2273.

Grewal, D., Puccinelli, N., \& Monroe, K. B. (2018). Meta-analysis: Integrating accumulated knowledge. Journal of the Academy of Marketing Science, 46(1), 9-30.

Gupta, A., Smith, K. G., \& Shalley, C. E. (2006). The interplay between exploration and exploitation. Academy of Management Journal, 49(4), 693-706.

*Gurtner, S., \& Reinhardt, R. (2016). Ambidextrous idea generation-antecedents and outcomes. Journal of Product Innovation Management, 33(S1), 34-54. 
*He, Z. L., \& Wong, P. K. (2004). Exploration vs. exploitation: An empirical test of the ambidexterity hypothesis. Organization Science, 15(4), 481-494.

*Ho, H., \& Lu, R. (2015). Performance implications of marketing exploitation and exploration: Moderating role of supplier collaboration. Journal of Business Research, 68(5), 1026-1034.

Holahan, P. J., Sullivan, Z. Z., \& Markham, S. K. (2014). Product development as core competence: How formal product development practices differ for radical, more innovative, and incremental product innovations. Journal of Product Innovation Management, 31(2), $329-345$.

*Hsu, C. W., Lien, Y. C., \& Chen, H. (2013). International ambidexterity and firm performance in small emerging economies. Journal of World Business, 48(1), 58-67.

Hughes, M. (2018). Organizational ambidexterity and firm performance: Burning research questions for marketing scholar. Journal of Marketing Management, 34(1-2), 178-229.

*Hughes, M., Martin, S. L., Morgan, R. E., \& Robson, M. J. (2010). Realizing product-market advantage in high-technology international new ventures: The mediating role of ambidextrous innovation. Journal of International Marketing, 18(4), 1-21.

*Jansen, J. J. P., Simsek, Z., \& Cao, Q. (2012) Ambidexterity and performance in multiunit contexts: Cross-level moderating effects of structural and resource attributes. Strategic Management Strategy, 33(11), 1286-1303.

*Jansen, J. J. P., Van Den Bosch, F. A. J., \& Volberda, H. W. (2006). Exploratory innovation, exploitative innovation, and performance: Effects of organizational antecedents and environmental moderators. Management Science, 52(11), 1661-1674. 
Jin, J. L., Zhou, K. Z., \& Wang, Y. (2016). Exploitation and exploration in international joint ventures: Moderating effects of partner control imbalance and product similarity. Journal of International Marketing, 24(4), 20-38.

Josephson, B. W., Johnson, J. L., \& Mariadoss, B. J. (2016). Strategic marketing ambidexterity: Antecedents and financial consequences. Journal of the Academy of Marketing Science, 44(4), 539-554.

Junni, P., Sarala, R. M., Taras, V., \& Tarba, S. Y. (2013). Organizational ambidexterity and performance: A meta-analysis. Academy of Management Perspectives, 27(4), 299-312.

*Lavie, D., \& Rosenkopf, L. (2006). Balancing exploration and exploitation in alliance formation. Academy of Management Journal, 49(4), 797-818.

*Lee, K., Woo, H. G., \& Joshi, K. (2017). Pro-innovation culture, ambidexterity and new product development performance: Polynomial regression and response surface analysis. European Management Journal, 35(2), 249-260.

Levinthal, D. A., \& March, J. G. (1993). The myopia of learning. Strategic Management Journal, 14(S2), 95-112.

*Lin, L. H., \& Ho, Y. L. (2016). Institutional pressures and environmental performance in the global automotive industry: The mediating role of organizational ambidexterity. Long Range Planning, 49(6), 764-775.

*Li, Y. H., \& Huang, J. W. (2012). Ambidexterity’s mediating impact on product development proficiency and new product performance. Industrial Marketing Management, 41(7), 11251132. 
*Li, D., Lin, J., Cui, W., \& Qian, Y. (2018). The trade-off between knowledge exploration and exploitation in technological innovation. Journal of Knowledge Management, 22(4), 781801.

*Lin, H. E., McDonough III, E. F., Lin, S. J., \& Lin, Y. Y. (2013). Managing the exploitation/exploration paradox: The role of a learning capability and innovation ambidexterity. Journal of Product Innovation Management, 30(2), 262-278.

*Lin, Z., Yang, H., \& Demirkan, I. (2007). The performance consequences of ambidexterity in strategic alliance formations: Empirical investigation and computational theorizing. Management Science, 53(10), 1645-1658.

Lord, M. D., \& Ranft, A. L. (2000). Organizational learning about new international markets: Exploring the internal transfer of local market knowledge. Journal of International Business Studies, 31(4), 573-589.

*Lubatkin, M. H., Simsek, Z., Ling, Y., \& Veiga, J. F. (2006). Ambidexterity and performance in small-to medium-sized firms: The pivotal role of top management team behavioral integration. Journal of Management, 32(5), 646-672.

*Lucena, A., \& Roper, S. (2016). Absorptive capacity and ambidexterity in R\&D: Linking technology alliance diversity and firm innovation. European Management Review, 13(3), 159-178.

*Luger, J., Raisch, S., \& Schimmer, M. (2018). Dynamic balancing of exploration and exploitation: The contingent benefits of ambidexterity. Organization Science, 29(3), 449470. 
*Luu, T. T., Rowley, C., \& Dinh, K. C. (2018). Enhancing the effect of frontline public employees' individual ambidexterity on customer value co-creation. Journal of Business \& Industrial Marketing, 33(4), 506-522.

*Kammerlander, N., Burger, D., Fust, A., \& Fueglistaller, U. (2015). Exploration and exploitation in established small and medium-sized enterprises: The effect of CEOs' regulatory focus. Journal of Business Venturing, 30(4), 582-602.

Kim, W. C., Hwang, P., \& Burgers, W. P. (1993). Multinationals' diversification and the riskreturn trade-off. Strategic Management Journal, 14(4), 275-286.

Kogut, B., \& Zander, U. (1992). Knowledge of the firm, combinative capabilities, and the replication of technology. Organization Science, 3(3), 383-397.

*Kortmann, S., Gelhard, C., Zimmermann, C., \& Piller, F. T. (2014). Linking strategic flexibility and operational efficiency: The mediating role of ambidextrous operational capabilities. Journal of Operations Management, 32(7-8), 475-490.

Koryak, O., Lockett, A. Hayton, J., Nicolaou, N., \& Mole, K. (2018). Disentangling the antecedents of ambidexterity: Exploration and exploitation. Research Policy, 47(2), 413427.

*Kouropalatis, Y., Hughes, P., \& Morgan, R. E. (2012). Pursuing "flexible commitment" as strategic ambidexterity: An empirical justification in high technology firms. European Journal of Marketing, 46(1), 1389-1417.

March, J. G. (1991). Exploration and exploitation in organizational learning. Organization Science, 2(1), 71-87. 
Mathias, B. D. (2014). Exploration, exploitation, ambidexterity, and firm performance: A metaanalysis. Exploration and Exploitation in Early Stage Ventures and SMEs (Technology, Innovation, Entrepreneurship and Competitive Strategy), 14, 289-317.

Mathias, B. D., Mckenny, A. F., \& Crook, T. R. (2018). Managing the tensions between exploration and exploitation: The role of time. Strategic Entrepreneurship Journal, 12(3), 316-334.

*Mavondo, F. T., Chimhanzi, J., \& Stewart, J. (2005). Learning orientation and market orientation: Relationship with innovation, human resource practices and performance. European Journal of Marketing, 39(11-12), 1235-1263.

McDermott, C. M., \& O’Connor, G. C. (2002). Managing radical innovation: An overview of emergent strategy issues. The Journal of Product Innovation Management, 19(6), 424-438.

McGrath, R. G., Macmillan, I. C., \& Venkataraman, S. (1995). Defining and developing competence: A strategic process paradigm. Strategic Management Journal, 16 (4), 251-275.

*Mehrabi, H., Ccoviello, N., \& Ranaweera, C. (2019). Ambidextrous marketing capabilities and performance: How and when entrepreneurial orientation makes a difference. Industrial Marketing Management, 77, 129-142.

*Menguc, B., \& Auh, S. (2008). The asymmetric moderating role of market orientation on the ambidexterity-firm performance relationship for prospectors and defenders. Industrial Marketing Management, 37(4), 455-470.

Milliman, J., von Glinow, M. A., \& Nathan, M. (1991). Organizational life cycles and strategic international human resource management in multinational companies: Implications for congruence theory. The Academy of Management Review, 16(2), 318-339. 
*Morgan, R. E., \& Berthon, P. (2008). Market orientation, generative learning, innovation strategy and business performance inter-relationships in bioscience firms. Journal of Management Studies, 45(8), 1329-1353.

Nadler, D. A., \& Tushman, M. L. (1980). A model for diagnosing organizational behavior. Organizational Dynamics, 9(2), 35-51.

*Neil, S., \& York, J. L. (2012). The entrepreneurial perceptions of strategy makers: Constructing an exploratory path in the pursuit of radical growth. Journal of Business Research, 65(7), 1003-1009.

*Nguyen, B., Yu, X., Melewar, T. C., \& Hemsley-Brown, J. (2016). Organizational dynamism and adaptive business model innovation: The triple paradox configuration. Journal of Business Research, 69(11), 5487-5493.

*Ngo, L. V., Bucic, T., Sinha, \& Lu, V. N. (2019). Effective sense-and-respond strategies: Mediating roles of exploratory and exploitative innovation. Journal of Business Research, $94,154-161$.

Nielsen, B. B., \& Gudergan, S. (2012). Exploration and exploitation fit and performance in international strategic alliances. International Business Review, 21(4), 558-574.

Nosella, A., Cantarello, S., \& Filippini, R. (2012). The intellectual structure of organizational ambidexterity: A bibliographic investigation into the state of the art. Strategic Organization, $10(4), 450-465$.

*O’Cass, A., Heirati, N., \& Ngo, L. V. (2014). Achieving new product success via the synchronization of exploration and exploitation across multiple levels and functional areas. Industrial Marketing Management, 43(5), 862-872. 
*Patel, P. C., Messersmith, J. G., \& Lepak, D. P. (2013). Walking the tightrope: an assessment of the relationship between high-performance work systems and organizational ambidexterity. Academy of Management Journal, 56(5), 1420-1442.

*Patel, P. C., Terjesen, S., \& Li, D. (2012). Enhancing effects of manufacturing flexibility through operational absorptive capacity and operational ambidexterity. Journal of Operations Management, 30(3), 201-220.

Piao, M., \& Zajac, E. J. (2016). How exploitation impedes and impels exploration: Theory and evidence. Strategic Management Journal, 37(7), 1431-1447.

Priem, R. L. (1994). Executive judgment, organizational congruence, and firm performance. Organization Science, 5(3), 421-437.

Raisch, S., \& Birkinshaw, J. (2008). Organizational ambidexterity: Antecedents, outcomes, and moderators. Journal of Management, 34(3), 375-409.

*Ricciardi, F., Zardini, A., \& Rossignoli, C. (2016). Organizational dynamism and adaptive business model innovation: The triple paradox configuration. Journal of Business Research, 69(11), 5487-5493.

*Salvador, F., Chandrasekaran, A., \& Sohail, T. (2014). Product configuration, ambidexterity and firm performance in the context of industrial equipment manufacturing. Journal of Operations Management, 32(4), 138-153.

*Sarkees, M., Hulland, J., \& Prescott, J. (2010). Ambidextrous organizations and firm performance: The role of marketing function implementation. Journal of Strategic Marketing, 18(2), 165-184.

*Sarkees, M., Hulland, J., \& Chatterjee, R. (2014). Investments in exploitation and exploration capabilities: Balance versus focus. Journal of Marketing Theory and Practice, 22(1), 7-24. 
Scott, G. M. (2000). Critical technology management issues of new product development in high-tech companies. Journal of Product Innovation Management, 17(1), 57-77.

Shi, X., Su, L. \& Cui, A. (2020). A meta-analytic study on exploration and exploitation. Journal of Business \& Industrial Marketing, 35(1), 97-115

*Solís-Molina, M., Hernández-Espallardo, M., \& Rodríguez-Orejuela, A. (2018). Performance implications of organizational ambidexterity versus specialization in exploitation or exploration: The role of absorptive capacity. Journal of Business Research, 91, 181-194.

*Sok, P., \& O’Cass, A. (2015). Achieving service quality through service innovation exploration-exploitation: The critical role of employee empowerment and slack resources. Journal of Services Marketing, 29(2), 137-149.

Sorescu, A. B., Chandy, R. K., \& Prabhu, J. C. (2003). Sources and financial consequences of radical innovation: Insights from pharmaceuticals. Journal of Marketing, 67(4), 82-102.

*Su, L., Cui, A., Samiee, S., \& Zou, S. Exploration, exploitation, ambidexterity, and the performance of international SMEs. Working paper.

*Subramani, M. (2004). How do suppliers benefit from information technology use in supply chain relationships? MIS Quarterly, 28(1), 45-73.

Simsek, Z., Heavey, C., Viega, J. F., \& Souder, D. (2009). A typology for aligning organizational ambidexterity's conceptualizations, antecedents, and outcomes. Journal of Management Studies, 46(5), 864-894,

*Soto-Acosta, P., Popa, S., \& Martinez-Conesa, I. (2018). Information technology, knowledge management and environmental dynamism as drivers of innovation ambidexterity: A study in SMEs. Journal of Knowledge Management, 22(4), 824-849 
Stubner, S., Blarr, W. H., Brands, C., \& Wulf, T. (2012). Organizational ambidexterity and family firm performance. Journal of Small Business \& Entrepreneurship, 25(2), 217-229.

*Tan, M, \& Liu, Z. (2014). Paths to success: an ambidexterity perspective on how responsive and proactive market orientations affect SMEs' business performance. Journal of Strategic Marketing, 22(5), 420-441.

*Tokman, M., Richey, R. G., Marino, L. D., \& Weaver, K. M. (2007). Exploration, exploitation and satisfaction in supply chain portfolio strategy. Journal of Business Logistics, 28(1), 2556.

*Úbeda-García, M., Claver-Cortés, E., Marco-Lajara, B., Zaragoza-Sáez, P., \& García-Lillo, F. (2018). High performance work system and performance: Opening the black box through the organizational ambidexterity and human resource flexibility. Journal of Business Research, 88, 397-406.

Uotila, J., Maula, M., \& Keil, T. (2009). Exploration, exploitation, and financial performance: Analysis of S\&P 500 corporations. Strategic Management Journal, 30(2), 221-231.

*Vagnani, G. (2015). Exploration and long-run organizational performance: The moderating role of technological interdependence. Journal of Management, 41(6), 1651-1676.

Van Looy, B., Martens, T., \& Debackere, K. (2005). Organizing for continuous innovation: On the sustainability of ambidextrous organizations. Creativity \& Innovation Management, 14(3), 208-221.

Verma, V., Sharma, D., \& Sheth, J. (2016). Does relationship marketing matter in online retailing? A meta-analytic approach. Journal of the Academy of Marketing Science, 44(2), 206-217. 
Vorhies, D. W., Orr, L. M., \& Bush, V. D. (2011). Improving customer-focused marketing capabilities and firm financial performance via marketing exploration and exploitation. Journal of the Academy of Marketing Science, 39(5), 736-756.

Voss, G. B., \& Voss, Z. G. (2013). Strategic ambidexterity in small and medium-sized enterprises: Implementing exploration and exploitation in product and market domains. Organization Science, 24(5), 1459-1477.

*Wadhwa, A., \& Basu, S. (2013). Exploration and resource commitments in unequal partnerships: An examination of corporate venture capital investments. Journal of Product Innovation Management, 30(5), 916-936.

*Wang, X. \& Dass, M. (2017). Building innovation capability: The role of top management innovativeness and relative-exploration orientation. Journal of Business Research, 76, 127 135.

*Wei, Z., Yi, Y., \& Guo, H. (2013). Organizational learning ambidexterity, strategic flexibility, and new product development. Journal of Product Innovation Management, 31(4), 832-847.

*Westerlund, M., \& Rajala, R. (2010). Learning and innovation in inter-organizational network collaboration. Journal of Business \& Industrial Marketing, 25(6), 435-442.

Winterhalter, S., Zeschky, M. B., \& Gassmann, O. (2016). Managing dual business models in emerging markets: An ambidexterity perspective. R\&D Management, 46(3), 464-479.

*Xia, T, \& Dimov, D. (2019). Alliances and survival of new biopharmaceutical ventures in the wake of the global financial crisis. Journal of Small Business Management, 57(2), 362-385.

Yalcinkaya, G., Calantone, R. J., \& Griffith, D. A. (2007). An examination of exploration and exploitation capabilities: Implications for product innovation and market performance. Journal of International Marketing, 15(4), 63-93. 
*Yli-Renko, H. Autio, E., \& Sapienza, H. J. (2001). Social capital, knowledge acquisition, and knowledge exploitation in young technology-based firms. Strategic Management Journal, 22(6-7), 587-613.

*Yang, H., Zheng, Y., \& Zhao, X. (2013). Exploration or exploitation? Small firms' alliance strategies with large firms. Strategic Management Journal, 35(1), 146-157.

Zahra, S. A., Ireland, R. D., \& Hitt, M. A. (2000). International expansion by new venture firms: International diversity, mode of market entry, technological learning, and performance. Academy of Management Journal, 43(5), 925-950.

*Zhan, W., \& Chen, R. (2013). Dynamic capability and IJV performance: The effect of exploitation and exploration capabilities. Asia Pacific Journal of Management, 30(2), 601632.

*Zhang, J. A., Edgar, F., Geare, A., \& O'Kane, C. (2016). The interactive effects of entrepreneurial orientation and capability-based HRM on firm performance: The mediating role of innovation ambidexterity. Industrial Marketing Management, 59, 131-143.

*Zhang, D., Linderman, K., \& Schroeder, R. G. (2012). The moderating role of contextual factors on quality management practices. Journal of Operations Management, 30(1-2), 1223.

Zhang, H., Wu, F., \& Cui, A. S (2015). Balancing market exploration and market exploitation in product innovation: A contingency perspective. International Journal of Research in Marketing. 32(3). 297-308.

Zhou, K. Z., Yim, C. K., \& Tse, D. K. (2005). The effects of strategic orientations on technology- and marketing-based breakthrough innovations. Journal of Marketing, 69(2), 42-60. 


\section{ARTICLE 2 - EXPLORATION, EXPLOITATION, AMBIDEXTERITY, AND THE PERFORMANCE OF INTERNATIONAL SMALL- AND MEDIUM-SIZED ENTERPRISES}

\section{Introduction}

According to the U.S. Department of Commerce, 98\% of exporting companies in 2015 consisted of small- and medium-sized enterprises (SMEs) with fewer than 500 employees (U.S. Trade Overview 2017). However, exports account for less than $10 \%$ of total sales of nearly onehalf (47\%) of international SMEs (ISMEs), and only one-third of total merchandise trade consists of ISMEs' exports (NSBA Report 2016). Further, 59\% of ISMEs export to only one market (NSBA Report 2016). These statistics demonstrate the need for ISMEs to become more active players in the global marketplace through international expansion.

The exporting literature has extensively examined a wide range of obstacles facing exporting firms as well as avenues for the conversion of less active and sporadic exporters into more active ones. ${ }^{1}$ Contributing to this literature, the goal in this investigation is to address the strategic choice facing ISMEs when embarking on intensifying their exporting activities. A common challenge facing these exporters is whether to extend current domestic capabilities and strategies to export markets (i.e., exploitation), adopt new strategies for export markets (i.e., exploration), or use a combination of the two (i.e., ambidexterity). The choice between these strategic directions is largely resource and environment dependent, which is always a critical issue for ISMEs. Indeed, three major concerns that prevent ISMEs from expanding their

\footnotetext{
${ }^{1}$ Obstacles to achieving greater intensity in exporting are many. These include deep interest in and knowledge of export marketing in particular, and the international business environment in general, government support, lack of well-trained exporting staff, and inadequate export promotion programs to name a few (e.g., Leonidou et al. 2015; Leonidou 1995; Morgan and Katsikeas 1997; Samiee and Walters, 1991; 1999).
} 
international sales include limited resources devoted to exporting, market and demand uncertainty, and environmental turbulence (NSBA Report 2016).

Based on environmental munificence literature and contingency theory (Goll and Rasheed 2004; Staw and Szwajkowski 1975), the present paper posits that, to handle the concerns and capitalize on strategies, ISMEs should enhance their adaptive marketing capabilities (AMCs) to acclimate to the competitive environments and enhance their potential (Burns and Stalker 1961). Alternatively, ISMEs should carefully choose markets with suitable business environments to ensure a strategic fit (Cyert and March 1963). Consistent with this logic, this study examines the moderating effects of AMCs and home-host country similarities on the relationship between ISMEs' international strategies and firm performance.

This study contributes to the international marketing (IM) literature in the following ways. First, I provide a theoretical explanation for the inconclusive findings on the impact of exploration, exploitation, and ambidexterity on ISMEs' performance. As suggested by environmental munificence and contingency theory, a firm's performance should be a function of the fit between internal resources and capabilities, strategic actions, and its external environment (Goll and Rasheed 2004; Staw and Szwajkowski 1975). Following this logic, I examine internal (e.g., AMCs) and external (e.g., market characteristics) conditions under which these strategic actions would be most effective.

Second, this study seeks to provide empirical evidence that ISMEs could maximize their competitive advantage by developing and deploying AMCs, which, per Day (2011), are defined as "the capabilities that enable firms to anticipate rapid market shifts and reconfigure process activities as needed" (p. 188). Day (2011) posits that developing strong AMCs is vital to firms' market performance as it transforms static resources into competitive advantages. However, with 
minor exceptions (e.g., Mu 2015), the impact of AMCs on firm performance has received very limited empirical attention. This investigation represents an initial investigation on how AMCs influence ISMEs' global performance. I argue that AMCs are especially important for ISMEs because one distinctive advantage ISMEs have over multinational enterprises (MNEs) is their flexibility and adaptability when formulating and implementing IM decisions (Falk and de Lemos 2019). The decision-making process in an MNE is often slow due to embedded bureaucracy in the added levels of hierarchy inherent in larger firms (Singhapakdi et al. 2010; Lee et al. 2010). ISMEs are able to respond more swiftly to market uncertainty due to their ability to adapt to environment changes (Falk and Figueira de Lemos 2019). Therefore, AMCs enable ISMEs to reconfigure processes and activities according to the interpretation of vague market signals (Day 2011; 2014), which refer to activities that convey information beyond the activity per se and constitute data from which a firm can infer and predict market changes (Herbig and Milewicz 1994).

Third, I aim to provide practical strategic guidance to ISMEs' internationalization efforts by examining how ISMEs utilize relatively limited resources and convert them into competitive advantages. Compared to large MNEs, ISMEs have fewer tangible and intangible resources available to pursue ambidexterity (Brouthers and Nakos 2004; Erramilli and Rao 1993). As a result, ISMEs may not achieve the same level of superior performance by adopting ambidexterity as MNEs do (Ebben and Johnson 2005; Voss and Voss 2013). Despite numerous constraints and challenges, many ambitious entrepreneurial ISMEs continue to exhibit a strong interest in pursuing ambidexterity (Voss and Voss 2013). A central issue is whether and to what extent ISMEs can successfully pursue any of the three strategies. Prima facie, given resource limitations in most ISMEs, at the very least one would expect the pursuit of ambidexterity to have a negative 
influence on their performance. In this regard, I aim to find potential solutions to attenuating the potential negative influence of ambidexterity on ISMEs.

In the remainder of the paper, I first review environmental munificence and contingency theory and the research on exploration, exploitation, and ambidexterity, and then propose hypotheses. Next, I detail methodology and test the hypotheses with data collected from U.S. ISMEs. Finally, I discuss the findings and detail their implications, and offer future research directions.

\section{Theory and hypotheses}

\subsection{Environmental munificence and contingency theory}

Since ISMEs usually possess limited internal resources, obtaining resources from external environments is critical to the effectiveness of their strategies ( $\mathrm{Li}$ et al. 2013). The relationship between strategic actions, internal resources, and external resources is articulated by environmental munificence and contingency theory. Environmental munificence theory explains the interaction between organizational actions and environments (Staw and Szwajkowski 1975). Environmental munificence refers to the extent of "abundance of critical resources needed by firms operating within an environment" (Castrogiovanni 1991, p. 542). The resources can be examined in terms of production factors such as natural resources, physical infrastructure, and human resources, and institutional factors such as political, legal, and societal environments (Wan and Hoskisson 2003). Generally, in a munificent environment, natural resources and human resources are abundant, physical infrastructure is dependable, and institutional environment is healthy (Wan and Hoskisson 2003). Therefore, it is easy for ISMEs to obtain critical resources that are lacking within firms from a munificent environment (Castrogiovanni 1991). 
Extant literature suggests that environmental munificence influences firms' decisions, actions, and organizational structures (Goll and Rasheed 2004). For example, when firms are operating in a less munificent environment, they should pursue a strategy that does not require production factors that are lacking in the environment. In contrast, when environment is munificent, firms could benefit from optimization of available production and institutional factors (Wan and Hoskisson 2003). Since ISMEs are usually restricted to internal resources, the amount of resources that ISMEs could obtain from the environment to compensate for internal resources largely determines the effectiveness of organizational learning strategies ( $\mathrm{Li}$ et al. 2013). In other words, ISMEs should achieve a fit between internal resources, external resources, and strategies to build and maintain competitive advantage, and this view is supported by contingency theory.

Contingency theory posits that firms' internal and external resources should fit with strategies for the purposes of achieving a better performance (Ruekert et al. 1985). In other words, performance depends on "the nature of the task, the way in which the task is organized, and the nature of its environment" (Ruekert et al. 1985, p17). Based on environmental munificence and contingency theory, I assert that the effectiveness of strategies should depend on the extent to which they fit with both internal and external resources possessed by firms. As for internal resources, my research investigates a relatively under-studied capability, AMCs (Day 2011), as moderators between strategies and firm performance. As for external resources, I examine home-host country similarity, which I define as the extent to which host countries are similar to ISMEs' home country in terms of geographical, social, cultural, and/or economic factors (Klein 1989). 
In summary, this study investigates the influence of exploration, exploitation, and ambidexterity on ISMEs' performance and the moderating effects of AMCs and home-host country similarity. The theoretical framework is shown in figure 2 .

Figure 2: The moderating effect of AMCs and home-host country similarity

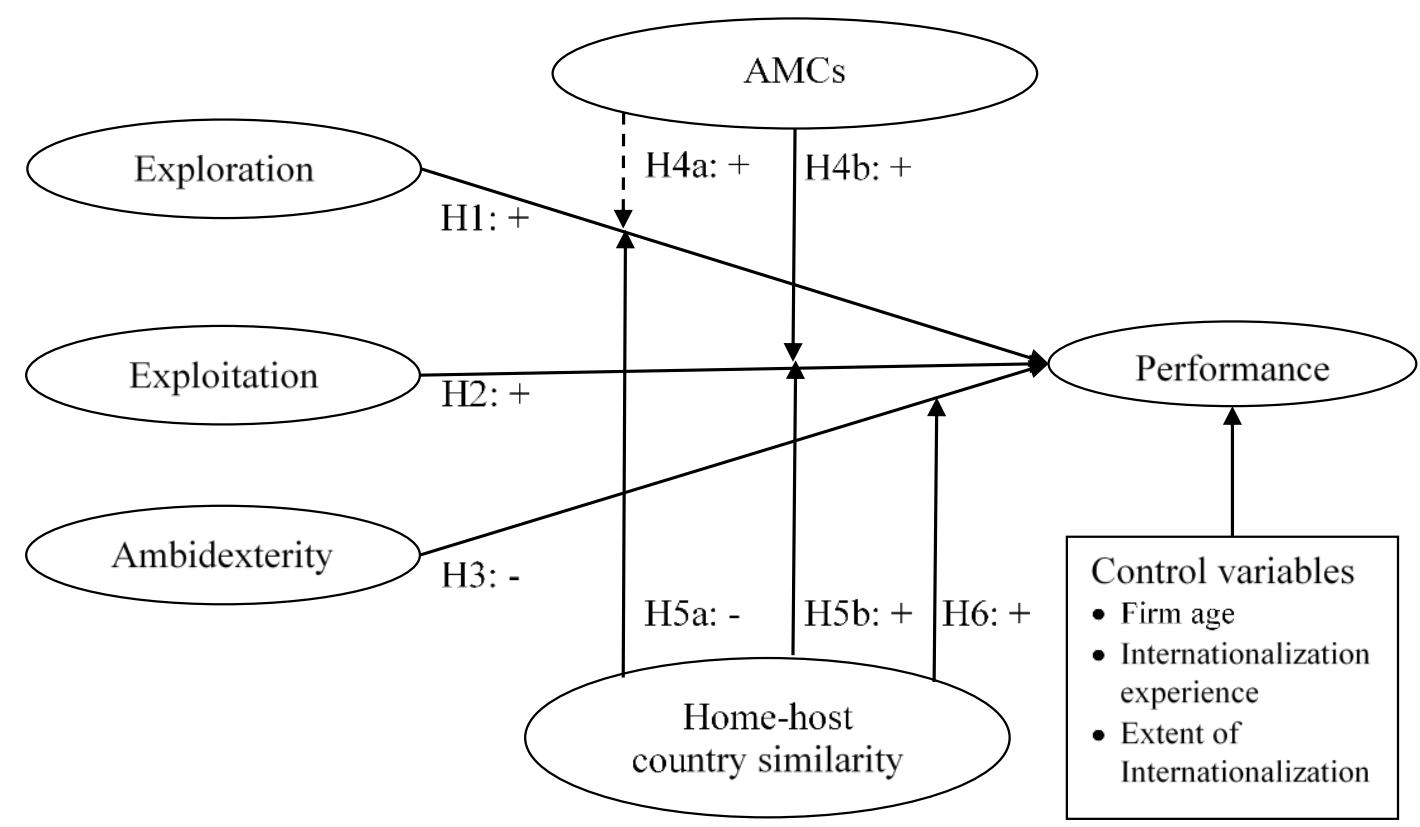

Note: Dashed lines represent the non-significant relationships.

\subsection{Exploration and exploitation}

Exploration includes firm activities "such as search, variation, risk taking, experimentation, play, flexibility, discovery, and innovation," and exploitation is represented by activities such as "refinement, choice, production, efficiency, selection, implementation, and execution" (March 1991, p. 71). Exploration focuses on "the experimentation with new alternatives," while exploitation focuses on "the refinement of the existing knowledge" (March 1991, p. 71).

In the IM literature, the quintessential explorative marketing-related activity is adaptation, which allows international firms to adapt their marketing programs (product, 
promotion, etc.) to idiosyncratic foreign markets to meet local customers' demands (Theodosiou and Leonidou 2003; Zeriti et al. 2014; Rao-Nicholson and Khan 2017). In contrast, the essential exploitative marketing-related activity is standardization, which means international firms standardize their marketing programs, including product designs and production processes, and provide the same or rather similar products internationally (Theodosiou and Leonidou 2003; Zeriti et al., 2014; Rao-Nicholson and Khan, 2017). Since standardization can achieve significant economies of scale and reduces managerial complexity compared to adaptation (Theodosiou and Leonidou 2003; Cavusgil et al. 1993), exploitation is often less costly than exploration.

Moreover, exploration often requires considerably more changes to current products, business processes, and marketing activities than does exploitation (Dasí et al. 2015), so it usually embraces high risks and failure rates (Raisch and Birkinshaw 2008). In general, given the small size and limited international resources of ISMEs (e.g., international networks and experience, channel dominance, the role and importance of exports to their overall business models), I anticipate much greater control over product- and process-related activities and internationalization efforts on their part and very limited influence on such marketing activities as host market promotion or pricing. Accordingly, I view ISMEs' explorative and exploitative initiatives as product related and internationalization centered.

Even though exploration provides unique challenges for ISMEs due to their limited resources (Han and Celly 2008), for three reasons it may pay off once ISMEs achieve a major breakthrough in product innovation and/or new market expansion (Özsomer and Gençtürk 2003, Voss et al. 2008). First, exploration could increase ISMEs' performance by providing tailored products to satisfy distinct consumers' needs across different markets (Theodosiou and Leonidou 2003). Explorative activities such as adaptation enable ISMEs to offer different products to 
different markets, which could help ISMEs attract new consumers and retain current consumers in each local market (Theodosiou and Leonidou 2003). In addition, ISMEs would eventually comprehend each market better by acquiring and integrating knowledge from multiple markets so that they could provide better products and services for each market (Garcia et al. 2003; Lisboa et al. 2013).

Second, exploration could increase ISMEs' firm performance by engaging in innovation (Yalcinkaya et al. 2007). Explorative firms tend to invest more resources on experimentation, proactive research, and new discoveries (Nielsen and Gudergan 2012), leading to strong innovative capabilities (Yalcinkaya et al. 2007). Given the intense competition in the global marketplace, innovative ISMEs could differentiate from their competitors to strengthen their competitive advantages (Prange and Pinho 2017). In addition, innovative ISMEs may well respond to the fast-changing global market trends by offering new products and minimizing the risks of product obsolescence (March 1991; Özsomer and Gençtürk 2003, Voss et al. 2008).

Finally, exploration could help build entrepreneurial culture within firms, which is a key factor to success for ISMEs. Many ISMEs may not own sufficient resources, so they have to engage in entrepreneurial activities and continuously seek new resources, opportunities, and technologies (Shirokova et al. 2013). When taking an exploration strategy, a firm is equipped with an entrepreneurial culture (Kollmann and Stöckmann 2014), which could ready top management and employees to take risks, acquire and absorb new knowledge, and leverage new possibilities (Shirokova et al. 2013). As such, ISMEs could acquire resources, opportunities, and technologies in global markets, ultimately increasing firm performance. Based on the discussion above, I hypothesize that:

H1: Exploration positively influences ISMEs’ performance. 
In contrast to exploration, exploitation emphasizes such activities as refinement, efficiency, and implementation, and features experience-based learning processes (Dasí et al. 2015). Since exploitation centers on the refinement of existing products, I argue that exploitation could increase ISMEs' performance for three reasons (Özsomer and Gençtürk 2003). First, exploitative activities such as standardization involve minimal risks and require limited investments (Miller et al. 2006), which is one reason why resource-constrained ISMEs are attracted to exploitation (Cui et al. 2014). They sell similar products across different markets, making mass production and economies of scale possible (Theodosiou and Leonidou 2003; Cavusgil et al. 1993). Therefore, exploitation can boost ISMEs' international performance by increasing efficiency and decreasing costs.

Second, exploitation helps ISMEs avoid risks associated with developing new products (March 1991). The pursuit of product innovation involves high risks and high failure rates (Yalcinkaya et al. 2007). In fact, as many as $95 \%$ of new products fail within their first year on the market (Nobel 2011). When firms pursue an exploitation strategy, they do not assume such risks. Finally, exploitation often leads to strong relationships with firms' current partners and customers (Lisboa et al. 2013). By improving their existing products and services, firms are able to maintain/improve the satisfaction level of their partners and customers (Lee et al. 2003). This enhanced relationship with business partners and customers could reduce transaction costs and increase firm performance (Lisboa et al. 2013). In sum, I hypothesize that:

H2: Exploitation positively influences ISMEs' performance.

\subsection{Ambidexterity}

Since exploration and exploitation bring benefits in different ways and in different time frames, some scholars posit that firms should adopt exploration and exploitation simultaneously, 
which is termed ambidexterity (March 1991). However, March (1991) highlights the difficulties in seeking ambidexterity. The primary difficulties include 1) exploration and exploitation compete for limited resources; and 2) exploration and exploitation require different mindsets and organizational routines (March 1991). To overcome these difficulties, firms should develop internal and external resources and recruit and engage experienced managers capable of amalgamating different people. Large firms usually have sufficient resources and capabilities to implement such measures (Chen and Hambrick 1995), and the literature demonstrates the positive influence of ambidexterity on firm performance among large firms (e.g., Sarkees et al. 2010). However, due to limited availability of resources, ISMEs are less likely to overcome these difficulties to benefit from ambidexterity.

First, ambidexterity may lower ISMEs' cumulative investments on each strategy to a point that it negates profits and hurts firm performance. Exploration and exploitation compete for resources especially within resource-constrained SMEs (March 1991); that is, increased investments in one strategy will cannibalize those available for the other strategy (Gupta et al. 2006). The threshold effect of firm resources suggests that resources boost firm performance only when resources exceed a certain threshold level (Naldi et al. 2014). When allocating resources to both exploration and exploitation, it is possible that resources for each strategy will fall below the critical threshold. For example, when ISMEs attempt to both enter a new international market (i.e., exploration) and upgrade manufacturing facilities to increase current products' quality (i.e., exploitation), it is possible that firms may fail at both initiatives as a result of suboptimal allocation of resources to support both exploration and exploitation efforts.

Second, ISMEs are less likely to possess well-rounded managers who can eliminate the conflicts of internal goals, mindsets, and routines between exploration and exploitation (Ebben 
and Johnson 2005), thus hindering the effectiveness of ambidexterity (Andriopoulos and Lewis 2009; Raisch et al. 2009). As March (1991) posited, “exploiting interesting ideas often thrives on commitment more than thoughtfulness, narrowness more than breadth, cohesiveness more than openness" (p. 280). Therefore, achieving a balance between commitment and thoughtfulness, between narrowness and breadth, and between cohesiveness and openness is a key to boost the effectiveness of ambidexterity. ISMEs typically lack the managerial talents that can achieve the necessary balance (Ebben and Johnson 2005).

In addition, various functional departments may have different mindsets and routines. For example, manufacturing focuses on producing uniform products (i.e., exploitation) to speed up production and achieve greater efficiency (Andriopoulos and Lewis 2009), but marketing seeks exploration to remain more customer-oriented by meeting different segments' demands (Andriopoulos and Lewis 2009). Different goals held by different departments could increase the incompatibility between exploration and exploitation, especially for SMEs since managers in SMEs may fail to align goals of different departments. In sum, due to insufficient resources and management skills, ISMEs' performance often suffers when tackling the paradoxes of ambidexterity. Therefore, I posit that:

H3: Ambidexterity negatively influences ISMEs' performance.

\subsection{The moderating effects of AMCs}

AMCs are rooted in the resourced-based view, which is commonly used to explain the nature of firms' competitive advantages (Barney 1991). Firm resources "include all assets, capabilities, organizational processes, firm attributes, information, and knowledge controlled by the firm" (Barney 1991, p. 101). Such resources offer the firm sustainable competitive 
advantages over competitors if they are valuable, rare, inimitable, and non-substitutable resources (Barney 1991). Firm-based capabilities are recognized as resources that allow firms to be competitive in different ways. I define capabilities as complex bundles of skills and accumulated knowledge that enable firms to coordinate activities and remain competitive (Day 1994). In general, ways in which firm assets, including capabilities, are configured and deployed influence the firm's level of competitiveness. As a result, firms with similar resources may exhibit different levels of competitiveness.

AMCs start with outside environmental factors and adapt to the market through discovery, experimentation, and risk taking (Day 2011). In essence, AMCs consider how a firm leverages internal resources, acquires new resources from outside, and adapts to environmental factors based on anticipation of weak market signals (Day 2011). An adaptive organization takes actions prior to the changes based merely on weak market signals. Strong AMCs could ready a firm to take immediate appropriate measures for unexpected market shifts (Day 2014; Leonidou et al. 2011).

AMCs capture the type of capability that allows firms to anticipate trends and events before they are fully apparent and then respond to these trends effectively (Kozlenkova et al. 2014). Although ISMEs' access to fine-grain international market information is constrained or non-existent (Westhead et al. 2001), superior international market information acquisition and interpretation capabilities can help ISMEs raise their international competitiveness vis-à-vis their rivals (Lu et al. 2010). In addition, the value of acquired information is dependent on ISMEs' flexibility in adapting to external environments based on the information (Lu et al. 2010). Accordingly, I assert that two dimensions of AMCs are especially vital for ISMEs: 1) vigilantly 
acquire information about the unmet needs of their target markets and, 2) proactively implement market experimentation (Day 2011; Lu et al. 2010).

Vigilant market learning capabilities refer to "the capabilities of enhancing deep market insights with an advance warning system to anticipate market changes and unmet needs" (Day 2011 p. 183). Firms with strong vigilant market learning capabilities stay alert and vigilant to the market trends, take actions ahead of their competitors, excel at interpreting market signals still in infancy, and find new opportunities from vague signals (Day 2011). Adaptive market experimentation capability refers to firms' expertise "to invest in small experiments that can generate new insights for existing beliefs" (Day 2011, p. 189). Through market experimentation, a firm can expand its repertoire of customer knowledge, enhance its capabilities to respond to heterogeneous markets (Day 2011), and boost its performance through sharing knowledge within the organization (Day 1994).

In this sense, the tenets of AMCs are consistent with those of exploration. Both AMCs and exploration require a firm to embrace high risks, openness, and diversity (Day 2011). To build strong AMCs, firms should create a culture of discovery, encourage curiosity, and focus on long-term results (Day 2011). Such firms are more likely to seek explorative activities. Therefore, I expect that AMCs could help ISMEs fully realize the advantages of exploration and enhance their positive impacts on firm performance. In contrast, for ISMEs with low AMCs, the potential harms of exploration can be more detrimental as these firms lack the capability to anticipate and mitigate the risks in the uncertain and dynamic environment. For example, once new products unexpectedly fail in markets, firms with low AMCs might not be able to control possible damage in a timely manner. It thus follows that AMCs positively moderate the relationship between exploration and ISMEs' firm performance. 
In addition, I propose that AMCs positively moderate the relationship between exploitation and firm performance. Even though exploitation focuses on current business processes while AMCs emphasize future market trends, firms using exploitation cannot ignore rapidly changing markets and technology. This is especially true in today's marketplace where consumers are empowered by unprecedented technologies, social media, and large arrays of information (Lemon and Verhoef 2016). Consumers can easily access information at any time and in any place through multiple channels (Neslin et al. 2006). This requires firms to be responsive to changes in consumers' demands, even when firms primarily focus on exploitation. In addition, one disadvantage of exploitation is possible obsolescence of technology and products. Especially in global markets, updates and upgrades of technology are rapid and profoundly influence ISMEs' survival and development. However, AMCs could enable ISMEs to keep up with state-of-the-art technologies to reduce the possibility of obsolescence. Concurrently, exploiting firms could deploy avant-garde technologies to reduce costs and improve quality. As such, AMCs could increase efficiency of exploitative activities. Based on the discussion above, I hypothesize that:

H4: AMCs positively moderate the relationship between (a) exploration and (b) exploitation and ISMEs' performance.

\subsection{The moderating effects of home-host country similarity}

Environmental munificence and contingency theory assert that ISMEs should choose an appropriate host market for which their strategies are appropriate (Goll and Rasheed 2004; Ruekert, et al. 1985; Staw and Szwajkowski 1975). American ISMEs enjoy one of the most munificent business environments in the world where well-established institutional factors such as contract enforcement mechanisms, social norms, and efficient government bureaucracy 
facilitate relatively fair and intense competition (Wan and Koskisson 2003). Thanks to intense competition, ISMEs have a good chance of challenging or even replacing incumbent firms by increasing product competitiveness (Wan and Koskisson 2003). Since success in a munificent environment largely depends on firms' efficiency to deploy available resources, it is particularly beneficial for ISMEs to focus on refinement of some specialized product-market expertise rather than exploring new expertise (Wan and Koskisson 2003). When American ISMEs enter a similar host market that is as munificent as their home market, they may also benefit more from exploitation than exploration. In contrast, when American ISMEs enter a dissimilar market (e.g., an emerging market), in most cases the market is less munificent than their home market ( $\mathrm{Li}$, et al. 2013). In a less munificent market, institutional factors are usually not adequate, making political ties critical to firm performance (Li et al. 2013). Because of the support of local government, incumbent firms in a less munificent market usually enjoy monopolistic advantages (Li et al. 2013). When American ISMEs enter such a market, they should expand in diverse fields to increase the possibilities of fostering relationships with incumbent firms and government (Wan and Koskisson 2003). In sum, American ISMEs could benefit more from exploitation in a similar host market but benefit more from exploration in a dissimilar host market.

Moreover, when home and host countries are dissimilar, home market knowledge is devalued because it might not be applicable to the new markets (Klein 1989; Song and Shin 2008). In such cases, firms should actively seek new market knowledge in dissimilar host countries (Lisboa et al. 2013), thus decreasing the importance of exploitation but enhancing the importance of exploration. In addition, dissimilar markets also give ISMEs unique opportunities 
to test new ideas, products, and marketing activities (Cui et al. 2014). Therefore, dissimilar host markets should motivate ISMEs to seek exploration rather than exploitation.

On the other hand, when home and host countries are similar, it is easier to transfer existing information and knowledge from home countries to host countries (Mitra and Golder 2002). In addition, existing products are less likely to evoke consumers' hostility in a host country that holds similar ethnics and cultural values as the home country (Baltar and Icart 2013). Therefore, ISMEs could sell current products to similar host markets without significant modifications, reducing production costs through economies of scale (Cui et al. 2014). Under this circumstance, the efficiency of transferring ISMEs' current knowledge to similar host countries may be more rewarding than risky investments in R\&D and innovation (Cui et al. 2014; Mitra and Golder 2002). Consequently, exploration is less critical for ISMEs when host countries are similar to home countries. In other words, the success in similar foreign markets depends on how efficiently ISMEs implement exploitation. Accordingly, I assert that:

H5: Home-host country similarity (a) negatively moderates the relationship between exploration and ISMEs' performance and (b) positively moderates the relationship between exploitation and ISMEs' performance.

Furthermore, I anticipate the negative impact of ambidexterity may be more pronounced when ISMEs enter a new market dissimilar to their home market. Existing knowledge cannot be directly applied to dissimilar host countries, and managers must learn new knowledge to handle new markets (Cui et al. 2014). Therefore, managers might feel less environmental munificence, so they are less motivated to execute high-risk strategies. In other words, ambidexterity requires considerable resources and poses appreciable challenges to managers. Hence, managers might not want to deploy ambidexterity in a less munificent environment. 
In addition, when host market countries are dissimilar, firms face more uncertainties and are more likely to have less control over the unfamiliar business environments (Day 2011; Mitra and Golder 2002). As a result, ambidexterity in a dissimilar country involves more risks and is more likely to hurt performance. That is to say, ambidexterity, an already challenging task even in familiar markets, is particularly difficult to implement in a dissimilar market for ISMEs. Accordingly, ambidexterity is more likely to fail in a dissimilar than a similar host market. Therefore, the negative influence of ambidexterity on firm performance is more salient when host and home countries are dissimilar than when they are similar. Therefore, I hypothesize that:

H6: Greater similarity across home and host markets attenuates the negative influence of ambidexterity on ISMEs' performance.

\section{Research methodology}

\subsection{Data collection process and sample}

To test the theoretical model (See Figure 2), I began with a thorough literature review and followed with a qualitative study of three ISMEs. The information gathered through these efforts served as the basis for developing my survey instrument. I used a professional marketing research firm for data collection. The firm sent online questionnaires to 1,660 CEOs and senior IM managers of ISMEs in its national pool of U.S. ISMEs. I obtained 238 responses, achieving a response rate of 14.30 percent. For the purposes of this investigation, I leveraged the U.S. Small Business Administration's definition of ISMEs as firms with up to 500 employees. Nineteen firms exceeded this threshold and were dropped from further consideration. Another 100 questionnaires were incomplete and deleted from the data set, leaving 119 cases for analysis.

On average, responding firms had about 103 employees, had been in business for 43 years, and engaged in IM for 28 years. Additionally, they sold $41 \%$ of their total product lines to 
19 countries, which accounted for $27.30 \%$ of total their sales. About $39.82 \%$ of respondents held such titles as president and CEO, with the remainder serving as senior IM managers, senior international sales managers, or other managers (Table 4, sample characteristics). On average, presidents and CEOs speak 2 foreign languages, $90 \%$ of them have undergraduate or graduate degrees, and $85 \%$ of them were male. Senior marketing managers, on the other hand, on average speak 1.6 foreign languages, $73 \%$ of them had a bachelor or a higher degree, and $83 \%$ were male.

Table 4. Sample descriptions

\begin{tabular}{lll}
\hline & Average & SD \\
\hline Number of Employees & 102.98 & 126.66 \\
Percentage of Employees outside US & $14.29 \%$ & $37.27 \%$ \\
Years in Business & 43.39 & 32.33 \\
Years in Global Market & 27.60 & 21.37 \\
Percentage of Product Lines Sold Globally & $40.98 \%$ & $38.41 \%$ \\
Percentage of Sales in Foreign Markets & $27.30 \%$ & $29.75 \%$ \\
Countries Selling to & 18.99 & 26.16 \\
Job Title & President/CEO = 39.82\% \\
& Senior International Marketing Manager = \\
& $25.66 \%$ & Senior International Sales Manager = 15.04\% \\
& Marketing/Sales Manager = 14.16\%
\end{tabular}


Gender

Education Level

\subsection{Measures}

Responding ISMEs were asked to evaluate their firm's most recent international market entry using the items shown in Table 5. All items were measured using 7-point scales.

Table 5: The measurements of the constructs

\begin{tabular}{llll}
\hline Construct & Source & Items & Coding \\
(Cronbach's $\alpha)$ & & (Factor Loadings) & \\
\hline Exploration & Cui et al. & (1) Our firm has included some new & To what extent, \\
$(0.85)$ & $2014 ;$ & aspects to its processes, products and & you agree with \\
& Yalcinkaya & services compared to prior strategies. & the description: \\
& et al., 2007 & (0.81) & completely \\
& & (2) Our firm constantly pursuits new & disagree (1) or \\
& & opportunities to expand internationally. & completely agree \\
& & (0.83) & (7). \\
& & (3) Instead of focusing on the current & \\
& & &
\end{tabular}


developing new products and service for

our international markets. (0.77)

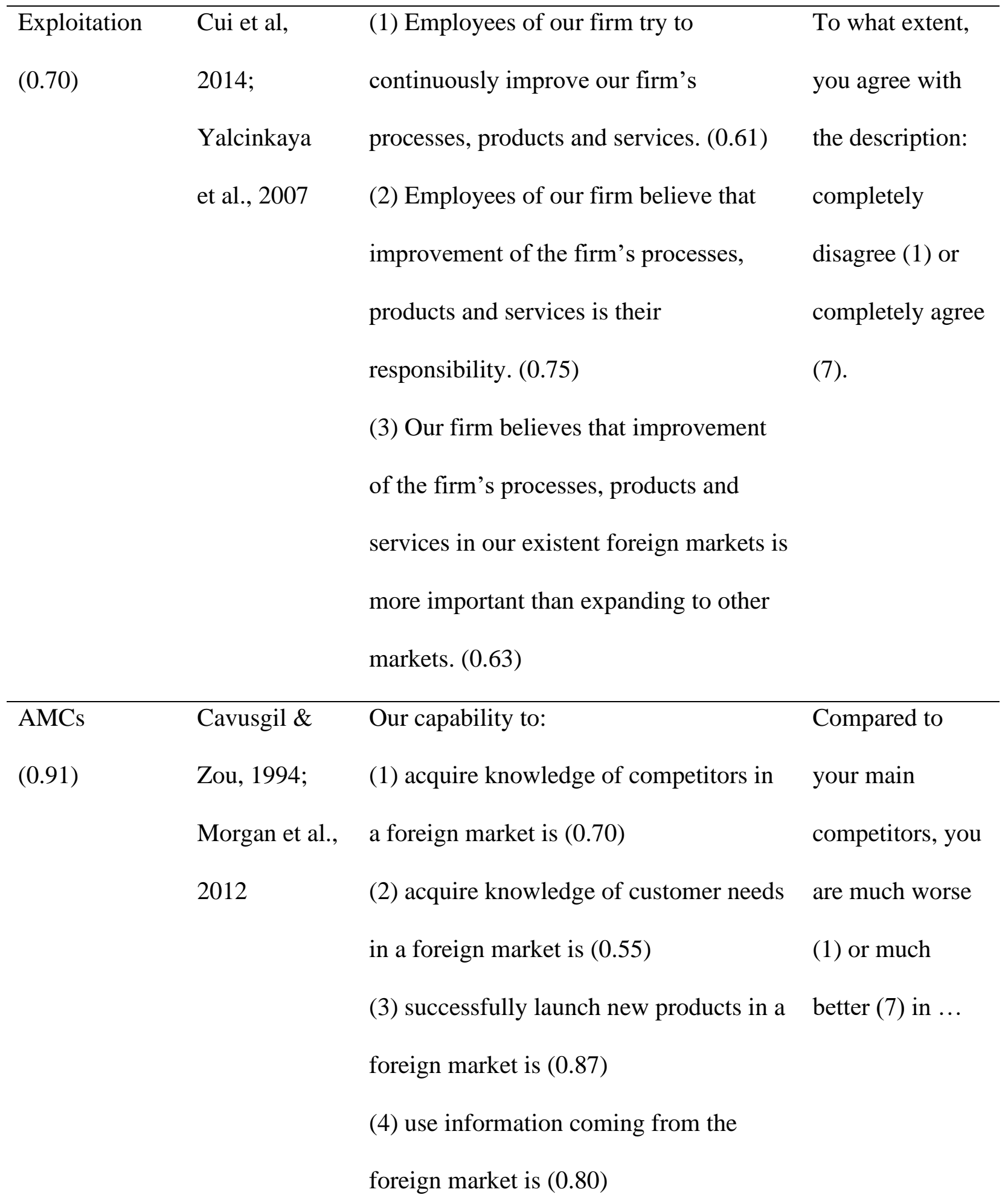


(5) utilize technology in international

marketing efforts is $(0.77)$

(6) adapt to international market needs

and requirements is

(7) acquire knowledge of culture in

countries outside of home market is

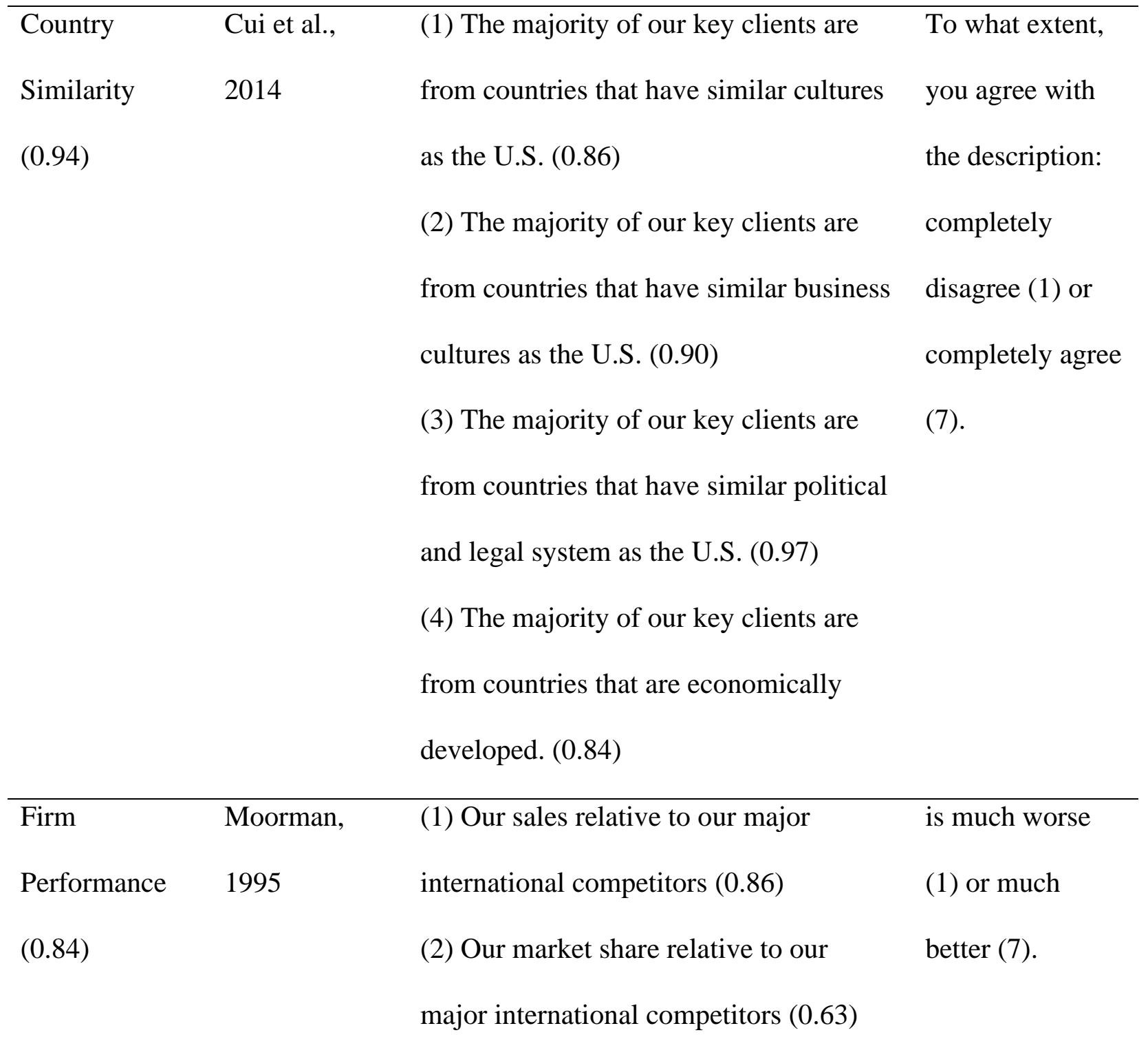


(3) Our profit margins relative to our

major international competitors (0.94)

\begin{tabular}{ll}
\hline International & How many years has your firm been \\
experience & doing business internationally
\end{tabular}

Firm size

Total number of employees

Extent of

How many countries has your firm been

Int'lization

selling products to?

Exploration and Exploitation. Measures for exploration and exploitation were adapted from Cui et al. (2014) and Yalcinkaya et al. (2007). I used three items to measure each strategy.

Ambidexterity. Consistent with previous research, I used the product item of meancentered exploration and mean-centered exploitation to measure ambidexterity (He and Wong 2004).

AMCs. I adapted seven items from previous research to measure AMCs. Sample items include capability to acquire knowledge of customer needs in a foreign market, capability to adapt to international market needs and requirements, and capabilities to acquire cultural knowledge in a foreign market (Cavusgil and Zou 1994; Morgan et al. 2012).

International Performance. I measured international firms' performance using a threeitem scale adopted from Moorman (1995).

Country Similarity. I measured country similarity using a four-item scale adopted from Cui et al. (2014).

Control Variables. Consistent with previous research, I controlled firm size, which was measured by the number of employees. I also controlled firm international experience, that is, the 
number of years a firm has been engaged in exporting. Finally, I controlled for the extent of ISMEs' internationalization as measured by the number of host countries to which ISMEs market.

\subsection{Ex ante considerations to reduce common method variance}

To avoid potential common method bias, I first stated the anonymity and confidentiality of the study and informed the respondents that there were no right or wrong answers in a cover letter (Chang et al. 2010). Also, as recommended, I counterbalanced and used an itemrandomizer to randomize the order and types of questions.

\section{Data analysis and results}

\subsection{Descriptive statistics}

I checked descriptive statistics to determine the normality and outliers of the key variables in the model. The results showed that all variables were normally distributed except control variables. Therefore, I took the log values of control variables in the regression model. Moreover, to check multicollinearity I calculated the variance inflation factor for each variable in a regression model, with performance as a dependent variable, exploration, exploitation, ambidexterity, AMCs, home-host country similarity, the interaction terms (mean centered before constituting product terms), and control variables as independent variables. The values of VIF ranged between 1.10 and 2.89, indicating that multicollinearity is not a concern.

\subsection{Measurement model}

Confirmatory factor analysis indicated that the measurement model after modifications was adequate $\left(\chi^{2} 157=266.41, p<0.01 ; C M I N / D F=1.70 ; C F I=0.94, G F I=0.84, R M S E A=\right.$ 0.08). All standardized factor loadings were larger than 0.55 (See Table 5). The results provided support for convergent validity for each construct. Composite reliability for the model constructs 
ranged between .83 and .93 , and Cronbach's $\alpha$ ranged between 0.70 and 0.94 , indicating good reliability. Moreover, average variance extracted (AVE) was greater than $63 \%$ for all constructs, and all correlation coefficients between two constructs were less than the square root of AVEs of each construct. The results provided support for discriminant validity. For the results of validity, reliability, and correlations between the constructs, see Table 6 .

Table 6: The results of validity, reliability, and correlations

\begin{tabular}{llllll}
\hline & Performance & Exploration & Exploitation & AMCs & Country \\
& & & & & Similarity \\
\hline Performance & 0.87 & & & & \\
Exploration & $0.37^{* *}$ & 0.88 & & & \\
Exploitation & $0.36^{* *}$ & $0.43^{* * *}$ & 0.79 & & \\
AMCs & $0.46^{* * *}$ & $0.53^{* * *}$ & $0.37^{* * *}$ & 0.81 & \\
Country Similarity & -0.14 & -0.09 & 0.18 & $-0.28^{* *}$ & 0.92 \\
& & & & & \\
AVE & 0.76 & 0.77 & 0.63 & 0.84 & 0.66 \\
Composite Reliability & 0.90 & 0.91 & 0.83 & 0.93 & 0.84 \\
Cronbach's $\alpha$ & 0.84 & 0.85 & 0.70 & 0.91 & 0.94 \\
\hline
\end{tabular}

Note: The values on the diagonal are the square roots of AVE.

$* * * \mathrm{p}<0.01 \quad * * \mathrm{p}<0.05 \quad * \mathrm{p}<0.1$

\subsection{Non-response bias test}

I checked non-response bias by comparing data collected at the beginning of the data collection process (the first 33\%) with data collected at the end (the last 33\%) on seven key 
variables. Specifically, I conducted independent $t$-tests on performance $(t=1.25, p=0.22)$, exploration $(\mathrm{t}=1.47, \mathrm{p}=0.17)$, exploitation $(\mathrm{t}=0.38, \mathrm{p}=0.70)$, AMCs $(\mathrm{t}=1.25, \mathrm{p}=0.22)$, home-host country similarity $(\mathrm{t}=0.23, \mathrm{p}=0.82)$, firm size $(\mathrm{t}=-1.61, \mathrm{p}=0.11)$, firm internationalization experience $(\mathrm{t}=1.45, \mathrm{p}=0.15)$, and ISMEs' extent of internationalization $(\mathrm{t}=$ $1.55, \mathrm{p}=0.12$ ). Based on the results, I conclude that non-response bias should not be a major concern in this investigation.

\subsection{Common method bias test}

To detect common method bias, I first used Harman's one factor test, in which one single factor was extracted in an exploratory factor analysis. The single factor accounted for $34.97 \%$ of the variance among variables, which is lower than the cut-off value-50\% (Fuller et al. 2016). The results indicate that common method bias is not problematic in the present research. Next, I employed a more rigorous procedure proposed by Williams et al. (2010) at two stages to detect common method variance. The results of the two stages collectively support that the common method variance is not a concern since it did not bias the correlation coefficients between substantive variables or their reliabilities.

\subsection{Hypotheses testing}

In line with recent studies in the field (Dasí et al. 2015; Kammerlander et al. 2015), I built three multiple regression models to test the proposed hypotheses. The first model included only control variables, the second model added independent variables (i.e., exploration, exploitation, and ambidexterity), and interaction terms were added in the third model (Table 7). The increase in adjusted $\mathrm{R}^{2}$ demonstrates that adding three strategies significantly improves the explained variance (Adjusted $\mathrm{R}^{2}=0.24$ versus $\mathrm{R}^{2}=0.08$ ), and adding interaction terms significantly enhances it (Adjusted $R^{2}=0.48$ versus $R^{2}=0.24$ ). 
Table 7: The results of regression models

\begin{tabular}{|c|c|c|c|c|c|c|}
\hline \multirow[t]{2}{*}{ IVs: Performance } & \multicolumn{2}{|c|}{ Model 1} & \multicolumn{2}{|c|}{ Model 2} & \multicolumn{2}{|c|}{ Model 3} \\
\hline & $\mathrm{r}(\mathrm{SE})$ & $\mathrm{t}(\mathrm{p})$ & $\mathrm{r}(\mathrm{SE})$ & $\mathrm{t}(\mathrm{p})$ & $r(\mathrm{SE})$ & $\mathrm{t}(\mathrm{p})$ \\
\hline \multirow[t]{2}{*}{ Firm size } & 0.20 & 0.91 & 0.24 & 1.12 & 0.34 & 2.03 \\
\hline & $(0.22)$ & $(0.36)$ & $(0.20)$ & $(0.24)$ & $(0.17)$ & $(<0.05)^{* *}$ \\
\hline \multirow{2}{*}{$\begin{array}{l}\text { International } \\
\text { experience }\end{array}$} & -0.01 & -0.02 & -0.46 & -1.12 & -0.17 & -0.50 \\
\hline & $(0.43)$ & $(0.98)$ & $(0.41)$ & $(0.27)$ & $(0.35)$ & $(0.62)^{*}$ \\
\hline \multirow{2}{*}{$\begin{array}{l}\text { ISMEs' } \\
\text { Internationalization }\end{array}$} & 1.02 & 3.08 & 0.79 & 2.48 & 0.73 & 2.59 \\
\hline & $(0.33)$ & $(<0.01)^{* * *}$ & $(0.32)$ & $(<0.05)^{* *}$ & $(0.28)$ & $(<0.05)^{* *}$ \\
\hline \multirow[t]{2}{*}{ Exploration } & & & 0.18 & 1.79 & -0.02 & -0.22 \\
\hline & & & $(0.10)$ & $(<0.10)^{*}$ & $(0.10)$ & $(0.83)$ \\
\hline \multirow[t]{2}{*}{ Exploitation } & & & 0.33 & 3.02 & 0.34 & 3.36 \\
\hline & & & $(0.11)$ & $(<0.01)^{* * * *}$ & $(0.10)$ & $(<0.01) * * *$ \\
\hline \multirow[t]{2}{*}{ Ambidexterity } & & & -0.14 & -2.44 & -0.21 & -2.94 \\
\hline & & & $(0.06)$ & $(<0.05)^{* *}$ & $(0.07)$ & $(<0.01) * * *$ \\
\hline \multirow[t]{2}{*}{ AMCs } & & & & & 0.46 & 4.24 \\
\hline & & & & & $(0.11)$ & $(<0.01) * * *$ \\
\hline \multirow[t]{2}{*}{ Similarity } & & & & & -0.04 & -0.44 \\
\hline & & & & & $(0.09)$ & $(0.66)$ \\
\hline Exploration * & & & & & 0.12 & 1.47 \\
\hline AMCs & & & & & $(0.08)$ & $(0.15)$ \\
\hline \multirow{2}{*}{$\begin{array}{l}\text { Exploitation } \\
* \text { AMCs }\end{array}$} & & & & & 0.19 & 2.02 \\
\hline & & & & & $(0.10)$ & $(<0.05)^{* *}$ \\
\hline
\end{tabular}




\begin{tabular}{|c|c|c|c|c|}
\hline $\begin{array}{l}\text { Exploration * } \\
\text { Similarity }\end{array}$ & & & -0.18 & $\begin{array}{l}-2.66 \\
(<0.01) * * * *\end{array}$ \\
\hline $\begin{array}{l}\text { Exploitation * } \\
\text { Similarity }\end{array}$ & & & $\begin{array}{l}0.29 \\
(0.07)\end{array}$ & $\begin{array}{l}4.34 \\
(<0.01) * * *\end{array}$ \\
\hline $\begin{array}{l}\text { Ambidexterity * } \\
\text { Similarity }\end{array}$ & & & $\begin{array}{l}0.05 \\
(0.03)\end{array}$ & $\begin{array}{l}1.68 \\
(<0.10)^{*}\end{array}$ \\
\hline $\mathrm{R}^{2}$ & 0.11 & 0.28 & & 0.53 \\
\hline Adjusted $\mathrm{R}^{2}$ & 0.08 & 0.24 & & 0.48 \\
\hline
\end{tabular}

$\mathrm{H} 1$ and $\mathrm{H} 2$ assert that both exploration and exploitation positively influence ISMEs' performance. The results of model 2 supported the hypothesis $(r=0.18, t=1.79, p<0.10$, for exploration; $\mathrm{r}=0.33, \mathrm{t}=3.02, \mathrm{p}<0.01$, for exploitation). Therefore, $\mathrm{H} 1$ and $\mathrm{H} 2$ are supported. $\mathrm{H} 3$ asserts that ambidexterity negatively influences ISMEs' performance. The results of model 2 also support this hypothesis $(\mathrm{r}=-0.14, \mathrm{t}=-2.44, \mathrm{p}<0.05)$.

$\mathrm{H} 4$ posits that AMCs positively moderate the impact of (a) exploration and (b) exploitation on ISMEs' performance. The results from model 3 do not support $\mathrm{H} 4 \mathrm{a}(\mathrm{r}=0.12, \mathrm{t}=$ 1.47, $\mathrm{p}>0.10)$, but do support $\mathrm{H} 4 \mathrm{~b}(\mathrm{r}=0.19, \mathrm{t}=2.02, \mathrm{p}<0.05)$. Panel A in Figure 3 demonstrates that the influence of exploitation on the firm is stronger when it possesses superior AMCs. 
Figure 3: Plotting significant two-way interactions

Panel A: Exploitation $\times$ AMCs $(\mathrm{H} 4 \mathrm{~b})$

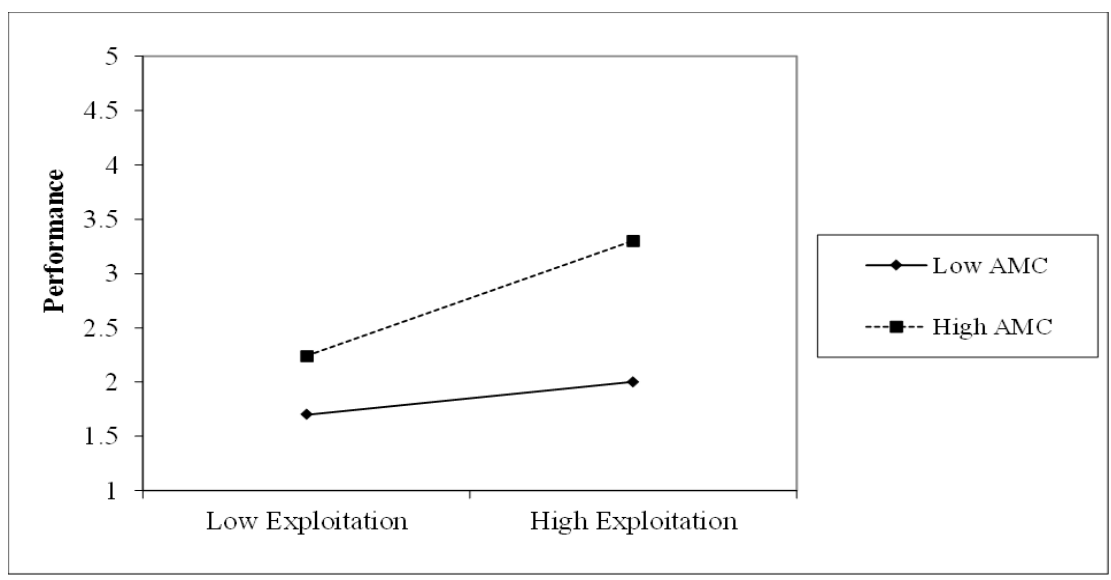

Panel B: Exploration $\times$ Home-host country similarity (H5a)

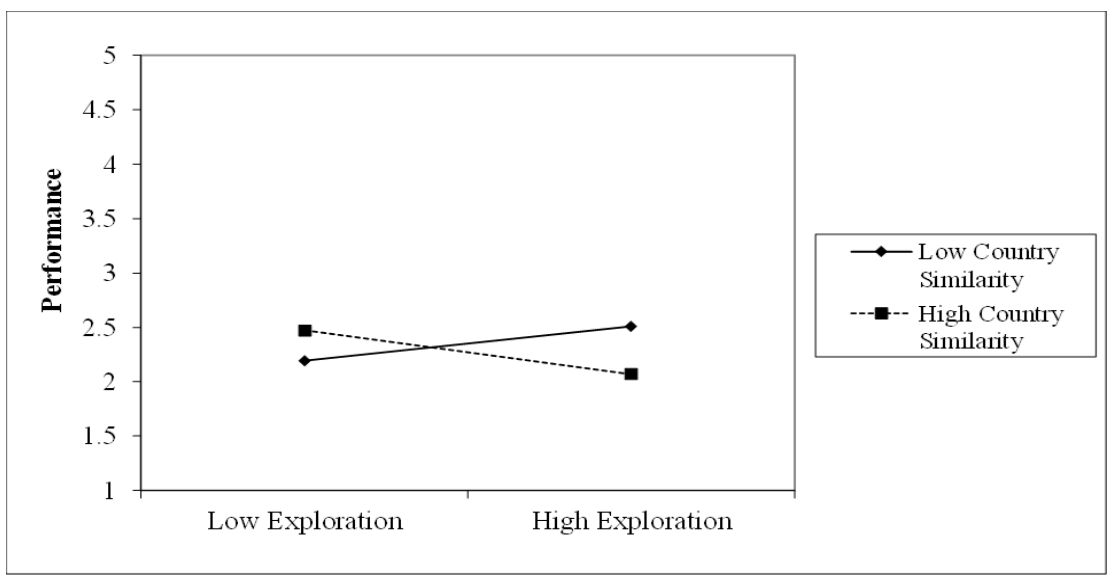

Panel C: Exploitation $\times$ Home-host country similarity (H5b)

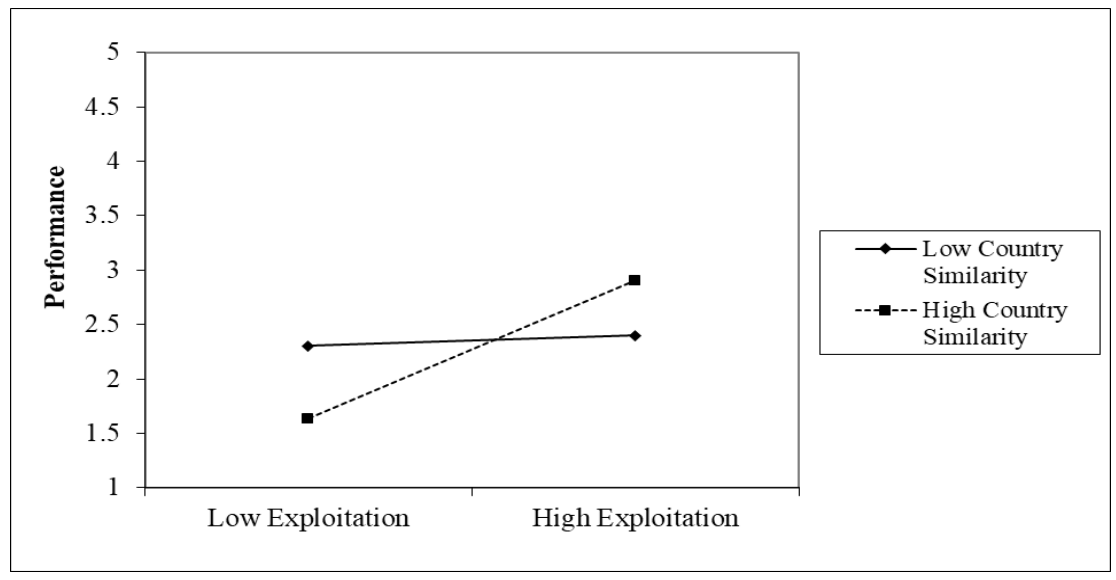


Panel D: Ambidexterity $\times$ Home-host country similarity (H6)

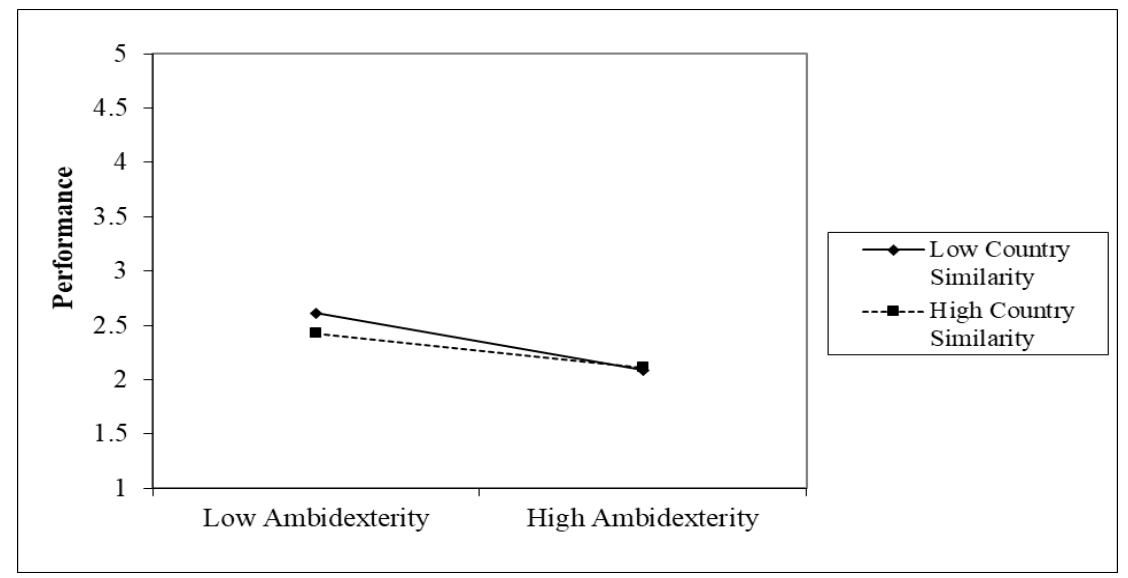

H5 posits that home-host country similarity (a) negatively moderates the relationship between exploration and ISMEs' performance and (b) positively moderates the relationship between exploitation and ISMEs' performance. The results of model 3 support both hypotheses $(\mathrm{r}=-0.18, \mathrm{t}=-2.66, \mathrm{p}<0.01$, for exploration $\times$ Home-host Country Similarity; $\mathrm{r}=0.29, \mathrm{t}=4.34$ $\mathrm{p}<0.01$, for exploitation $\times$ Home-host Country Similarity). Specifically, as shown in Panels B and $\mathrm{C}$ in Figure 3, exploration positively influences ISMEs' performance only when home-host country similarity is low. In contrast, only when home-host country similarity is high does exploitation positively influence ISMEs’ performance.

Finally, I expect home-host country similarity to attenuate the negative influence between ambidexterity and firm performance in H6. Model 3 provides support for this hypothesis ( $\mathrm{r}=$ 0.05, $\mathrm{t}=1.68, \mathrm{p}<0.10$ ). As shown in Panel D (Figure 3), when home and host countries are 
similar, the negative influence of ambidexterity on firm performance diminishes. I also checked the robustness of the results by omitting six outlier cases, and the results remained the same. ${ }^{2}$

\section{General discussion}

The impacts of exploration, exploitation, and ambidexterity have been examined from different perspectives such as top management team (Kammerlander et al. 2015; Lubatkin et al. 2006), learning theory (Skarmeas et al. 2016), organizational structure (Heavey and Simsek 2017), and IM, among others (Jin et al. 2016; Zhang et al. 2016). However, very few studies have examined exploration, exploitation, and ambidexterity from the perspective of SMEs' internationalization (e.g., Hughes et al. 2010; Lisboa et al. 2013; Shirokovaet al. 2013). Given that ISMEs are facing more intensive challenges than MNEs or domestic SMEs, examining unique problems and circumstances is vital to expanding the knowledge base regarding these firms. The findings provide insights to the following questions: (1) How do exploration, exploitation, and ambidexterity influence ISMEs' firm performance, and (2) How do factors within and outside firms enhance positive influences or attenuate negative influences?

My results support ISMEs' adoption of either exploration or exploitation when entering the global marketplace, but caution on implementing ambidextrous strategies. I also find evidence suggesting that AMCs play an important role in ISMEs' international strategies. These research findings make the following theoretical and managerial contributions.

\subsection{Theoretical implications}

The findings provide important insights regarding exploration, exploitation, and ambidexterity, particularly as they pertain to IM. I provide empirical evidence of the effects of

\footnotetext{
${ }^{2}$ To check the robustness of the results, I also run structural equation models via SmartPLS. The results of SEM showed the same pattern as the results of multiple regression except that p-values regarding H1, H4b, and H6 increased to $0.16,0.13$, and 0.29 .
} 
exploration, exploitation, and ambidexterity on firm performance within the context of ISMEs. Prior studies have not adequately addressed how ISMEs might benefit from these strategies (cf. Hughes et al. 2010; Lisboa et al. 2013; Shirokova et al. 2013). My findings suggest that either exploration or exploitation enhances ISMEs’ performance, whereas ambidexterity retards performance. Ambidexterity exerts undue pressure on ISMEs' limited resources, thus negatively influencing the outcomes associated with the pursuit of this strategy.

There are indications regarding the practice of mimetic isomorphism by smaller international firms (e.g., Samiee and Chirapanda 2019); however, thoughtless copying of larger firms' and MNEs' strategies, without taking ISMEs' resources into consideration will result in suboptimum performance. Whereas large firms possess many advantages and are well-situated to simultaneously implement exploration and exploitation, ISMEs need to remain focused. According to environmental munificence and contingency theories, ISMEs should achieve a fit between internal resources, external resources, and strategies to build and maintain a competitive advantage. When resources are scarce, pursuing ambidexterity may stretch the limited resources available to ISMEs even thinner among too many initiatives. This practice dilutes the strategic emphasis on both exploration and exploration strategies, leading to suboptimal international performance.

In addition, my findings provide a new perspective for interpreting the conflicting results of the influence of ambidexterity on firm performance. Since both positive and negative relationships have been reported in the literature, I argue that the influence of ambidexterity on firm performance might vary by contexts (He and Wong 2004). Focusing on ISMEs, my results indicate that while ambidexterity may impede firm performance, its negative influence can be 
attenuated by home-host country similarity. That is, performance consequences of firms' strategic actions are to some extent dependent on markets in which they implement their plans.

Furthermore, I empirically tested the impact of an understudied firm capability, namely AMCs, on ISMEs' international performance and uncovered new moderating effects. AMCs positively moderate the relationship between exploitation and ISMEs' performance. ISMEs can develop AMCs to navigate the highly competitive global marketplace. Unlike the inside-out perspective of dynamic capability that emphasizes the value of internal resources, AMCs operate on an outside-in premise with a focus on external environmental factors and adapt to the market through experimentation, discovery, and risk-taking (Day 2011). In essence, AMCs consider how a firm leverages internal resources, acquires new resources from outside, and adapts to environmental factors based on anticipation of weak market signals (Day 2011). AMCs start with the external environmental forces and emphasize new opportunities rather than efficiency (Oktemgil and Greenley 1997). Superior AMCs help international firms focus on external environments, explore product-market opportunities, and adapt to market changes (Oktemgil and Greenley 1997). It is evident that AMCs are critical to ISMEs' international marketing performance, as AMCs will maximize the advantage of ISMEs' flexibility in resource configuration, decision-making efficiency, and fast information acquisition speed. This study represents an initial inquiry into this important but often overlooked capability for ISMEs by providing a reliable scale and establishing relationships with other variables in a nomological framework.

Finally, this investigation delineates boundary conditions for the effects of exploration and exploitation on ISMEs' performance. In particular, exploration boosts ISMEs' performance only when the firms run business in host countries that are not similar to home countries, while 
exploitation leads to enhanced performance when home-host country similarity is high. The results suggest that ISMEs need to take into consideration the external environment where they operate when selecting between exploration and exploitation.

\subsection{Managerial implications}

From a managerial viewpoint, ISMEs are often tempted to follow industry trends set by MNEs. However, this can prove to be a very risky strategy. ISMEs need to realize that successful strategies for MNEs may underperform among ISMEs. Although following the lead of a successful MNEs in a host market can certainly be reassuring and useful in formulating a focused ISMEs' strategy (i.e., mimetic isomorphism), such as exploration or exploitation, ISMEs must remain very focused and only selectively copy their larger counterparts' strategies. That is, based on my results, the pursuit of successful broad-based MNEs' strategies, such as ambidexterity, will dilute ISMEs' resources and yield weak results. Specifically, ambidexterity can be a very risky strategy for ISMEs. Lacking the level of resources that are required for a firm to implement ambidexterity, ISMEs may find themselves in a dilemma where exploration and exploitation are pulling resources toward two opposite directions. As an outcome, ISMEs may end up with failed initiatives on both exploration and exploitation. My findings suggest that ISMEs should exert extra caution deciding whether to implement ambidexterity.

My findings also provide insights on how ISMEs can take full advantage of exploitation. As competition in the global marketplace is increasingly fierce, a growing number of international firms stand out in global competition by relying on exploitation strategies. My results suggest that ISMEs should build AMCs development into their success formula of exploitation. The global business environment is rapidly and unpredictably changing, which requires ISMEs to provide timely responses to changes in the market. One advantage ISMEs 
have over MNEs is their flexibility and responsiveness to market changes. As ISMEs' corporate structure is flatter and less bureaucratic than MNEs, they are more likely to act quickly in the volatile marketplace. ISMEs should take full advantage of developing strong AMCs by actively collecting information about their customers and competitors and converting this useful information to appropriate marketing strategies. Combining focused an exploitation strategy and strengthened AMCs, ISMEs can achieve superior international performance in an increasingly competitive global marketplace.

\subsection{Limitations and future research}

Although my research provides new insights on ISMEs' internationalization, future research is needed to bolster my findings in non-U.S. contexts. First, emerging and developing countries compete for an increasing share of world exports; however, these markets are more complex and less stable than developed countries, and thus ISMEs in these countries face more stringent institutional environments. Furthermore, developing- and emerging-market ISMEs lack access to fine-grain market information that is a precursor to developing AMCs in other markets and which is ultimately essential for success in these markets. Another developing- and emerging-market context that deserves research attention pertains to demand level and competitive rivalry in these markets. In some developing markets, demand for [at least some] products exceeds supply, leading to a sellers' market condition. The extent to which such conditions influence ISMEs' export marketing strategies and their respective AMCs in such markets has not been investigated but warrant scholarly scrutiny. In other words, will ISMEs be more likely to use exploitation in those emerging markets characterized as a sellers' market?

Second, the data collected for this study is cross-sectional. Future research should adopt a longitudinal approach and examine how changes in capabilities influence strategies. For 
example, current resources and capabilities usually serve as a foundation for developing future capabilities. Longitudinal data would help uncover the impact of different stages on strategy deployment and capabilities development.

Third, I did not collect objective data from firms. Because the marketing research firm that I used to collect data did not disclose firms' names to me, I could not collect objective data such as financial figures of firms. As a result, it is not possible to use objective data when conducting CMV or non-response bias tests.

Finally, even though my results show good reliability and validity of the scale measuring AMCs, it is worthwhile for future research to follow a more rigorous procedure to develop a scale to measure this construct. 


\section{References}

Andriopoulos, C. \& Lewis, M. W. (2009). Exploitation-exploration tensions and organizational ambidexterity: Managing paradoxes of innovation. Organization Science, 20(4), 696-717.

Baltar, F. \& Icart, I. (2013). Entreprenuerial gain, cultural similarity and transnational entrepreneurishi. Global Networks, 13(2), 200-219.

Barney, J. (1991). Firm resources and sustained competitive advantage. Journal of Management, 17(1), 99-120.

Brouthers, K. D. \& Nakos, G. (2004). SME entry mode choice and performance: A transaction cost perspective. Entrepreneurship Theory and Practice, 28(3), 229-247.

Castrogiovanni, G. J. (1991). Environmental munificence: A theoretical assessment. Academy of Management Review, 16(3), 542-565.

Cavusgil, S. T., \& Zou, S. (1994). Marketing strategy-performance relationship: An investigation of the empirical link in export market ventures. The Journal of Marketing, 58(January), 1-21.

Cavusgil, S. T., Zou, S. \& Naidu, G. M. (1993). Product and promotion adaptation in export ventures: an empirical investigation. Journal of International Business Studies, 24(3), 479506.

Chang, S. J., van Witteloostuijn, A., \& Eden, L. (2010), From the editors: Common method variance in international business research. Journal of International Business Studies, 41(2), 178-184.

Chen, M. J., \& Hambrick, D. C. (1995). Speed, stealth, and selective attack: How small firms differ from large firms in competitive behavior. Academy of Management Journal, 38(2), 453-482. 
Cui, A. P., Walsh, M. F., \& Zou, S. (2014). The importance of strategic fit between host-home country similarity and exploration exploitation strategies on small and medium-sized enterprises' performance: A contingency perspective. Journal of International Marketing, 22(4), 67-85.

Cyert, R., \& March, J. (1963). A behavioral theory of the firm. Englewood Cliffs, NJ: Prentice Hall.

Dasí, A., Iborra, M., \& Safón, V. (2015). Beyond path dependence: Explorative orientation, slack resources, and managerial intentionality to internationalize in SMEs. International Business Review, 24(1), 77-88.

Day, G. S. (1994). The capabilities of market-driven organizations. The Journal of Marketing, $58(4), 37-52$.

Day, G. S. (2011). Closing the marketing capabilities gap. Journal of Marketing, 75(July), 183195.

Day, G. S. (2014). An outside-in approach to resource-based theories. Journal of the Academy of Marketing Science, 42(1), 27-28.

Ebben, J. J., \& Johnson, A. C. (2005). Efficiency, flexibility, or both? Evidence linking strategy to performance in small firms. Strategic Management Journal, 26(13), 1249-1259.

Erramilli, M. K., \& Rao, C. P. (1993). Service firms’ international entry-mode choice: A modified transaction-cost analysis approach. Journal of Marketing, 57(3), 19-38.

Falk, M., \& de Lemos, F. F. (2019). Complementarity of R\&D and productivity in SME export behavior. Journal of Business Research, 96, 157-168.

Fuller, C. M., Simmering, M. J., Atinc, G., Atinc, Y., \& Babin, B. J. (2016). Common methods variance detection in business research. Journal of Business Research, 69(8), 3192-3198. 
Garcia, R., Calantone, R. \& Levine, R. (2003). The role of knowledge in resource allocation to exploration versus exploitation in technologically oriented organizations, Decision Sciences, $34(2), 323-349$.

Goll, I., \& Rasheed, A. A. (2004). The moderating effect of environmental munificence and dynamism on the relationship between discretionary social responsibility and firm performance. Journal of Business Ethics, 49(1), 41-54.

Gupta, A. K., Smith, K. G., \& Shalley, C. E. (2006). The interplay between exploration and exploitation. Academy of Management Journal, 49(4), 693-706.

Han, M., \& Celly, N. (2008). Strategic ambidexterity and performance in international new ventures. Canadian Journal of Administrative Sciences, 25(4), 335-349.

He, Z. H., \& Wong, P. K. (2004). Exploration vs. exploitation: An empirical test of the ambidexterity hypothesis. Organization Science, 15(4), 481-494.

Heavey, C., \& Simsek, Z. (2017). Distributed cognition in top management teams and organizational ambidexterity: The influence of transactive memory systems. Journal of Management, 43(3), 919-945.

Herbig, P., \& Milewica, J. (1994). Marketing signals in service industries: Implications for strategic decision making and profitability. Journal of Services Marketing, 8(2), 19-35.

Hughes, M., Martin, S. L., Morgan, R. E., \& Robson, M. J. (2010). Realizing product-market advantage in high-technology international new ventures: The mediating role of ambidextrous innovation. Journal of International Marketing, 18(4), 1-21.

Jin, J. L., Zhou, K. Z., \& Wang, Y. (2016). Exploitation and exploration in international joint ventures: Imbalance and product similarity. Journal of International Marketing, 24(4), 2038. 
Kammerlander, N., Burger, D., Fust, A., \& Fueglistaller, U. (2015). Exploration and exploitation in established small and medium-sized enterprises: The effect of CEOs' regulatory focus. Journal of Business Venturing, 30(4), 582-602.

Klein, S. (1989). A transaction cost explanation of vertical control in international markets. Journal of the Academy of Marketing Science, 17(3), 253-260.

Kollmann, T., \& Stöckmann, C. (2014). Filling the entrepreneurial orientation-performance gap: The mediating effects of exploratory and exploitative innovations. Entrepreneurship Theory and Practice, 38(5), 1001-1026.

Kozlenkova, I. V., Samaha, S. A., \& Palmatier, R. W. (2014). Resource-based theory in marketing. Journal of the Academy of Marketing Science, 42(1), 1-21.

Lee, J., Lee, J. \& Lee, H. (2003). Exploration and exploitation in the presence of network externalities, Management Science, 49(4), 553-570.

Lee, S. L., Park, G., Yoon, B. \& Park, J. (2010). Open innovation in SMEs-An intermediated network model. Research Policy, 39(2), 290-300.

Lemon, K. N., \& Verhoef, P. C. (2016). Understanding customer experience throughout the customer journey. Journal of Marketing, 80 (6), 69-96.

Leonidou, L.C. (1995). Empirical research on export barriers: Review, assessment, and synthesis. Journal of International Marketing, 3(1), 29-43.

Leonidou, L. C., Palihawadana, D., \& Theodosiou, M. (2011). National export-promotion programs as drivers of organizational resources and capabilities: Effects on strategy, competitive advantage, and performance. Journal of International Marketing, 19(2), 1-29.

Leonidou, L.C., Samiee, S., \& Geldres, V. V. (2015). Using national export promotion programs to assist smaller firm's international entrepreneurial initiatives, in Handbook of 
Research on International Entrepreneurial Strategies: Impact on SME performance globally. In Ghauri, , P.N. \& Kirpalani, V.H.M. (eds.), Edward Elgar Publishing.

Levinthal, D. A. \& March, J. G (1993). The myopia of learning. Strategic Management Journal, 14(Winter), 95-112.

Li, Y., Wei, Z., Zhao, J., Zhang, C., \& Liu, Y. (2013). Ambidextrous organizational learning, environmental munificence and new product performance: Moderating effect of managerial ties in China. International Journal of Production Economics, 146(1), 95-105.

Lisboa, A, Skarmeas, D., \& Lages, C. (2013). Export market exploitation and exploration and performance: Linear, moderated, complementary and non-linear effects. International Marketing Review, 30(3), 211-230.

Lu, Y., Zhou, L., Bruton, G., \& Li, W. (2010). Capabilities as a mediator linking resources and the international performance of entreprenurial firms in an emerging economy. Journal of International Business Studies, 41(3), 419-436.

Lubatkin, M. H., Simsek, Z., Ling, Y., \& Veiga, J. F. (2006). Ambidexterity and performance in small-to medium-sized firms: The pivotal role of top management team behavioral integration. Journal of Management, 32(5), 646-672.

March, J. G. (1991). Exploration and exploitation in organizational learning. Organizational Science, 2(1), 71-87.

Miller, K. D., Zhao, M., \& Calantone, R. J. (2006). Adding interpersonal learning and tacit knowledge to March's exploration-exploitation model. Academy of Management Journal, 49(4), 709-722.

Mitra, D., \& Golder, P. N. (2002). Whose culture matters? Near-market knowledge and its impact on foreign market entry timing. Journal of Marketing, 39(3), 350-365. 
Moorman, C. (1995). Market organizational processes: Product cultural outcomes information antecedents and new product outcomes. Journal of Marketing Research, 32(3), 318-335.

Morgan, R.E., \& Katsikeas, C. S. (1997). Obstacles to export initiation and expansion. Omega, 25(6), 677-690.

Morgan, N. A., Katsikeas, C. S. \& Vorhies, D. W. (2012). Export marketing strategy implementation, export marketing capabilities, and export venture performance. Journal of the Academy of Marketing Science, 40(2), 271-289.

Mu, J. (2015). Marketing capability, organizational adaptation and new product development performance. Industrial Marketing Management, 49 (August), 151-166.

Naldi, L., Wikström, P., \& Von Rimscha, M. B. (2014). Dynamic capabilities and performance: An empirical study of audiovisual producers in Europe. International Studies of Management \& Organization, 44(4), 63-82.

Neslin, S. A., Grewal, D., Leghorn, R., Shankar, V., Teerling, M. L., Thomas, J. S., \& Verhoef, P. C. (2006). Challenges and opportunities in multichannel customer management. Journal of Service Research, 9(2), 95-112.

Nielsen, B. B., \& Gudergan, S. (2012). Exploration and exploitation fit and performance in international strategic alliances. International Business Review, 21(4), 558-574.

Nobel, C. (2011). Clay Christensen's milkshake marketing, (accessed January 21, 2019), [available at https://hbswk.hbs.edu/item/clay-christensens-milkshake-marketing]. NSBA (2016). 2016 year-end economic report. research report, (accessed February 28, 2018), [available at http://www.nsba.biz/wp-content/uploads/2017/02/Year-End-Economic-Report2016.pdf ] 
Oktemgil, M., \& Greenley, G. (1997). Consequences of high and low adaptive capability in UK companies. European Journal of Marketing, 31(7), 445-466.

Özsomer, A., \& Gençtürk, E. (2003). A resource-based model of market learning in the subsidiary: The capabilities of exploration and exploitation. Journal of International Marketing, 11(3), 1-29.

Prange, C., \& Phinho, J. C. (2017). How personal and organizational drivers impact on SME international performance: The mediating role of organizational innovation. International Business Review, 26(6), 1114-1123.

Raisch, S., \& Birkinshaw, J. (2008). Organizational ambidexterity: Antecedents, outcomes, and moderators. Journal of Management, 34(3), 375-409.

Raisch, S., \& Birkinshaw, J., Probst, G., \& Tushman, M. L. (2009). Organizational ambidexterity: Balancing Exploitation and exploration for sustained performance. Organization Science, 20(4), 685-695.

Rao-Nicholson, R., \& Khan, Z. (2017). Standardization versus adaptation of global marketing strategies in emerging market cross-border acquisitions. International Marketing Review, 34(1), 138-158.

Ruekert, R. W., Walker, O. C., \& Roering, K. J. (1985). The organization of marketing activities: A contingency theory of structure and performance. Journal of Marketing, 49(1), 13-25.

Samiee, S., \& Chirapanda, S. (2019). International marketing strategy in emerging-market exporting firms. Journal of International Marketing, 27(1), 20-37.

Samiee, S., \& Walters, P. G. (1999). Determinants of structured export knowledge acquisition. International Business Review, 8(4), 373-397. 
Samiee, S., \& Walters, P.G.P. (1991). Segmenting corporate exporting activities: Sporadic versus regular exporters. Journal of the Academy of Marketing Science, 19(2), 93-104.

Sarkees, M., Hulland, J., \& Prescott, J. (2010). Ambidextrous organizations and firm performance: The role of marketing function implementation. Journal of Strategic Marketing, 18(2), 165-184.

Shirokova, G., Vega, G., \& Sokolova, L. (2013). Performance of Russian SMEs: Exploration, exploitation and strategic entrepreneurship. Critical Perspectives on International Business, $9(1 / 2), 173-203$.

Singhapakdi, A., Sirgy, M. J., \& Lee, D. J. (2010). Is small business better than big business for marketing managers? Journal of Business Research, 63(4), 418-423.

Skarmeas, D., Lisboa, A., \& Saridakis, C. (2016). Export performance as a function of market learning capabilities and intrapreneurship: SEM and FsQCA findings. Journal of Business Research, 69(11), 5342-5347.

Song, J., \& Shin, J. (2008). The paradox of technological capabilities: A study of knowledge sourcing from host countries of overseas R\&D operations. Journal of International Business Studies, 39(2), 291-303.

Staw, B. M., \& Szwajkowski, E. (1975). The scarcity-munificence component of organizational environments and the commission of illegal acts. Administrative Science Quarterly, 20(3), 345-354.

Theodosiou, M., \& Leonidou, L. C. (2003). Standardization versus adaptation of international marketing strategy: An integrative assessment of the empirical research. International Business Review, 12(2), 141-171. 
U.S. Department of Commerce (2017). U.S. Trade Overview, 2016. research report, (accessed February 28, 2018), [available at https://www.trade.gov/mas/ian/build/groups/public/@tg_ian/documents/webcontent/tg_ian_ 005537.pdf ]

Voss, G. B., \& Voss, Z. G. (2013). Strategic ambidexterity in small and medium-sized enterprises: Implementing exploration and exploitation in product and market domains. Organization Science, 24(5), 1459-1477.

Voss, G. B., Sirdeshmukh, D., \& Voss, Z. G. (2008). The effects of slack resources and environmentalthreat on product exploration and exploitation. Academy of Management Journal, 51(1), 147-164.

Wan, W. P., \& Hoskisson, R. E. (2003). Home country environmnets, corporate diversification strategies, and firm performance. Academy of Management Journal, 46(1), 27-45.

Westhead, P., Wright, M., \& Ucbasaran, D. (2001). The internationalization of new and small firms: A resource-based view. Journal of Business Venturing, 16(4), 333-358.

Williams, L. J., Hartman, N., \& Cavazotte, F. (2010). Method variance and marker variables: A review and comprehensive CFA marker technique. Organizational Research Methods, $13(3), 477-514$.

Yalcinkaya, G., Calantone, R. J., \& Griffith, D. A. (2007). An examination of exploration and exploitation capabilities: Implications for product innovation and market performance. Journal of International Marketing, 15(4), 63-93.

Zeriti, A., Robson, M. J., Spyropoulou, S., \& Leonidou, C. N. (2014), Sustainable export marketing strategy fit and performance. Journal of International Marketing, 22(4), 44-66. 
Zhang, J. A., Edgar, F., Geare, A., \& Kane, C. O. (2016). The interactive effects of entrepreneurial orientation and capability-based hrm on firm performance: The mediating role of innovation bmbidexterity. Industrial Marketing Management, 59, 131-143. 


\section{ARTICLE 3 - UNDERSTANDING THE MARKETING RESOURCES INTEGRATION IN CROSS-BORDER ACQUISITIONS}

\section{Introduction}

In order to improve global competitiveness, an increasing number of emerging-market (EM) firms have been acquiring firms from developed economies over the last two decades (e.g., India-based Tata acquired Jaguar and Land Rover in 2008; China-based TCL acquired French electronics company Thomson in 2003). One of the key motivations behind those cross-border acquisitions (CBAs) is to immediately obtain resources and capabilities from acquired firms that would require considerable investments to develop in house (Luo and Tung 2007). In addition, CBAs give EM acquirers opportunities to learn advanced skills (e.g., managerial skills) from acquired firms (Luo and Tung 2007). However, not all EM acquirers were able to increase their competitiveness via CBAs (Liu and Woywode 2013; Ma et al. 2016). For example, Tata has significantly increased its global brand awareness through acquiring Jaguar and Land Rover, while TCL witnessed its first financial loss since its establishment in the year after acquiring Thomson (Chen 2008). Current literature also demonstrates conflicting results on the influence of CBAs on acquirers' firm performance (Wu et al. 2016). Given the high opportunity cost of CBAs, it is necessary to investigate how EM acquirers could benefit from CBAs that normally involve significant resources input.

The majority of studies on CBAs are based on both acquirers and acquired firms from developed countries so these findings are not fully applicable to EM acquirers (e.g., Bommaraju et al. 2018; Capron and Hulland 1999). The inapplicability is because that EM acquirers' motivations behind CBAs are different than those of acquirers from developed economies and are embedded with different political, cultural, and economic environments from acquired firms 
(Luo et al. 2011; Luo and Tung 2018). Recently, to explain CBAs conducted by EM acquirers, a number of theoretical perspectives, such as the springboard perspective and institutional-based view, have been adopted to examine factors that influence the outcomes of CBAs, including business relatedness between acquirers and acquired firms (e.g., Yu et al. 2016), institutional environments (e.g., Mass et al. 2019), firm capabilities (e.g., Björkman et al. 2007; Lu et al. 2010), cultural differences (Huang et al. 2017), social networks (e.g., Lin et al. 2009), acquisition motives (e.g., Nicholson and Salaber 2013; Rui and Yip 2008), and firm attributes (e.g., Wu et al. 2016). However, our knowledge is still limited due to two major gaps existing in the current literature.

First, previous studies have not provided substantial insights about what types of marketing resources acquirers could possibly use after CBAs. One of the key motivations behind EM acquirers' CBAs is to gain access to resources owned by acquired firms in developed economies (Luo and Tung 2007). However, because of the stickiness of resources, not all resources could be redeployed by acquirers after the acquisition (Teece et al. 1997). However, extant studies have not answered what marketing resources could be redeployed by acquirers. Answering this question is even more urgent when CBAs are initiated by EM acquirers because acquired firms will probably resist integration of resources (Zhu and Zhu 2016). Since extant research on CBAs has predominantly focused on CBAs initiated by firms from developed countries, existing findings may not be applicable to CBAs when acquirers are from EMs. Hence, it is necessary to develop a framework pertinent to EM acquirers' post-merger integration (PMI) management in a CBA.

Second, little is known about the mechanism through which EM acquirers could translate the integrated marketing resources into superior firm performance after they acquire firms from 
developed economies. As resource-based view (RBV) and its extensions posit, it is not the possession of rare, valuable, inimitable, and non-substitutable resources, but the way of utilizing the resources that determines firms' sustainable competitive advantages (Teece 2014). In the case of CBAs, integrated resources per se will not help EM acquirers increase competitiveness unless the resources are utilized in a proper way. However, given that PM performance varies significantly across different CBAs (i.e., some CBAs result in better performance for the acquirers while others do not), it is necessary to investigate what strategies could better leverage integrated resources.

To bridge these gaps, the present study aims to investigate the following research questions:

(1) What types of marketing resources can be integrated by acquirers after CBAs?

(2) How can EM acquirers better use integrated resources to increase PM performance?

By filling these gaps, the present study contributes to the literature in four ways. First, this study identifies five potential ways of integrating marketing resources after CBAs by performing a context analysis on 136 CBAs between emerging brands and developed brands. Previous studies have generally recognized the importance of PMI of marketing resources (e.g., Birkinshaw et al. 2000; Lin et al. 2009). However, the process of integrating marketing resources has attracted surprisingly little empirical attention except for the work by Capron and her colleagues based on 253 horizontal acquisitions between U.S. and European firms. They used a cross-sectional survey to examine the influence of integration of brand, salesforce, and general marketing expertise on PM performance (Capron 1999; Capron and Hulland 1999; Capron and Pistre 2002; Capron et al. 1998). Because of the sporadic research attention, scholars and managers are not clear what types of marketing resources to integrate and how to better utilize 
those integrated resources. Therefore, the present study provides an initial attempt to open the blackbox of the integration process of marketing resources, thus providing managers with better understanding of how to make CBAs successful.

Second, the findings of this study provide insights on how marketing resources integration influences firm performance from EM firms' perspective. Early studies mainly focus on investigating CBAs initiated by developed-country firms and find that the firms use CBAs mainly to exploit their resources in foreign markets (Dunning 1988). By contrast, recent research suggests that EM acquirers purchase firms in developed economies for the purposes of gaining valuable resources and learning advanced knowledge from acquired firms (Luo 2010; Luo and Tung 2007). However, no studies have shed light on how EM acquirers should manage PMI to learn and use advanced resources and knowledge. When acquiring firms from developed economies, EM acquirers usually suffer liability of foreignness, smallness, and newness because the acquirers do not have strong brand awareness in global markets, especially in developed economies (Shimizu et al. 2004). Therefore, PMI management is likely extremely challenging. The findings of this essay offer some practical suggestions for managers of EM firms to better leverage the resources obtained from CBAs to improve their own performance.

Third, the present study contributes to the CBAs literature by uncovering the dynamics of the process of integrated marketing resources affecting a firm's PM performance. The findings of this study reveal that not all marketing resources integrations can enhance a firm's performance. Specifically, some marketing resources (e.g., brand) are difficult and risky to integrate and may result in unfavorable outcomes for EM firms. Therefore, this study highlights the potential risks of mis-integrating marketing resources after CBAs and proposes that an appropriate strategy will be needed to capitalize on the integrated resources. 
Finally, the present study provides an alternative technique to examine PMI activities. Although scholars agree on the importance of integration in the success of CBAs, only a small number of studies have scrutinized issues relating to marketing integration activities, and most of them rely on cross-sectional surveys (e.g., Capron and Hulland 1999; Sinkovics et al. 2015). Single-sourced and cross-sectional data are often insufficient to provide strong causal interface to explain the questions of interest. To solve this issue, consistent with Paruchuri et al. (2006), the present study uses text analysis to extract marketing integration activities from news press. These findings provide a new direction and an alternative method for future research investigating PMI management.

In the remainder of the paper, I first review the literature of CBAs of EM firms, marketing resources integration, and RBV. Then, research framework and hypotheses will be proposed. Next, I will discuss the data collection process and results. Finally, implications, limitations, and future research directions will be discussed.

\section{Theoretical background}

\subsection{Internationalization of emerging-market (EM) firms}

Earlier internationalization theory well explains developed-country firms' CBAs and proposes that those firms engage in CBAs with the purpose of exploiting their current resources (Dunning 1988). However, exploitation of resources is not the main reason of CBAs of EM firms since EM firms usually lack resources to exploit in developed economies (Kumar et al. 2020). By contrast, scholars posit that obtaining valuable resources and capabilities is the main reason behind CBAs initiated by EM firms with an ultimate goal of increasing global competitiveness and compensating for latecomer disadvantages (Luo and Tung 2007). Firms from developed economies have been incumbents in global markets for nearly one century and have accumulated 
a plethora of advanced knowledge and skills (Zhu and Zhu 2016). However, EM firms have actively participated in global competition only as late as the beginning of this century when governments from EMs lifted restrictions on international trades. For example, since Chinese government formulated its "Going abroad" policy in 2000 and joined the WTO in 2001, many Chinese firms have been entering developed markets (Luo et al. 2010). Especially when many firms from developed economies suffered financial deficiency due to the economic crisis in 2008, Chinese firms have accelerated international expansion by acquiring those firms. However, Chinese firms are still constrained with insufficient resources and novices with little management and marketing knowledge compared to their global competitors. More importantly, dynamic and turbulent global environments do not give Chinese firms enough time to develop such knowledge in an organic method. As such, CBAs constitute an effective tool for Chinese firms to procure rare resources and to obtain advanced technological and managerial skills to leapfrog their competitors and compensate for latecomer disadvantages (Luo and Tung 2007).

\subsection{Marketing resources integration in CBAs: A resources-based view}

RBV has been widely used to explain CBAs initiated by EM acquirers since the main motivations behind CBAs include resources and opportunity seeking (Zhu and Zhu 2016). RBV views firm resources as all assets, capabilities, organizational processes, firm attributes, information, and knowledge controlled by a firm (Barney 1991). These resources allow the firm to implement actions that improve its efficiency and effectiveness (Barney 1991). To achieve sustainable competitive advantages over competitors, a firm should hold valuable, rare, inimitable, and non-substitutable resources (Barney 1991). Since marketing resources could help firms build sustainable competitive advantages (Homburg and Bucerius 2005), and EM acquirers 
do not own the resources, they resort to acquiring marketing resources from firms in developed economies to gain access to the resources in a timely fashion.

When attempting to use acquired marketing resources, EM acquirers face two challenges. First, not all marketing resources are possible to redeploy by acquirers after the purchases due to the stickiness of resources, which is defined as the extent to which the amount of resources could be adjusted quickly according to situations and can be applied to other ends interchangeably (Mishina et al. 2004). Sticky resources are difficult to manage because they are not easily adapted to the changes of situations (Mishina et al. 2004). In addition, sticky resources become less useful once they are used in a different situation or for a different task (Mishina et al. 2004). Since marketing resources usually cannot be gauged by a standard unit and are somehow specific to a market, the extent of stickiness of marketing resources is generally high. Therefore, the prerequisite of using acquired marketing resources is to fully integrate and absorb them into acquirers' business processes (Graebner et al. 2017). Therefore, the present study centers on the influence of marketing resources integration on PM performance. Marketing resources integration is defined "as the combination of two marketing activities between the acquirer and acquired into an integrated process which includes bundling, coordinating, and managing of formerly dispersed marketing resources and structures into a strategically consolidated unit” (Sinkovics et al. 2015, p. 3). Because of cultural, institutional, and environmental differences between EMs and developed economies, PMI management is extremely difficult among CBAs initiated by EM firms ( $\mathrm{Li}$ et al. 2016). Unsuccessful marketing resources integration is likely to hinder the efficiency of EM acquirers learning advanced marketing knowledge from acquired firms based in developed countries. Therefore, it is necessary to know what types of marketing knowledge can be integrated. 
The second challenge is related to the selection of strategies by EM acquirers to leverage integrated marketing resources. As Teece et al. (1997) point out, "even when an asset can be purchased, firms may stand to gain little by doing so" (Teece et al. 1997, p. 514). Based on resource orchestration theory, I suggest that EM acquirers need to adopt appropriate strategies to increase effectiveness of integrated marketing resources. Resource orchestration theory is an extension of RBV, and it posits that firms should effectively manage resources by structuring, bundling, and leveraging the resources to increase competitive advantages (Sirmon et al. 2011). Structuring refers to acquiring or divesting resources to form firms' unique resource portfolio (Sirmon et al. 2011). Bundling refers to integrating resources, and leveraging refers to mobilizing, coordinating, and deploying existing resources to leverage market opportunities (Sirmon et al. 2011). Based on resource orchestration theory, the influence of firms' resources on performance depends on strategies adopted to leverage the resources. For example, Sirmon and Hitt (2009) demonstrate that resource investments decrease firm performance when strategies do not fit with the resource investments. As Mahoney and Pandian (1992) point out, it is firms' decisions of making better use of their resources rather than the resources per se that help firms achieve competence. In other words, firm resources describe what a firm has, and strategy describes what the firm does (Kauppila 2015), and its performance is ultimately determined by "what a firm does" with "what the firm has" (Hitt et al. 2011). However, extant literature has not examined the fit between strategies EM acquirers adopt and marketing resources they acquire from firms based in developed economies.

In sum, to meet EM acquirers' objectives of acquiring firms from developed economies, EM acquirers ought to choose proper marketing resources to integrate and select proper strategies to make the most of the integrated resources. Therefore, this essay examines the 
influence of marketing resources integration on PM performance and the moderating effects of strategies.

\section{Hypotheses}

To examine the influence of marketing resources integration on PM performance, I first conducted a content analysis on press news about 136 CBAs initiated by Chinese firms to identify common marketing resources integration activities. The results reveal five major marketing resources integrations: brand integration, R\&D integration, supply chain integration, market integration, and salesforce integration. The methodology section at length explains the process of the content analysis. Then, I examine the moderating effects of marketing strategies between marketing resources integration and PM performance (See Figure 4).

Figure 4: Theoretical framework

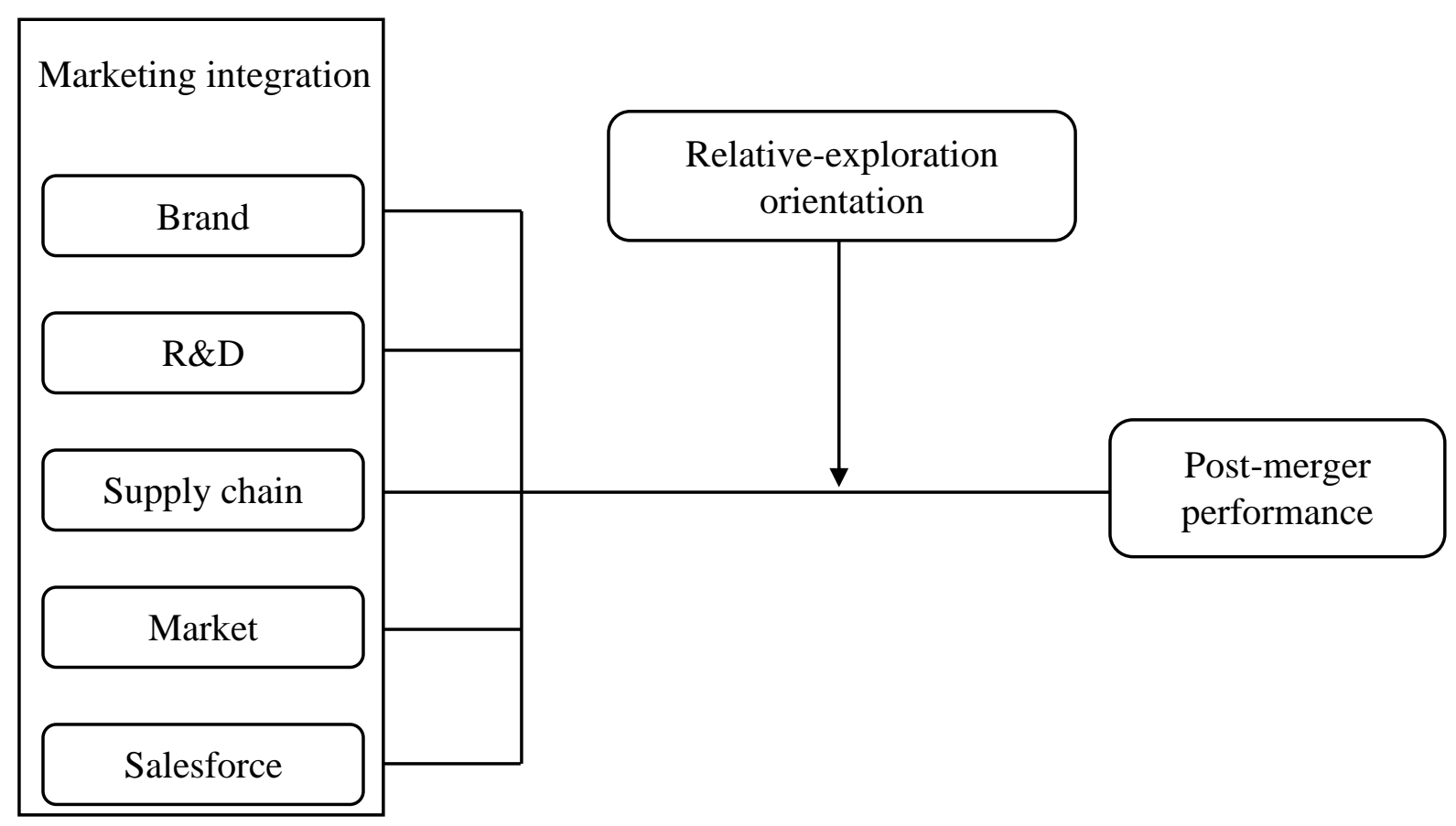




\subsection{Brand integration}

In this study, brand integration refers to an activity in which EM acquirers mobilize brand resources of acquired firms to promote their own brands (Liu et al. 2018). There are multiple ways to mobilize acquired firms' brand resources: divesture of acquired brands, combination of two brands, alignment of two brands, and the creation of new brands (Vu et al. 2009). For example, after acquiring IBM's PC division, Lenovo placed its brand logo on all the acquired product lines to combine the two brands (Osawa and Luk 2014). The primary purpose of brand integration is to increase an inferior brand's (e.g., EM acquirers) image and awareness by leveraging the strength of a superior brand (e.g., acquired firms) with a relatively low cost (Simonin and Ruth 1998). The rationale behind brand integration is that when consumers hold positive evaluations toward the superior brand, it is possible that the positive evaluations will be transferred to the inferior brand (Aaker and Keller 1990).

However, brand image transfer is extremely challenging since a brand is often heavily coupled with a specific firm culture that has been formulated during a long period by a firm (Heinberg et al. 2016). In addition, a branding process involves very few routines. Therefore, brand resources are likely difficult to integrate. In this sense, free riding of brand image may not be easily achieved when EM acquirers execute brand integration (Anderson and Gatignon 1986). Specifically, when the acquired brand and the acquiring brand do not fit in terms of target market or brand positioning, the transfer might be inhibited (Aaker and Keller 1990). This is because the misfit between the acquired brand and the acquiring brand increases consumers' difficulties in connecting the two brands (Aaker and Keller 1990). In addition, the misfit may evoke consumers' suspicions of two brands' motivations behind brand integration activities (Aaker and 
Keller 1990). Consequently, consumers may not appreciate marketing offerings provided by the integrated brand (Heinberg et al. 2016). Therefore, I hypothesize that:

H1: Brand integration negatively influences PM performance.

\section{2. $R \& D$ integration}

R\&D integration refers to an activity in which acquirers and acquired firms integrate their $R \& D$ resources and allocate the resources to various strategic ends such as new product development. Because innovation is one of the key factors that drive an international firm's success (Knight and Kim 2009), R\&D resources are thus one of the most attractive assets that motivate EM firms to acquire firms based in developed economies (Luo and Tung 2007). Since R\&D resources are developed through highly embedded and path-dependent processes (Swart and Kinnie 2003), they often contain specific features that cannot be easily transferred to other organizations or other projects. Hence, though R\&D resource can be integrated after CBAs, those integrated $R \& D$ resources may not be able to help EM acquirers establish competitive advantages. Considering the efforts required by $R \& D$ integration, it might not be able to improve PM performance.

In addition, $R \& D$ resources often reside in human capitals associated with $R \& D$ activities, such as engineers or scientists (King et al. 2008). Previous studies have shown that firms often suffer the loss of human capitals (e.g., scientists) after integration (Paruchuri et al. 2006). In addition, CBAs often involve significant cultural and organizational reconstruction, and the creativity and productivity of the R\&D department are likely to be negatively influenced because of disruption caused by integration (Paruchuri et al. 2006). This situation becomes even worse when acquirers are inferior to acquired firms because acquired employees are not confident in the future of the new firm (Bauer et al. 2016). Therefore, I hypothesize that: 
H2: R\&D integration negatively influences PM performance.

\subsection{Supply chain integration}

Supply chain integration refers to an activity in which EM acquirers use acquired firms' established distribution channels to sell their own products (Palmatier et al. 2007a). Based on RBV, well-established distribution channels are valuable marketing resources because they can help to improve acquirers' efficiency in foreign markets by reducing coordination and monitoring costs (Palmatier et al. 2007a). Therefore, acquired firms' supply chains should be able to contribute to the acquirers' long-term profitability (Srivastava et al. 1998).

In addition, supply chain development requires significant resource inputs (Palmatier et al. 2007a). Therefore, gaining access to an established channel can significantly reduce operation costs for EM acquirers in foreign markets. In addition, integrating an established channel can also provide EM acquirers with access to markets that otherwise would not be accessible. For example, when Lenovo acquired IBM's PC business, it obtained access to not only the channel of IBM but also the business market that was formerly unavailable to Lenovo (Osawa and Luk 2014). Thus, supply chain is one of most valuable marketing resources that EM acquirers aim to obtain through CBAs (Luo et al. 2010; Wu et al. 2016; Zhu and Zhu 2016). In addition, supply chain integration can reduce or eliminate political barriers to entering a foreign market (Peng et al. 2008). In sum, by integrating the channels of acquired firms, EM acquirers could use acquired distribution channels to reach local customers and leverage EM firms' low manufacturing costs, boosting firm performance (Luo and Tung 2007). Overall, supply chain integration could serve as an effective way for EM acquirers to establish competitive advantages in developed economies. Therefore, I hypothesize that:

H3: Supply chain integration positively influences PM performance. 


\subsection{Market integration}

Market integration means that acquired firms share clients with EM acquirers. Because of the latecomer disadvantages, EM firms missed the opportunities to set their foot in global markets in the last century. To leapfrog their global competitors, a fast and cost-effective way for EM firms to obtain clients in somewhat saturated markets is to share acquired firms' clients. Certainly, local consumers would not accept offerings of EM acquirers without any qualms because of country-of-origin effects, consumer animosity, and so on (Lee et al. 2013). However, since the global market is changing with an accelerating speed, customer relationships with firms vary constantly (Day 2011). Moreover, the manufacturing process of end products distributes in multiple countries, and customers cannot accurately tell which countries the product really belongs to (Samiee et al. 2005). In addition, as globalization develops in depth and width, every corner of the global market is exposed to products from every country (Day 2011). Therefore, it is possible for consumers to accept or at least try acquirers' products endorsed by acquired locally reputable firms.

More importantly, market integration could offer EM acquirers legal rights to sell products in a specific market. For instance, access the licenses is an important reason why hightechnology EM firms acquire firms based in developed economies (Peng et al. 2008). As a result, EM acquirers could increase their market shares in a specific market. In sum, market integration could afford EM acquirers with new clients and rights to sell products in a market, so I hypothesize that:

H4: Market integration positively influences PM performance. 


\subsection{Salesforce integration}

Another marketing-based asset that EM firms aim to acquire from firms in developed economies is salesforce. By using acquired firms' salesforce, EM acquirers expect to increase the amount of sales via motivating acquired salespeople to sell acquirers' products. Generally, salesforce develops over a long-time period along with firms' unique cultures, systems, conditions, routines, and processes (Capron and Hulland 1999). Hence, salespeople grasp rich knowledge of firms and clients and thus constitute key contact employees building and sustaining relationships between firms and clients (Zhang et al. 2013). Therefore, they are crucial assets to firms' competitive advantages (Palmatier et al. 2007b). By integrating acquired firms' salespeople, acquirers may secure salespeople' relationships with customers and thus gain access to acquired firms' customers, increasing PM performance.

In addition, salespeople are good sources for market intelligence as they deal directly with customers (Hughes et al. 2013). When entering a new market, EM acquirers desire to gain knowledge about local markets and consumers' feedback on their products and services (Luo and Tung 2007). Since salespeople are key contact people with external customers and have customers' direct evaluations of products and services (Capron and Hulland 1999), integrating salespeople could help firms gain first-hand market intelligence, which in turn would help EM acquirers adjust products and services. Thus, EM acquirers can increase PM performance through salesforce integration.

Admittedly, as a type of human capital, salespeople may resist integration because of loss of position, identification, or self-esteem. However, the resistance is not impossible to repair. For example, emphasis on strategic intents and distinctiveness could increase salesforces' organizational identification, which in turn could increase salespeople' performance after an 
acquisition (Bommaraju et al. 2018). In sum, I argue that salespeople are important assets for competitive advantages, which could help EM acquirers gain access to customers in developed economies and garner consumers' feedback on products and services. Eventually, EM acquirers' PM performance could increase through integrating salespeople in acquired firms. Therefore, I hypothesize:

H5: Salesforce integration positively influences PM performance.

\subsection{The moderating effects of firm strategies}

As proposed above, brand and R\&D integration may decrease PM performance, and supply chain, market, and salesforce integration may increase PM performance. Therefore, it is important to investigate how to mitigate the negative influences and enhance the positive influences. Based on RBV and resource orchestration theory, firm performance increases when strategies fit resources. In this study, I examine the fit between integrated resources and relativeexploration orientation, which is defined as the likelihood that firms choose exploration over exploitation (Wang and Dass 2017). Exploration includes "things captured by terms such as search, variation, risk taking, experimentation, play, flexibility, discovery, innovation," (March

1991, p. 71) and it focuses on new opportunities and possibilities (Levinthal and March 1993). In contrast, exploitation comprises "such things as refinement, choice, production, efficiency, selection, implementation, execution" (March 1991, p. 71), and it focuses on old certainties (Levinthal and March 1993). For example, exploration-oriented acquirers may immediately launch new products or enter new markets after integration while exploitation-oriented acquirers may sell their products in existing markets without significant modifications.

I focus on exploration and exploitation because they reflect different approaches that acquirers deploy marketing skills obtained from acquired firms (Vermeulen and Barkema 2001). 
When adopting exploration, acquirers use integrated knowledge learned from acquired firms to develop new products jointly or scrutinize new markets unfamiliar to both firms. By contrast, when adopting exploitation, acquirers use acquired knowledge to sell their existing products. In this sense, exploration entails more uncertainties than does exploitation. Therefore, exploration requires stronger entrepreneurship than does exploitation, which is defined as firms' willingness to take risks and experiment with new offerings ( $\mathrm{Li}$ et al. 2006).

Since EM acquirers usually have strong entrepreneurship (Luo and Tung 2007), I propose that exploration fits better with integrated marketing resources than does exploitation. Thus, exploration should help EM firms better leverage integrated marketing resources than does exploitation. Specifically, EM firms capable of engaging in CBAs are usually industrial leaders in their home markets. Therefore, they do not have to expand globally since rents brought by monopolistic positions in home countries could help them survive (Luo and Tung 2007). However, many executives of these leading firms appreciate global competition and intend to serve worldwide customers (Luo and Tung 2007). In addition, these executives also use CBAs to proactively reinvent their core values and routines to foster long-term survival (Gubbi et al. 2010). Because EM acquirers usually have strong entrepreneurship, they are willing to take more risks accompanied with new product development, new opportunities, and new processes. In this sense, exploration fits the nexus of integration in CBAs more than does exploitation.

In addition, marketing resources integration triggers further exploration instead of exploitation. When marketing resources integration is implemented, it is highly likely to lead to clashes and tensions within acquiring firms (Sinkovics et al. 2015). Instead of decreasing acquirers' performance, the clash and tensions could enrich acquirers' knowledge and help to break rigidities within firms (Vermeulen and Barkema 2001). In other words, when acquirers 
encounter new problems during integration, they need to proactively seek solutions outside of their existing knowledge base, triggering exploration (Luo and Tung 2007). Turning to the research context in this study, when acquired resources are new and less related to EM acquirers, the acquirers are motivated to learn, absorb, and apply the new knowledge to existing day-to-day operations (Zheng et al. 2016). Because exploration incorporates new knowledge experimentation, it puts marketing resources to better use than would exploitation. Therefore, it is anticipated that marketing resources integration should trigger exploration, which in turn could better utilize the integrated resources than would exploitation. For example, Cui et al (2014) suggest that when a firm enters an unfamiliar market, exploration rather than exploitation could increase firm performance because new markets provide firms more opportunities to explore. Therefore, this study posits that:

H6: Marketing resources integration can lead to better PM performance when a firm has a higher degree of relative-exploration orientation.

\section{Methodology}

\subsection{Sample and data collection process}

To test the hypotheses, I choose CBAs initiated by Chinese firms as research setting for two reasons. First, China has the biggest economy among EMs as its GDP exceeded $\$ 14.3$ trillion in 2019. Second, Chinese firms have invested the most considerable resources into purchases of firms in developed economies compared to other EM firms. Specifically, in 2019, the total value of transactions between Chinese acquirers and acquired firms in the U.S. reached $\$ 3$ billion, and the number between Chinese acquirers and acquired firms in Europe soared to $\$ 60.4$ billion. 
I used SDC platinum database to identify transactions where Chinese public firms purchased firms from 23 developed economies ${ }^{3}$ between 2003 and 2015 . Two criteria were used to screen cases. First, since the present study focuses on Chinese firms integrating, learning, and transferring marketing knowledge from acquired firms, I only kept transactions after which Chinese firms have authority to make changes in acquired firms. Therefore, only transactions after which Chinese firms own at least $50 \%$ share of the acquired firms remained for further data analysis (Gubbi et al. 2010). At this stage, 171 cases were left. Second, the present study extracted firms' marketing resources integration activities from news press, so I kept only transactions that were covered in news media. This screening process yielded 136 observations. Next, I collected data for the dependent variable, the moderator, and the control variables. After removing transactions with missing values, 115 transactions remained to test the model (See Table 8). This sample size is comparable to studies in the field of CBAs, most of which have sample sizes ranging between 50 and 250 (e.g., Capron and Hulland 1999; Huang et al. 2017; Reus et al. 2016).

Table 8: The distribution of countries of acquired firms

\begin{tabular}{ll}
\hline Country & Frequency \\
\hline Australia & 2 \\
Canada & 4 \\
Denmark & 2 \\
France & 4
\end{tabular}

\footnotetext{
${ }^{3}$ Australia, Austria, Belgium, Canada, Cyprus, Czechia, Denmark, Estonia, Finland, France, Germany, Greece, Hong Kong, Iceland, Ireland, Israel, Italy, Japan, South Korea, Latvia, Lithuania, Luxembourg, Malta, Netherlands, New Zealand, Norway, Portugal, Singapore, Slovakia, Slovenia, Spain, Sweden, Switzerland, Taiwan, UK, the U.S.
} 
Germany

Hong Kong

Italy

Japan

Netherlands

New Zealand

1

Singapore

4

South Korea

3

Spain

1

Sweden

1

Switzerland

1

United Kingdom

6

United States

35

\subsection{Dependent variable}

The present study examines the influence of marketing resources integration on firm performance, and the process of integration usually takes a long period (Graebner et al. 2017). Therefore, consistent with previous studies, return on asset (ROA) one year after the acquisition is used to measure the consolidated performance of acquiring firms. ROA is calculated by the ratio of a firm's net income to total assets, which were obtained from the database of COMPUSTAT and MergentOnline. 


\subsection{Independent variables and moderators}

Since few studies have focused on marketing resources integration after M\&As, I followed an induction process consisting of reading and grouping based on the similarity of content. Induction process has been commonly used to categorize content in the marketing research (e.g., Ellen et al. 2006; Bitner et al. 1990). Based on previous studies, I first developed a coding framework with two marketing integration activities: brand and salesforce integration (Capron and Hulland 1999; Sinkovics et al. 2015). If a PMI activity is not similar to either of these two activities, I created a new category. Finally, following Bitner's (1990) procedure, I sorted, combined, and re-sorted the activities iteratively until all activities within a category are similar and fully capture the nature of the assigned PMI activity. The induction process led to five types of marketing integration activities: brand, R\&D, supply chain, market, and salesforce integration. Specifically, brand integration means that acquirers and acquired firms engage in branding activities by co-advertisement, cross-selling, brand names changes, creation of new brands, etc. R\&D integration describes that acquirers and acquired firms collaborate on new product developments. Supply chain integration means that acquirers use acquired firms' suppliers to sell products. Market integration means that acquired firms share clients with acquirers so that acquirers can do business with acquired firms' clients. Salesforce integration means that acquirers train salespeople of acquired firms so that salespeople sell acquirers' products.

I coded these integration activities by examining press releases extracted from Factiva for the two-year period after the announcement of the acquisition. Previous studies point out the necessities of coding intentions (Paruchuri et al. 2006). First, announcements convey clear information to investors, stakeholders, and other observers and so influence stock prices. 
Therefore, announcements about intentions to integrate acquired firms' resources are carefully phrased and somehow reflect acquirers' initial plans (Paruchuri et al. 2006). Second, previous studies confirm that all integration plans in the acquisition announcements are executed (Paruchuri et al. 2006). Therefore, coding intentions is equally important as coding actual integration activities. Hence, I coded both actual integration activities and acquirers' intentions to integrate acquired firms' marketing resources in acquisition announcements. I coded integration activities as a binary variable, coded to one if acquirer intentionally or actually integrated specific marketing resources. Otherwise, it is 0 (See Table 9 for coding samples).

Table 9: Samples of marketing integration resources

\begin{tabular}{ll}
\hline Marketing integration activities & \multicolumn{1}{c}{ Samples } \\
\hline Brand integration & "The two companies will spend another \$10 million in \\
advertising also." & "Now we would like to consolidate. We will now try to \\
& draw synergy and drive benefits of co-advertising \\
& products." \\
"[Acquirer] implemented an aggressive product & \\
R\&D integration & development schedule that leverages [acquired firm]'s \\
& world leading CAD/CAM/CAE/PDM software expertise to \\
& enhance [acquirer's] technology offerings." \\
& "In March last year, [acquired] had acquired [acquired firm] \\
& to structure complex solution capabilities in the CAE space. \\
& The marked [acquirer]'s foray into the engineering services \\
& activity within the scientific and engineering space."
\end{tabular}


Supply chain integration

Market integration

Salesforce integration
“[Acquirer] integration with [acquired firm] helps it leverage hard-to-acquire skills such as ... marketing channels in Japan.”

"We obtained a well-established channel to cross-sell our products in rail and industrial automation segments and seasoned management team to form the core of our future international team in a highly accretive manner."

“[Acquirer] has a presence in the cancer market only through [acquired firm], the Swiss research firm that the company acquired in August 2006.”

"For instance, [acquired firm] brought in top-drawer clients such as British Gas, British Petroleum, World Bank, OECD and Gaz de France."

"We continue to look at strengthening our direct sales force in the overseas market and that's part of the key reasons for our acquisition of [acquired firm].” “[Acquirer]'s press release also highlights [acquired firm]'s sales and marketing capabilities, with the acquisition including a mainly developed-market-focused sales force covering Canada, Scandinavia, Germany, and particularly the United States." 
The moderator in the study is relative-exploration orientation. Consistent with previous studies (Josephson et al. 2016; Mizik and Jacobson 2003; Reinartz et al. 2005), I use the ratio of the difference between $R \& D$ and sales expenses to total assets to measure relative-exploration orientation. R\&D, sales expenses, and total assets were extracted from COMPUSTAT and firms' annual reports.

$$
\text { Relative-exploration orientation }=\frac{(\mathrm{R} \& \mathrm{D} \text { expenses }- \text { Sales expenses })}{\text { Total assets }}
$$

In terms of interpretations, the greater the ratio, the more exploration-oriented firms are.

\subsection{Control variables}

I controlled for several variables that are expected to influence PMI management and PM performance.

Firm size of acquirers. Generally speaking, larger firms should have more resources and stronger capabilities to manage PMI than would small- and medium- sized firms. Thus, PM performance is expected to be better among large firms. I used the number (in thousand) of fulltime employees reported in annual reports to measure the size of acquirers.

Firm age. Since old firms should have more experience in managing overseas expansion and PMI, I expect that firm age positively influences PM performance. I used the years when firms were founded to measure firm year.

Similarity between acquirers and acquired firms. Some debates exist on the influence of similarity between acquirers and acquired firms (Yu et al. 2016). Some studies posit that similarity between acquirers and acquired firms increases PM performance because similarity could smooth the integration process (Yu et al. 2016). By contrast, some studies find that similarity decreases PM performance because high similarity reflects excessive overlapping of 
two firms' resources (Mukherji et al. 2011). As a result, newly integrated firms might suffer redundancy of resources, decreasing efficiency of operations and dampening generations of new ideas (Yu et al. 2016). Regardless, similarity between acquirers and acquired firms is expected to influence PMI and PM performance. Consistent with previous studies, I used the absolute value of the difference of codes of standard industrial classification (SIC) of acquirers and acquired firms to measure their similarities. SIC codes were obtained from COMPUSTAT.

Cultural differences. Cultural differences between two firms should influence PMI management (Graebner et al. 2017). The bigger the cultural differences, the more difficult the PMI management. Because it is somewhat impossible to know each firm's culture, especially acquired firms' culture because many acquired firms do not exist independently after acquisitions, previous studies in the field of CBAs use national culture as a proxy of firm culture. The rationale is that national culture is so stable that organizational culture and managers' normative views of management are implanted with national culture and tend not to change (Laurent 1983; Huang et al. 2017). National culture has six dimensions: individualism/collectivism, power distance, masculinity/femininity, uncertainty avoidance, longterm orientation, and indulgence/restraint. National cultural difference is measured by the following formula:

$$
\text { National cultural difference }=\sqrt{\sum\left(\mathrm{x}_{\mathrm{i}}-\mathrm{y}_{\mathrm{i}}\right)^{2}}
$$

In the formula, $x_{i}$ represents the value of the ith dimension of acquirers' national culture, and $y_{i}$ represents the value of the ith dimension of acquired firms' national culture.

Industry ROA. To control the influence of industry-related factors on PM performance (Peng et al. 2008), I controlled the average ROA of the industry that an acquirer belongs to. To 
calculate the average ROA, I pulled off all Chinese public firms' ROAs that were included in COMPUSTAT and took the average of ROA by industry.

Firms' past performance. Firms' past performance represents firms' slack resources available for integration and international expansion. Therefore, I controlled firms' previous performance by including ROA of the year of the acquisition in the model. Table 10 summarizes measurements of each variable and data source.

Table 10: Measures and data source

\begin{tabular}{|c|c|}
\hline Variable & $\begin{array}{l}\text { Measure } \\
\text { [Data source] }\end{array}$ \\
\hline Firm performance & Return on assets $=\frac{\text { Net income }}{\text { Total Assets }}$ \\
\hline & [COMPUSTAT, MergentOnline, Annual reports] \\
\hline Integration activities & $\begin{array}{l}\text { Coded dummy variable } \\
\text { [Factiva] }\end{array}$ \\
\hline $\begin{array}{l}\text { Relative exploration } \\
\text { orientation }\end{array}$ & $\frac{\text { (R\&D expenses }- \text { Sales expenses) }}{\text { Total assets }}$ \\
\hline & [COMPUSTAT, MergentOnline, Annual reports] \\
\hline Firm size & $\begin{array}{l}\text { Number of full-time employees (in thousand) } \\
\text { [COMPUSTAT, MergentOnline, Annual reports] }\end{array}$ \\
\hline Firm year & $\begin{array}{l}\text { The year of firms' establishment } \\
\text { [Firms' websites] }\end{array}$ \\
\hline Similarity between two firms & $\begin{array}{l}\text { |Acquirers' SIC - Acquired firms' SIC| } \\
\text { [COMPUSTAT] }\end{array}$ \\
\hline
\end{tabular}


Cultural difference

Industry ROA

$$
\sqrt{\sum\left(\mathrm{x}_{\mathrm{i}}-\mathrm{y}_{\mathrm{i}}\right)^{2}}
$$

[Hofstede Insights]

The average return on assets of firms in a specific industry [COMPUSTAT]

SIC: Standard Identification Code

$x_{i}$ : the value of the ith dimension of acquirers' national culture

$y_{i}$ : the value of the ith dimension of acquired firms' national culture.

\section{Results}

\subsection{Model development}

Table 11 reports the descriptive statistics and correlations of all variables. Table 12 reports the results of a series of linear regression models. In model 1, only moderators were included. In model 2, independent variables were added to test H1-H5. Finally, a moderator and interactive terms between independent variables and the moderator were added to model 3 to test the moderating effects of marketing strategy between marketing resources integration and PM performance.

Table 11: Descriptive statistic and correlation matrix

\begin{tabular}{lllllll}
\hline & 1 & 2 & 3 & 4 & 5 & 6 \\
\hline 1 PM Performance & 1 & & & & \\
2 Brand Integration & -0.288 & 1 & & & \\
3 R\&D Integration & 0.007 & 0.164 & 1 & & & \\
4 Supplier Integration & 0.073 & 0.074 & 0.321 & 1 & & \\
5 Market Integration & -0.059 & 0.158 & 0.321 & 0.201 & 1
\end{tabular}




\begin{tabular}{lcccccc} 
6 Salesforce Integration & 0.102 & 0.169 & 0.202 & 0.152 & 0.195 & 1 \\
7 Relative exploration orientation & 0.021 & 0.036 & 0.009 & -0.09 & 0.027 & 0.375 \\
8 Firm size & -0.015 & -0.052 & -0.091 & -0.092 & 0.121 & -0.059 \\
9 Firm year & -0.148 & 0.103 & 0.068 & 0.082 & -0.014 & 0.085 \\
10 Similarity between two firms & 0.123 & 0.264 & 0.012 & -0.052 & 0.12 & 0.088 \\
11 Cultural difference & -0.018 & -0.046 & 0.187 & 0.178 & 0.169 & 0.066 \\
12 Industry ROA & 0.032 & -0.088 & 0.032 & -0.131 & -0.136 & -0.004 \\
13 Past performance & 0.547 & -0.106 & 0.062 & 0.090 & 0.049 & -0.011 \\
\hline & 7 & 8 & 9 & 10 & 11 & 12 \\
\hline 8 Firm size & -0.028 & 1 & & & & \\
9 Firm year & 0.125 & -0.291 & 1 & & & \\
10 Similarity between two firms & -0.02 & -0.101 & 0.043 & 1 & & \\
11 Cultural difference & -0.152 & 0.174 & 0.033 & -0.022 & 1 & \\
12 Industry ROA & -0.012 & -0.016 & -0.041 & -0.018 & 0.038 & 1 \\
13 Past performance & -0.007 & -0.029 & -0.118 & 0.151 & -0.212 & 0.009 \\
\hline
\end{tabular}

Note: Correlations greater than 0.180 are significant.

Table 12: Regression results

\begin{tabular}{lllllll}
\hline IVs & \multicolumn{2}{c}{ Model 1 } & \multicolumn{2}{c}{ Model 2 } & \multicolumn{2}{c}{ Model 3 } \\
& $\beta($ S. E.) & $\mathrm{t}-\mathrm{value}(\mathrm{p})$ & $\beta$ (S. E.) & $\mathrm{t}$-value (p) & $\beta$ (S. E.) & $\mathrm{t}$-value (p) \\
\hline Constant & 3.313 & 0.186 & 3.121 & 1.176 & 1.986 & 0.811 \\
& $(2.794)$ & $(0.238)$ & $(2.653)$ & $(0.242)$ & $(2.449)$ & $(0.419)$ \\
\multirow{2}{*}{ Firm size } & -0.000 & -0.456 & -0.000 & -0.164 & -0.000 & -0.146 \\
& $(0.000)$ & $(0.649)$ & $(0.000)$ & $(0.870)$ & $(0.000)$ & $(0.885)$
\end{tabular}




\begin{tabular}{|c|c|c|c|c|c|c|}
\hline \multirow[t]{2}{*}{ Firm year } & -0.002 & -1.195 & -0.002 & -1.179 & -0.001 & -0.812 \\
\hline & $(0.001)$ & $(0.235)$ & $(0.001)$ & $(0.241)$ & $(0.001)$ & $(0.419)$ \\
\hline \multirow[t]{2}{*}{ Similarity between firms } & 0.000 & 0.663 & 0.000 & $1.677 *$ & 0.000 & 1.062 \\
\hline & $(0.000)$ & $(0.509)$ & $(0.000)$ & $(<0.10)$ & $(0.000)$ & $(0.291)$ \\
\hline \multirow[t]{2}{*}{ Cultural differences } & 0.000 & 1.142 & 0.000 & 0.855 & 0.000 & 0.708 \\
\hline & $(0.000)$ & $(0.256)$ & $(0.000)$ & $(0.395)$ & $(0.000)$ & $(0.481)$ \\
\hline \multirow[t]{2}{*}{ Industry ROA } & 0.010 & 0.278 & -0.003 & -0.092 & -0.008 & -0.259 \\
\hline & $(0.035)$ & $(0.782)$ & $(0.034)$ & $(0.927)$ & $(0.030)$ & $(0.796)$ \\
\hline \multirow[t]{2}{*}{ Past performance } & 0.568 & $6.55 * * *$ & 0.529 & $6.147 * * *$ & 0.572 & $6.865 * * *$ \\
\hline & $(0.087)$ & $(<0.01)$ & $(0.085)$ & $(<0.01)$ & $(0.083)$ & $(<0.01)$ \\
\hline \multirow[t]{2}{*}{ Brand integration } & & & -0.205 & $-3.360 * * *$ & -0.417 & $-5.946 * * *$ \\
\hline & & & $(0.061)$ & $(<0.01)$ & $(0.070)$ & $(<0.01)$ \\
\hline \multirow[t]{2}{*}{ R\&D integration } & & & 0.005 & 0.200 & 0.005 & 0.245 \\
\hline & & & $(0.024)$ & $(0.842)$ & $(0.021)$ & $(0.807)$ \\
\hline \multirow[t]{2}{*}{ Supply chain integration } & & & 0.016 & 0.467 & 0.032 & 0.995 \\
\hline & & & $(0.034)$ & $(0.642)$ & $(0.032)$ & $(0.322)$ \\
\hline \multirow[t]{2}{*}{ Market integration } & & & -0.029 & -1.230 & -0.021 & -1.008 \\
\hline & & & $(0.023)$ & $(0.222)$ & $(0.021)$ & $(0.316)$ \\
\hline \multirow[t]{2}{*}{ Salesforce integration } & & & 0.094 & $1.960 *$ & -0.018 & -0.343 \\
\hline & & & $(0.048)$ & $(<0.10)$ & $(0.052)$ & $(0.733)$ \\
\hline \multirow{2}{*}{$\begin{array}{l}\text { Relative exploration } \\
\text { orientation }\end{array}$} & & & & & 0.358 & 1.269 \\
\hline & & & & & $(0.282)$ & $(0.207)$ \\
\hline \multirow{2}{*}{$\begin{array}{l}\text { Brand integration } \times \\
\text { Relative exploration } \\
\text { orientation }\end{array}$} & & & & & 5.455 & $4.815^{* * *}$ \\
\hline & & & & & (1.133) & $(<0.01)$ \\
\hline $\begin{array}{l}\text { R\&D integration } \times \\
\text { Relative exploration } \\
\text { orientation }\end{array}$ & & & & & 0.301 & 0.816 \\
\hline
\end{tabular}


Supply chain integration $x$

Relative exploration

orientation

Market integration $\times$

Relative exploration

orientation

Salesforce integration $x$

Relative exploration

orientation
$0.291 \quad 0.805$

$-0.901 \quad-2.759 * * *$

0.314

1.006

$(0.312)$

(0.317)

Adjusted $\mathrm{R}^{2}$

0.283

0.350

0.487

Model 1 included six control variables, among which only past performance positively influences PM performance $(\beta=0.568, \mathrm{p}<0.01)$. Model 2 added the main effects of the marketing resources integrations to test $\mathrm{H} 1-\mathrm{H} 5$, yielding stronger results than Model 1 since adjusted $\mathrm{R}^{2}$ is increased to 0.350 from 0.283 . The results show that brand integration is significantly negatively related to PM performance $(\beta=-0.246, p<0.01)$, supporting H1. R\&D integration $(\beta=0.047, p>0.10)$, supply chain integration $(\beta=0.016, p>0.10)$, and market integration $(\beta=-0.028, \mathrm{p}>0.10)$ are not significantly related to PM performance. Therefore, H2H4 are not supported. Finally, salesforce integration is significantly positively related to PM performance $(\beta=0.094, \mathrm{p}<0.06)$, supporting H5.

Model 3 included the interactive terms of marketing resources integration with relativeexploration orientation, yielding stronger results than Model 2 since adjusted $\mathrm{R}^{2}$ is increased to 0.487 from 0.350 . The coefficients of interactive terms in Model 3 demonstrate that the moderating effects of relative-exploration orientation between the integration of brand and market and PM performance are significant. The plots in Figure 5 illustrate the moderating 
effects. Specifically, as hypothesized, when acquirers' relative-exploration orientation is high, brand integration is significantly positively related to PM performance. When acquirers' relativeexploration orientation is low, brand integration is significantly negatively related to PM performance. Surprisingly, market integration is significantly negatively related to PM performance when acquirers' relative-exploration orientation is high but positively related to PM performance when relative-exploration orientation is low. Finally, relative-exploration orientation does not moderate the relationship between integration of $R \& D$, supply chain, and salesforce resources and PM performance.

Figure 5: Interaction plots

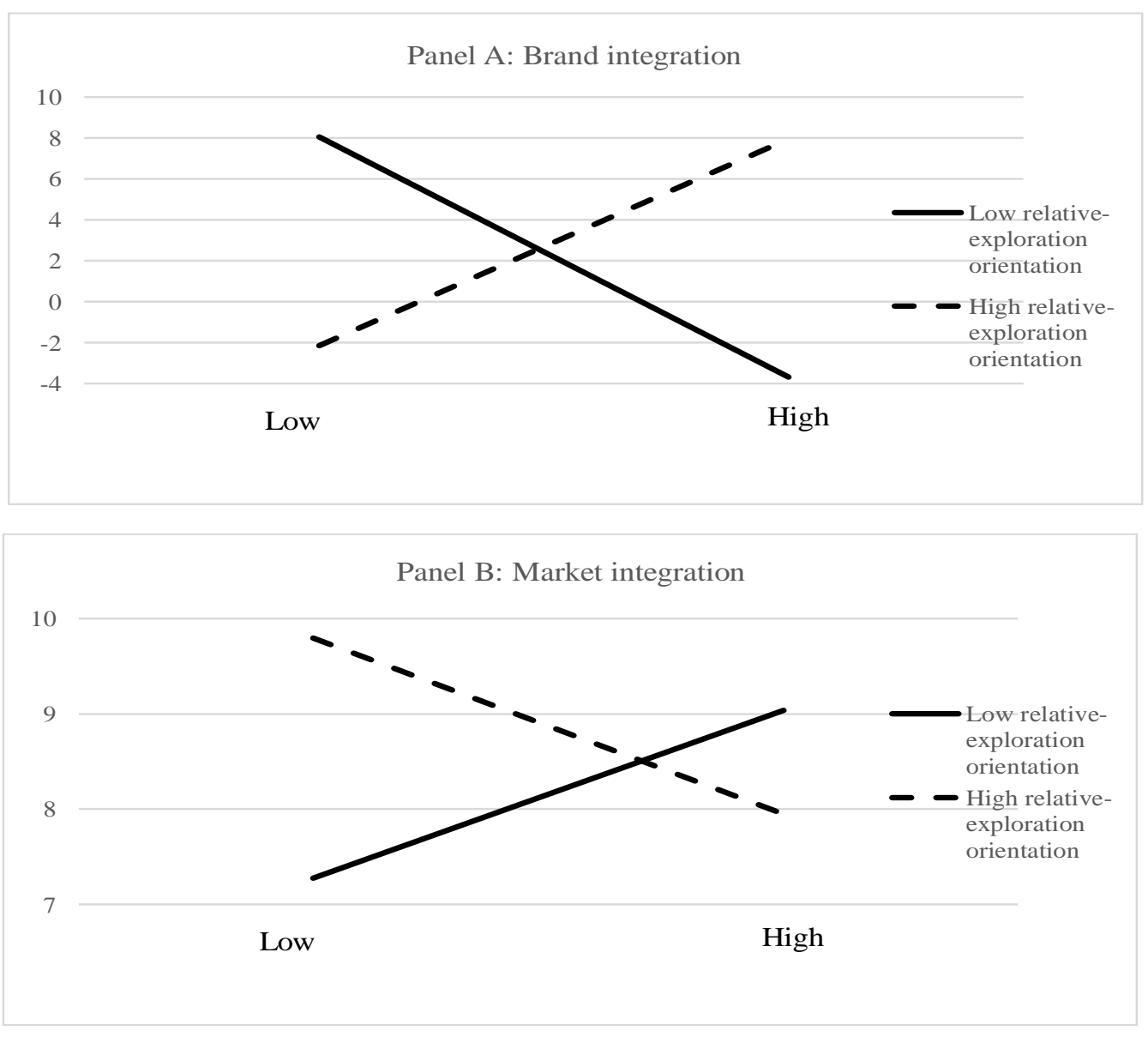




\subsection{Endogeneity}

Endogeneity prevails in international marketing research and might bias estimations of coefficients when studies rely on secondary data (Jean et al. 2016). Endogeneity means that variables that are included in the model as exogenous variables are essentially endogenous to the dependent variable (Chenhall and Moers 2007). Endogeneity occurs when models do not include variables that might influence both dependent variables and independent variables (i.e., omitted variables) or independent variables are caused by the dependent variable (i.e., simultaneity) (Chenhall and Moers 2007). Since the dependent variable I used in the model is one-year lagged firm performance from independent variables, simultaneity is less likely to happen in the present study. However, omitted variables might constitute a threat to the results.

To test the possible endogeneity caused by omitted variables, I followed the procedure proposed by Hult et al. (2018). First, I used the Gaussian copula approach to test endogeneity issues of the model only including independent variables (i.e., marketing resources integration). The results of the Gaussian copula show that endogeneity is a threat to the results of the model (Park and Gupta 2012). Then, as Hult et al. (2018) suggest, I added control variables in the model. After adding control variables, none of the Gaussian copula was significant. Therefore, endogeneity is not likely to be a threat to the coefficient estimations of model 2 and 3. In addition, error terms in models 2 and 3 were not significantly correlated to independent variables, confirming that endogeneity is not problematic in the present study (Chenhall and Moers 2007). 


\section{Discussion}

\subsection{Overview of findings}

More and more EM firms have been acquiring firms based in developed economies to learn advanced marketing skills and thus increase global competitiveness. However, many of such CBAs failed, and during the process of integrations in CBAs EM acquirers may not obtain marketing knowledge that they intend to learn. Since only limited research attention has been paid to this international business practice, the present study, based on RBV and resource orchestration theory, answers two questions: (1) What marketing resources integration could EM acquirers' benefit from? and (2) What strategies could leverage integrated marketing resources to increase PM performance?

Consistent with RBV and resource orchestration theory, the results show that not all marketing resources could be redeployed by EM acquirers because of stickiness of resources. In addition, to increase PM performance, EM acquirers should adopt an appropriate strategy to better use integrated marketing resources. Specifically, as hypothesized, brand integration decreases PM performance, and the negative influence holds when relative-exploration orientation is low. This may be because the mismatch of products of two brands makes it difficult for consumers to transfer the images of the superior brand to the inferior brand. By contrast, when acquirers' relative-exploration orientation is high, brand integration could increase PM performance. This might be because when EM acquirers and acquired firms colaunch brand new products to the markets, the mismatch of products disappears since there is only one single product. In addition, consumers may believe that technologies of acquired firms could guarantee product quality. 
Second, R\&D and supply chain integration do not increase PM performance, and the relationships are not moderated by relative-exploration orientation. Inconsistent with previous studies showing the negative influence of R\&D integration on PM performance (King et al. 2008), my results show that $R \& D$ integration per se does not hurt PM performance. Therefore, it is safe to integrate acquired firms' $R \& D$ resources, buttressing the main goal of EM acquirers' CBAs. However, how to take full advantage of integrated R\&D resources is still a question since my findings show that relative-exploration orientation cannot capitalize on the integrated $R \& D$ resources. Similarly, my results show that supply chain integration does not increase PM performance, and neither exploration nor exploitation could take advantage of acquired supply chain resources.

Third, the results show that market integration does not significantly influence PM performance. However, market integration increases PM performance when EM acquirers' relative-exploration orientation is low but decreases PM performance when EM acquirers' relative-exploration is high. These findings are not consistent with my hypotheses. The basic assumption of the proposed model is that EM acquirers can learn marketing skills from acquired firms and apply such knowledge into their business via CBAs, increasing long-term performance. By contrast, the results indicate that EM acquirers might not be able to learn marketing skills when they develop new products for acquired clients. This might be because acquired marketers also need to invest plenty of resources to develop new marketing skills when launching new products, decreasing efficiency of knowledge transfer to acquirers.

Finally, the results show that salesforce integration increases PM performance, and the relationship holds constant regardless of the level of relative-exploration orientation. These findings are very encouraging for EM acquirers since salesforce is demonstrated to be one of the 
most tradable resources among marketing resources. In addition, although previous studies have highlighted the difficulties of integrating human resources because of cultural differences between EM acquirers and acquired firms in developed economies, the results show that salespeople integration could increase PM performance. This might be because salespeople are frontline employees and spend plenty of time travelling outside firms (Anderson and Oliver 1987). Therefore, integration may cause only minimal loss of identification, which could be easily repaired by internal measures (Bommaraju et al. 2018).

\subsection{Theoretical implications}

The findings based on Chinese acquirers' CBAs make significant contributions to extant literature and could provide insights for acquirers from other EMs that tend to acquire firms from developed economies. First, the findings respond to calls for more studies on understanding CBAs occurring between EM acquirers and acquired firms based in developed economies (Luo and Tung 2018). CBAs between EM acquirers and acquired firms in developed economies have become a popular tool for EM firms to expand globally and catch up with global competitors. But such CBAs are very likely to fail. Until recently, only a small number of scholars have been devoted to understanding this relatively new phenomenon, such as by examining influential factors of success of acquisitions (e.g., Li et al. 2016; Luo and Tung 2007; Huang et al. 2017). Taking a lens of RBV and resource orchestration theory, the present study examines how marketing resources integration and relative-exploration orientation influence the success of a CBA. Using Chinese firms' CBAs activities as a research setting, my findings show that to increase PM performance, EM acquirers should focus on a narrow range of marketing resources to integrate. The findings would help to understand Chinese firms' CBAs activities in developed economies and could somehow be generalized to acquirers from other EMs. 
Second, the findings help to solve the puzzle of integration. Although previous studies have highlighted the importance of marketing resources integration in a CBA and reach a consensus that integration is critical for success of CBAs, the extant literature reveals very little about marketing integration so far (Capron and Hulland 1999). For example, it is unknown what marketing knowledge is likely to boost or hinder PM performance after integration, coordination, and synchronization. In addition, to take full advantage of integrated marketing resources, what should firms do? By investigating the activities in which Chinese acquirers integrate acquired firms in developed economies via an induction process, my findings help to differentiate marketing resources that are possible to integrate from those that are not.

Third, the study enriches organizational learning theory in the international business research. Recently, organizational learning theory has been applied to research of CBAs. However, many studies rely on organizational learning theory to explain the influence of the experience of managing acquisitions that firms learn from past acquisitions on the outcomes of subsequent acquisitions or alliances (Vermeulen and Barkema 2001). Few studies have examined the influence of managerial knowledge and skills learned from acquired firms on acquirers' performance. I argue that organizational learning theory is particularly pertinent to the phenomena of EM firms acquiring firms from developed economies since one purpose of the CBAs is to learn knowledge from acquired firms. Therefore, compared to accumulative experience and knowledge in managing acquisition pe ser (e.g., how to interact with third-party consultants), learning substantial knowledge from acquired firms is more important for acquirers' global competitiveness and long-term survival. Indeed, since CBAs reflect Chinese firms' ambitions to proactively seek opportunities and assets and their intentions to compete with counterparts in global markets, exploration is more effective than exploitation in many cases. 
Finally, my findings enrich international marketing theory regarding CBAs. International marketing findings have been fruitful on many topics such as cultural differences, entry mode, institutional environments, industrial forces, and marketing capabilities. Interdisciplinary research also advances the literature of transaction cost and barriers, laws and regulations, and so on. Surprisingly, though many studies on CBAs exist in the field of economics, management, finance, and accounting, marketing scholars disproportionately have paid less attention to CBAs (Yu 2013). My findings advance CBAs theories from a marketing perspective by testing the influence of marketing resources integration on PM performance. Certainly, more studies are needed from a marketing perspective to understand CBAs.

\subsection{Managerial implications}

Over the past two decades, more and more EM firms have been investing in buying firms from developed economies. On one hand, they expect to procure important resources unavailable in their home countries. On the other hand, they attempt to learn advanced knowledge from acquired firms. Some of CBAs achieve incredible success and help EM firms gain global recognition. For example, by buying IBM's PC division, Lenovo's brand awareness increased significantly. Unfortunately, because of inexperience in handling CBAs, some acquirers have confronted failures. For example, after acquiring a French electronics company, Thomson, in 2003, TCL, a Chinse TV manufacturer suffered its first financial loss since it was founded in 1981. Centering on this disastrous acquisition, one of its senior managers wrote a book titled, “The Rebirth of Eagles," to reflect on problems the company did not deal with properly during the acquisition and to share lessons with other Chinese firms. Similarly, by investigating 115 CBAs initiated by Chinese firms, my results also offer important lessons for acquirers and their managers from EMs. 
First, marketing knowledge learned from acquired firms is helpful for firm performance. Marketing knowledge is one of the most important resources that EM acquirers aim to learn through CBAs to compensate for latecomer disadvantages. In general, EM firms have been doing business globally for less than thirty years. Hence, they are not familiar with international business rules, lack versatile managers competent in handling global competition, and are short of international marketing skills. Therefore, buying managers and their marketing skills from firms based in developed economies constitutes a shortcut for EM firms to leapfrog their competitors. My findings confirm this argument. Even though many CBAs have not achieved their objectives, the results of this study show that marketing skills absorbed from acquired firms could eventually increase EM firms’ PM performance. For example, EM firms could learn marketing skills from acquired salespeople, which in turn could increase firm performance. Therefore, I suggest that EM acquirers view the short-term loss as "tuitions" that would pay off eventually.

Second, not all marketing resources are possible to integrate. Since many EM acquirers do not have sufficient experience in handling CBAs, integration is a very challenging or even dangerous task. Given that firms cannot reverse the integration process, managers should be very careful in selecting marketing resources to integrate. My results show that brand integration may hurt firm performance. In addition, R\&D integration, supply chain integration, and market integration do not significantly influence performance. Therefore, my results suggest that when acquirers pay "tuitions," they should register "classes" that could most boost their "grades."

Finally, it is naïve to presume that possession of advanced marketing skills could lead to better performance or that companies should integrate marketing resources as little as possible to avoid unintended negative consequences. Just because firms obtain some critical resources from 
acquired firms does not mean that their performance will increase. They need to put those resources in the most appropriate places. Said differently, firms need to do the right things (i.e., resources) right (i.e., strategies). Specific to my research context, acquirers should pursue exploration instead of exploitation if they integrate acquired firms' brand resources, while they should pursue exploitation rather than exploration if they integrate acquired firms' customers. Moreover, since the objectives of CBAs are learning marketing skills, they cannot eschew integrating or learning just because of potential losses. As long as they take proper strategic actions to the integrated marketing resources, firm performance will ultimately increase. For example, brand integration may decrease firm performance. However, if firms launch new products, brand integration could help to augment firm performance.

\subsection{Limitations and future research directions}

The present study suffers the following limitations. First, many missing values exist in CBAs' coverage and EM acquirers, decreasing the available sample size. Chinese firms have taken more than half of the shares of 171 firms from developed economies between 2003 and 2015. Because data about acquirers were not available, or press media did not report the acquisitions, only 115 events were used for hypotheses testing. Second, I have not included variables regarding acquired firms into the models. Many studies posit that characteristics of acquired firms influence the outcomes of CBAs (Yu et al. 2016). Unavailability of data about acquired firms did not allow me to do so. The unavailability of data is partly caused by the fact that many acquired firms were not public and partly that the data were not public after acquired firms were merged into acquiring firms. Third, private acquirers were not included in the sample because of data unavailability. Admittedly, private firms play important roles in CBAs. For example, Huawei is a prominent player in the technology industry and has been proactively 
participating in CBAs. However, because it is a private firm and does not disclose financial information, I cannot include such transactions into this analysis. Finally, I collected integration activities only from press releases. More data sources are needed to cross-validate the results. Therefore, future research should use survey and interviews with managers to investigate the influence of marketing resources integration on firms' capabilities and performance.

In addition, future research should examine how to gain acquired marketers' trust and confidence in acquirers so those marketers would be willing to contribute to the parent firms. Certainly, acquiring firms would like acquired talented managers to visit and work in China and make their unique contributions to the parent firms. For example, Volvo's car designers work with its acquirer, Geely, on improvement of car designs. However, because of acquired employees' unfamiliarity with China and distrust in parent firms, it may be difficult to increase employees' involvement in parent firms' operations. In addition, such high involvement would require acquired managers' confidence in Chinese parent firms. Hence, future research should investigate how to build acquired firms' trust and confidence, which could lead to attachment, commitment, and organizational citizenship behavior. As such, Chinese firms could not only utilize managers' knowledge in domestic markets but also create more opportunities for Chinese managers to learn from acquired managers.

Finally, future research must also investigate the phenomenon of Chinese small- and medium-sized firms' CBAs. Small- and medium- sized firms encounter more challenges in CBAs than do large firms, but CBAs sometimes are the only way for them to survive because of the competitive home market. They are pushed to their global competitors' backyard to make profits to avoid head-to-head competition in China. In addition, because of the limited amount of government support, they have competitive disadvantages to state-owned enterprises in Chinese 
market. Therefore, what resources small- and medium- sized firms should acquire, what they should learn from acquired firms, and how to best use integrated knowledge should be interesting and important research questions. 


\section{References}

Aaker, D. A., \& Keller, K. L (1990). Consumer evaluations of brand extensions. Journal of Marketing, 54(1), 27-41.

Anderson, E., \& Gatignon, H. (1986). Modes of foreign entry: A transaction cost analysis and propositions. Journal of International Business Studies, 17, 1-26.

Anderson, E., \& Oliver, R. L. (1987). Perspectives on behavior-based versus outcome-based salesforce control systems. Journal of Marketing, 51(4), 76-88.

Barney, J. (1991). Firm resources and sustained competitive advantage. Journal of Management, 17(1), 99-120.

Bauer, F., Matzler, K., \& Wolf, S. (2016). M\&A and innovation: The role of integration and cultural differences-a central European targets perspective. International Business Review, 25(1), 76-86.

Birkinshaw, J., Bresman, H., \& \& Håkanson, L. (2000). Managing the post-acquisition integration process: How the human integration and task integration processes interact to foster value creation. Journal of Management Studies, 37(3), 395-425.

Bitner, M. J., Booms, B. H., \& Tetreault, M. S. (1990). The service encounter: Diagnosing favorable and unfavorable incidents. Journal of Marketing, 54(1), 71-84.

Björkman, I., Stahl, G. K., \& Vaara, E. (2007). Cultural differences and capability transfer in cross-border acquisitions: the mediating roles of capability complementarity, absorptive capacity, and social integration. Journal of International Business Studies, 38, 658-672.

Bommaraju, R., Ahearne, M., Hall, Z. R., Tirunillai, S., \& Lam, S. K. (2018). The impact of mergers and acquisitions on sales force. Journal of Marketing Research, IV(April), 254264. 
Capron, L. (1999). The long-term performance of horizontal acquisitions. Strategic Management Journal, 20(11), 987-1018.

Capron, L., Dussauge, P., \& Mitchell, W. (1998). Resource redeployment following horizontal acquisitions in Europe and North America, 1988-1992. Strategic Management Journal, $19(7), 631-661$.

Capron, L., \& Hulland, J. (1999). Redeployment of brands, sales forces, and general marketing management expertise following horizontal acquisitions: A resource-based view. Journal of Marketing, 63(2), 41-54.

Capron, L., \& Pistre, N. (2002). When do acquirers earn abnormal returns? Strategic Management Journal, 23(9), 781-794.

Chen, Z. (2008). The rebirth of eagle-TCL development password. Shenzhen: Haitian Publishing House.

Chenhall, R. H., \& Moers, F. (2007). The issue of endogeneity within theory-based, quantitative management accounting research. European Accounting Review, 16(1), 173-195.

Cui, A., Walsh, M. F., \& Zou, S. (2014). The importance of strategic fit between host-home country similarity and exploration exploitation strategies on small and medium-sized enterprises’ performance: A contingency perspective. Journal of International Marketing, 22(4), 67-85.

Day, G. S. (2011). Closing the marketing capabilities gap. Journal of Marketing, 75(4), 183-195.

Dunbar, J. K. (2014). The leaders who make M\&A work. Harvard Business Review, 92(9), 28.

Dunning, J. (1988). The eclectic paradigm of international production: A restatement and some possible extensions. Journal of International Business Studies, 19(1), 1-31. 
Ellen, P. S., Webb, D. J., \& Mohr, L. A. (2006). Building corporate associations: Consumer attributions for corporate socially responsible programs. Journal of the Academy of Marketing Science, 34(2), 147-157.

Graebner, M. E., Heimerisk, K. H., Huy, Q. N., \& Vaara E. (2017). The process of postmerger integration: A review and agenda for future research. The Academy of Management Annals, 11(1), 1-32.

Gubbi, S. R., Aulakh, P. S., Ray, S., Sarkar, M. B., \& Chittoor, R. (2010). Do international acquisitions by emerging-economy firms create shareholder value? The case of Indian firms. Journal of International Business Studies, 41(3), 397-418.

Heinberg, M., Ozkaya, H. E., \& Taube, M. (2016). A brand built on sand: Is acquiring a local brand in an emerging market an ill-advised strategy for foreign companies? Journal of the Academy of Marketing Science, 44, 586-607.

Hitt, M. A, Ireland, R. D., Sirmon, D. G., \& Trahms, C. A. (2011). Strategic entrepreneurship: Creating value for individuals, organizations, and society. Academy of Management Perspectives, 25(2), 57-75.

Homburg, C., \& Bucerius, M. (2005). A marketing perspective on mergers and acquisitions: How marketing integration affects postmerger performance. Journal of Marketing, 69(1), 95-113.

Huang, Z., Zhu, H., \& Bass, D. J. (2017). Cross-border acquisitions and the asymmetric effect of power distance value difference on long-term post-acquisition performance. Strategic Management Journal, 38(4), 972-991. 
Hughes, D. E., Bon, J. L., \& Rapp, A. (2013). Gaining and leveraging customer-based competitive intelligence: The pivotal role of social capital and salesperson adaptive selling skills. Journal of the Academy of Marketing Science, 41, 91-110.

Hult, G. T. M., Hair, J. F., Proksch, D., Sarstedt, M., Pinkwart, A., \& Ringle, C. M. (2018). Addressing endogeneity in international marketing applications of partial least squares structural equation modeling. Journal of International Marketing, 26(3), 1-21.

Jean, R. J., Deng, Z., Kim, D., \& Yuan, X. (2016). Assessing endogeneity issues in international marketing research. International Marketing Review, 33(3), 483-512.

Josephson, B. W., Johnson, J. L., \& Mariadoss, B. J. (2016). Strategic marketing ambidexterity: Antecedents and financial consequences. Journal of the Academy of Marketing Science, 44(4), 539-554.

Kauppila, O. P. (2015). Alliance management capability and firm performance: Using resourcebased theory to look inside the process black box. Long Range Planning, 48(3), 151-167.

King, D. R., Slotegraaf, R. J., \& Kesner, I. (2008). Performance implications of firm resource interactions in the acquisition of R\&D-intensive firms. Organization Science, 19(2), 327340.

Knight, G. A., \& Kim, D. (2009). International business competence and the contemporary firm. Journal of International Business Studies, 40(2), 255-273.

Kumar, V., Singh, D., Purkayastha, A., Popli, M., \& Gaur, A. (2020). Springboard internationalization by emerging market firms: Speed of first cross-border acquisition. Journal of International Business Studies, 51, 172-193.

Laurent, A. (1983). The cultural diversity of western conceptions of management. International Studies of Management \& Organization, 13(1-2), 75-96. 
Lee, J. K., Lee, B. K., \& Lee, W. N. (2013). Country-of-origin fit's effect on consumer product evaluation in cross-border strategic brand alliance. Journal of Business Research, 66(3), 354-363.

Levinthal, D. A., \& March, J. G. (1993). The myopia of learning. Strategic Management Journal, 14 (S2), 95-112.

Li, J., Li, P., \& Wang B. (2016). Do cross-border acquisitions create value? Evidence from overseas acquisition by Chinese firms. International Business Review, 25(2), 471-483.

Li, Y., Liu, Y., \& Zhao Y. (2006). The role of market and entrepreneurship orientation and internal control in the new product development activities of Chinese firms. Industrial Marketing Management, 35(3), 336-347.

Lin, Z., Yang, H., \& Arya, B. (2009). Alliance partners and firm performance: Resource complementarity and status association. Strategic Management Journal, 30(9), 921-940.

Liu, Y, Öberg, C., Tarba, S. Y., \& X. Y. (2018). Brand management in mergers and acquisitions: Emerging market multinational venturing into advanced economies. International Marketing Review, 35(5), 710-732.

Liu, Y., \& Woywode, M. (2013). Light-touch integration of Chinese cross-border M\&A: The influences of culture and absorptive capacity. Thunderbird International Business Review, 55(4), 469-483.

Lu, Y., Zhou, L., Bruton, G., \& Li, W. (2010). Capabilities as a mediator linking resources and the international performance of entrepreneurial firms in an emerging economy. Journal of International Business Studies, 41(3), 419-436.

Luo, Y., \& Tung, R. L. (2007). International expansion of emerging market enterprises: A springboard perspective. Journal of International Business Studies, 38(4), 481-498. 
Luo, Y., \& Tung, R. L. (2018). A general theory of springboard MNEs. Journal of International Business Studies, 49(2), 129-152.

Luo, Y., Xue, Q., \& Han, B. (2010). How emerging market governments promote outward FDI: Experience from China. Journal of World Business, 45(1), 68-79.

Luo, Y., Zhao, H., Wang, Y., \& Xi, Y. (2011). Venturing abroad by emerging market enterprises: a test of dual strategic intents. Management International Review, 51(4), 433459.

Ma, X., Zhu, Y., \& Cai, W. (2016). The performance of cross-border acquirers from emerging economics: An empirical analysis of Chinese firms. Nankai Business Review International, 7(1), 21-38.

Mahoney, J. T., \& Pandian, J. R. (1992). The resource-based view within the conversation of strategic management. Strategic Management Journal, 13(5), 363-380.

March, J. G. (1991). Exploration and exploitation in organizational learning. Organization Science, 2(1), 71-87.

Mass, A. J. J., Heugens, P. P. M. A. R., \& Reus, T. H. (2019). Viceroys or emperors? An institution-based perspective on merger and acquisition prevalence and shareholder value. Journal of Management Studies, 56(1), 234-269.

Mishina, Y., Pollock, T. G., \& Porac, J. F. (2004). Are more resources always better for growth? Resource stickiness in market and product expansion. Strategic Management Journal, 25(12), 1179-1197.

Mizik, N., \& Jacobson, R. (2003). Trading off between value creation and value appropriation: The financial implications of shifts in strategic emphasis. Journal of Marketing, 67(1), $63-76$. 
Mukherji, P., Sorescu, A., Prabhu. J, \& Chandy, R. (2011). Behemoths at the gate: How incumbents take on acquisitive entrants (and why some do better than others). Journal of Marketing, 75(5), 53-70.

Nicholson, R. R., \& Salaber, J. (2013). The motives and performance of cross-border acquirers from emerging economies: Comparison between Chinese and Indian firms. International Business Review, 22(6), 963-980.

Osawa, J., \& Luk, L. (2014). How Lenovo built a Chinese tech giant. Available at [https://www.wsj.com/articles/lenovo-makes-bet-on-smartphones-1391081203]. Accessed on 02/24/2020.

Palmatier, R. W., Miao, C. F., \& Fang, E. (2007a). Sales channel integration after mergers and acquisitions: A methodological approach for avoiding common pitfalls. Industrial Marketing Management, 36(5), 589-603.

Palmatier, R. W., Scheer, L. K., \& Sttenkamp, J. E. M. (2007b). Customer loyalty to whom? Managing the benefits and risks of salesperson-owned loyalty. Journal of Marketing Research, 44(2), 185-199.

Park, S., \& Gupta, S. (2012). Handling endogenous regressors by joint estimation using copulas. Marketing Science, 31(4), 567-586.

Paruchuri, S. Nerkar, A., \& Hambrick, D. C. (2006). Acquisitions integration and productivity losses in the technical core: Disruption of inventors in acquired companies. Organizational Science, 17(5), 527-676.

Peng, M. W., Wang, D. Y., \& Jiang, Y. (2008). An institution-based view of international business strategy: A focus on emerging economies. Journal of International Business Studies, 39(5), 920-936. 
Paruchuri, S., Nerkar, A., \& Hambrick. (2006). Acquisition integration and productivity losses in the technical core: Disruption of inventors in acquired companies. Organization Science, $17(5), 527-676$.

Reinartz, W., Thomas, J. S., \& Kumar, V. (2005). Balancing acquisition and retention resources to maximize customer profitability. Journal of Marketing, 69(1), 63-79.

Reus, T. H., Lamont, B. T., \& Ellis, K. M. (2016). A darker side of knowledge transfer following international acquisitions. Strategic Management Journal, 37(5), 932-944.

Rui, H., \& Yip, G. S. (2008), Foreign acquisitions by Chinese firms: A strategic intent perspective. Journal of World Business, 43(2), 213-226.

Samiee, S., Shimp, T. A., \& Sharma, S. (2005). Brand origin recognition accuracy: Its antecedents and consumers' cognitive limitations. Journal of International Business Studies, 36(4), 379-397.

Shimizu, K., Hitt, M. A., Vaidyanath, D., \& Pisano, V. (2004). Theoretical foundations of crossborder mergers and acquisitions: A review of current research and recommendations for the future. Journal of International Management, 10(3), 307-353.

Simonin, B. L., \& Ruth, J. A. (1998). Is a company known by the company it keeps? Assessing the spillover effects of brand alliances on consumer brand attitude. Journal of Marketing Research, 35(1), 30-42.

Sinkovics, R. R., Sinkovics, N., Lew, Y, K., Jedin, M. H., \& Zagelmeyer, S. (2015). Antecedents of marketing integration in cross-border mergers and acquisitions: evidence from Malaysia and Indonesia. International Marketing Review, 32(1), 2-28. 
Sirmon, D. G., Hitt, M. A., Ireland, R. D., \& Gilbert, B. A. (2011). Resource orchestration to create competitive advantage: Breadth, depth, and life cycle effects. Journal of Management, 37(5), 1390-1412.

Srivastava, R. K., Shervani, T. A., \& Fahey, L. (1998). Market-based assets and shareholder value: A framework for analysis. Journal of Marketing, 66(1), 2-18.

Swart, J., \& Kinnie, N. (2003). Sharing knowledge in knowledge-intensive firms. Human Resource Management Journal, 13(2), 60-75.

Teece, D. J. (2014). A dynamic capabilities-based entrepreneurial theory of the multinational enterprise. Journal of International Business Studies, 45(1), 8-37.

Teece, D. J., Pisano, G., \& Shuen, A. (1997). Dynamic capabilities and strategic management. Strategic Management Journal, 18(7), 509-533.

Vermeulen, F., \& Barkema, H. (2001). Learning through acquisitions. Academy of Management Journal, 44(3), 457-476.

Vu, D. A., Shi, Y., \& Hanby, T. (2009). Strategic framework for brand integration in horizontal mergers and acquisitions, Journal of Technology Management in China, 4(1), 26-52.

Wang, X. \& Dass, M. (2017). Building innovation capability: The role of top management innovativeness and relative-exploration orientation. Journal of Business Research, 76, 127-135.

Wu, X., Yang, X., Yang, H, \& Lei, H (2016). Cross-border mergers and acquisitions by Chinese firms: Value creation or value destruction? Journal of Contemporary China, 25(97), 130145.

Yu, Y. (2013). Review of mergers and acquisitions research in marketing. Innovative Marketing, 9(1), 27-36. 
Yu, Y., Umashankar, N., \& Rao, V. R. (2016). Choosing the right target: Relative preferences for resource similarity and complementarity in acquisition choice. Strategic Management Journal, 37(8), 1808-1825.

Zhang, A. L., Baxter, R., \& Glynn, M. S. (2013). How salespeople facilitate buyers' resource availability to enhance seller outcomes. Industrial Marketing Management, 42(7), 11211130.

Zheng, N., Wei, Y., Zhang, Y., \& Yang, J. (2016). In search of strategic assets through crossborder merger and acquisitions: Evidence from Chinese multinational enterprises in developed economies. International Business Review, 25(1), 177-186.

Zhu, H., \& Zhu, Q. (2016). Mergers and acquisitions by Chinese firms: A review and comparison with other mergers and acquisitions research in the leading journals. Asia Pacific Journal of Management, 33(4), 1107-1149.

Zhu, H, Ma, X., Sauerwald, S., \& Peng, M. W. (2019). Home country institutions behind crossborder acquisition performance. Journal of Management, 45(4), 1315-1342. 